JAMA | Original Investigation

\title{
Effect of Radiofrequency Denervation on Pain Intensity Among Patients With Chronic Low Back Pain The Mint Randomized Clinical Trials
}

Johan N. S. Juch, MD; Esther T. Maas, PhD; Raymond W. J. G. Ostelo, PT, PhD; J. George Groeneweg, PT, PhD; Jan-Willem Kallewaard, MD; Bart W. Koes, PhD; Arianne P. Verhagen, PT, PhD; Johanna M. van Dongen, PhD; Frank J. P. M. Huygen, MD, PhD; Maurits W. van Tulder, PhD

IMPORTANCE Radiofrequency denervation is a commonly used treatment for chronic low back pain, but high-quality evidence for its effectiveness is lacking.

OBJECTIVE To evaluate the effectiveness of radiofrequency denervation added to a standardized exercise program for patients with chronic low back pain.

DESIGN, SETTING, AND PARTICIPANTS Three pragmatic multicenter, nonblinded randomized clinical trials on the effectiveness of minimal interventional treatments for participants with chronic low back pain (Mint study) were conducted in 16 multidisciplinary pain clinics in the Netherlands. Eligible participants were included between January 1, 2013, and October 24 , 2014, and had chronic low back pain, a positive diagnostic block at the facet joints (facet joint trial, 251 participants), sacroiliac joints (sacroiliac joint trial, 228 participants), or a combination of facet joints, sacroiliac joints, or intervertebral disks (combination trial, 202 participants) and were unresponsive to conservative care.

INTERVENTIONS All participants received a 3-month standardized exercise program and psychological support if needed. Participants in the intervention group received radiofrequency denervation as well. This is usually a 1-time procedure, but the maximum number of treatments in the trial was 3.

MAIN OUTCOMES AND MEASURES The primary outcome was pain intensity (numeric rating scale, $0-10$; whereby 0 indicated no pain and 10 indicated worst pain imaginable) measured 3 months after the intervention. The prespecified minimal clinically important difference was defined as 2 points or more. Final follow-up was at 12 months, ending October 2015.

RESULTS Among 681 participants who were randomized (mean age, 52.2 years; 421 women [61.8\%], mean baseline pain intensity, 7.1), 599 (88\%) completed the 3-month follow-up, and 521 (77\%) completed the 12-month follow-up. The mean difference in pain intensity between the radiofrequency denervation and control groups at 3 months was $-0.18(95 \% \mathrm{Cl},-0.76$ to 0.40$)$ in the facet joint trial; $-0.71(95 \% \mathrm{Cl},-1.35$ to -0.06$)$ in the sacroiliac joint trial; and $-0.99(95 \% \mathrm{Cl},-1.73$ to -0.25$)$ in the combination trial.

CONCLUSIONS AND RELEVANCE In 3 randomized clinical trials of participants with chronic low back pain originating in the facet joints, sacroiliac joints, or a combination of facet joints, sacroiliac joints, or intervertebral disks, radiofrequency denervation combined with a standardized exercise program resulted in either no improvement or no clinically important improvement in chronic low back pain compared with a standardized exercise program alone. The findings do not support the use of radiofrequency denervation to treat chronic low back pain from these sources.

TRIAL REGISTRATION trialregister.nl Identifier: NTR3531

JAMA. 2017;318(1):68-81. doi:10.1001/jama.2017.7918
Supplemental content

$+$ CME Quiz at jamanetwork.com/learning and CME Questions page 88
Author Affiliations: Author affiliations are listed at the end of this article.

Corresponding Author: Esther T. Maas, PhD, School of Population and Public Health, University of British Columbia, 2206 E Mall, Vancouver, BC V6T 1Z3, Canada (esther.maas @ubc.ca). 
ow back pain causes more disability than any other condition and has major social and economic consequences. ${ }^{1-3}$ In the Netherlands (16.5 million residents) the cost of low back pain was estimated at $€ 3.5$ billion (US $\$ 3.9$ billion) in 2007, and the majority of the costs were attributable to patients with chronic low back pain. In the United States (326 million residents), the costs of low back pain have not been recently estimated; however, a study by Dieleman et $\mathrm{al}^{4}$ evaluated health care spending from 1996 to 2013 in the United States and estimated the health care spending on low back and neck pain at $\$ 87.6$ billion.

Potential sources of low back pain of the spinal column include the facet joints, sacroiliac joints, and intervertebral disks. These sources of pain were classified as mechanical low back pain. ${ }^{5,6}$ Radiofrequency denervation is a commonly used treatment in pain clinics for chronic low back pain. In the United States, facet joint or sacroiliac joint interventions in Medicare recipients increased from approximately 425000 interventions in 2000 to 2.2 million interventions in 2013. ${ }^{7}$ Radiofrequency denervation aims to prevent the conduction of nociceptive impulses through the use of an electric current that damages the pain-conducting nerve. The effectiveness of radiofrequency denervation has not been consistently demonstrated. However, there is consensus among anesthesiologists that minimal interventional procedures such as radiofrequency denervation are effective for patients with mechanical low back pain. ${ }^{5}$ Systematic reviews and multidisciplinary clinical guidelines concluded that there is evidence of very low to moderate quality supporting the effectiveness of radiofrequency denervation in clinical practice for patients with chronic low back pain. ${ }^{5,8-10}$

The aim of this study was to evaluate whether radiofrequency denervation in addition to a standardized exercise program is more effective than the standardized exercise program alone for patients with chronic mechanical low back pain.

\section{Methods}

\section{Study Design and Participants}

The Cost-Effectiveness of Minimal Interventional Procedures for Patients with Chronic Low Back Pain (Mint) study ${ }^{11}$ was an initiative to evaluate minimally invasive treatments for patients with spinal column-related chronic low back pain, consisting of 4 trials and an observational study (participants who did not want to be randomized or who did not meet the inclusion criteria for the trials were asked to participate in the observational study, where they received usual care). The full protocol is available in Supplement 1. One trial was designed to evaluate radiofrequency denervation for pain from the intervertebral disks. This trial was prematurely terminated because of a lack of eligible participants. The other 3 trials are presented in this article: (1) the facet joint trial, (2) the sacroiliac joint trial, and (3) the combination trial (facet joint, sacroiliac joint, or the intervertebral disk). The Medical Ethics Committee of the Erasmus University Medical Centre in Rotterdam granted ethical approval. Local research governance was

\section{Key Points}

Question What is the effectiveness of radiofrequency denervation added to a standardized exercise program for patients with chronic low back pain?

Findings In 3 randomized clinical trials including 681 participants with chronic low back pain originating from the facet joints, sacroiliac joints, or a combination of these or the intervertebral disks, radiofrequency denervation combined with exercise compared with exercise alone resulted in either no significant difference in pain intensity, or a difference smaller than the prespecified minimal clinically important difference after 3 months.

Meaning The study findings do not support the use of radiofrequency denervation for chronic low back pain originating from these sources.

obtained from all participating pain clinics. All participants gave written informed consent.

In 16 multidisciplinary pain clinics in the Netherlands, pain specialists consecutively screened participants with chronic low back pain. Inclusion criteria were pain considered to be related to the facet joint, sacroiliac joint, or a combination of the facet joint, sacroiliac joint, or intervertebral disk; aged 18 to 70 years; and no improvement in symptoms after conservative treatment. Medical history and clinical examination followed a standard format and were performed by experienced clinicians to determine the likely source of the pain. To be considered for a diagnostic sacroiliac joint block, at least 3 of 6 provocation tests (compression test; distraction test; Flexion, Abduction, and External Rotation [FABER] test; Gaenslen test; thigh thrust test; Gillett test) had to have positive results. ${ }^{12,13}$ Participants with suspected isolated facet joint pain or isolated sacroiliac joint pain received a diagnostic anesthetic block prior to randomization and were only randomized if the diagnostic block was positive. Participants with a suspected combination of sources of pain were randomized based on participant history and physical examination prior to receiving the diagnostic blocks. This choice was made for ethical reasons. It would be unethical to give participants in the study multiple diagnostic blocks (ie, a facet joint diagnostic block, a sacroiliac joint diagnostic block, and a provocative discography) before treatment. Furthermore, it is common practice in Dutch pain clinics for participants with chronic low back pain due to facet joints, sacroiliac joints, or intervertebral disks (based on history taking and physical examination) to start with 1 diagnostic block. If the diagnostic block was positive, the intervention was provided. If the diagnostic block was negative, then another block was provided. If the second diagnostic block was positive, the intervention was provided. If the second diagnostic block was negative, the clinician provided a third block. All participants were considered candidates for intervention based on history taking and physical examination. For this reason, participants were randomized and included in the combination trial after history taking and physical examination, if the pain physician suspected that the pain originated from more than 1 source. 
Exclusion criteria for all trials were pregnancy, severe psychological problems (determined with psychological questionnaires), involvement in work-related conflicts or claims; body mass index (BMI; calculated as weight in kilograms divided by height in meters squared) higher than 35 ; or anticoagulant drug therapy or coagulopathy.

\section{Diagnostic Blocks}

For the facet joints, ${ }^{14}$ a 22 -gauge needle was inserted to the posterior primary root of the spinal nerve (medial branch) under C-arm fluoroscopy. L3-4, L4-5, and L5-6 were selected for diagnostic blocks. The lateral image was checked to confirm the correct position of the needle, after which $0.5 \mathrm{~mL}$ of $2 \%$ lidocaine was injected.

For the sacroiliac joints, ${ }^{14}$ a 25 -gauge needle was inserted $3 \mathrm{~mm}$ to $10 \mathrm{~mm}$ laterally of the sacral foramina S1-3 under fluoroscopy. The correct depth of the needle was confirmed laterally, after which $0.5 \mathrm{~mL}$ of $2 \%$ lidocaine was injected. The dorsal ramus of L5 was also blocked as described in the Spinal Intervention Society guidelines using $0.5 \mathrm{~mL}$ of $2 \%$ lidocaine.

The blocks were considered positive if the participant reported $50 \%$ or more pain reduction within 30 to 90 minutes after the block.

The current standard for diagnosing discogenic pain is pressure-controlled provocative discography using strict criteria and at least 1 negative control level. ${ }^{15}$

\section{Randomization and Masking}

Participants were randomized using a computerized random number generator (Alea II, Netherlands Cancer InstituteAntoni van Leeuwenhoek Hospital), accessed through a password-protected website and maintained independently. Randomization was performed at the individual level by means of block randomization (block size $=4$ ), prestratified for pain clinic. Participants were allocated (1:1) to receive either radiofrequency denervation with a standardized exercise program (intervention group) or a standardized exercise program alone (control group).

Participants and caregivers were not blinded. The Dutch Ministry of Health, Welfare, and Sport requested a pragmatic trial in which existing, commonly applied treatment options would be compared. Data handling, analysis, and interpretation of results were conducted blind to treatment allocation. All participants were sequentially assigned unique numbers. Participants' expectations and satisfaction ${ }^{16,17}$ were measured to evaluate a possible risk of bias due to a nonblinded study design.

\section{Interventions}

\section{Standardized Exercise Program}

All participants received a program based on the Dutch physical therapy guidelines ${ }^{18}$ in 1 of 102 participating physical therapy practices. The 8- to 12-hour programs focused on quality of movement and behavior, and took place during a 3-month intervention period. More details are available in the study protocol, which is available in Supplement 1. If necessary, participants were referred to psychological care.

\section{Radiofrequency Denervation}

Within 1 week after the first exercise session the intervention group received radiofrequency denervation. The technical details of the radiofrequency denervation procedures are included in the eAppendix in Supplement 2.19-22

\section{Co-Interventions}

In both treatment groups, participants were asked to refrain from co-interventions during the intervention period of 3 months (duration of the standardized exercise program). Co-interventions that were not allowed included (but were not limited to) surgery; manual therapy; chiropractic therapy; a change in current, back pain-related medication; or newly prescribed medication. Analgesics were not prescribed, but over-the-counter medication was allowed. Co-interventions or recurrence of the radiofrequency denervation was allowed after the intervention period of 3 months. These interventions were recorded. Psychological care was not considered a co-intervention and was provided when needed to participants in either treatment group.

\section{Outcomes}

The primary outcome was pain intensity, measured on an 11-point numerical rating scale (NRS; a score of 0 indicates no pain; 10 indicates worst pain imaginable) 3 months after the intervention. $^{23}$

Secondary outcomes were global perceived recovery, ${ }^{16}$ participant satisfaction ${ }^{17}$ (both measured by the 7-point, categorical Global Perceived Effect scale; a score of 1 indicates fully recovered; 4 indicates no change; 7 indicates worse than ever), functional status (measured by Oswestry Disability Index [ODI]; a score of 0 indicates no restrictions in daily activities; 100 indicates most restrictions in daily activities), ${ }^{24}$ health-related quality of life (measured by the 3-level EuroQol 5D Health Questionnaire [EQ-5D-3L]; a score of 0 indicates worst imaginable health state; 1 indicates best imaginable health state), ${ }^{25}$ general health (measured by RAND 36-Item Health Survey [Rand-36], a score of 0 indicates lowest general health score; 100 indicates highest general health score), ${ }^{26}$ and chronic pain experiences (measured by the West Haven-Yale Multidimensional Pain Inventory; a score of 0 indicates lowest score; 6 indicates highest score) ${ }^{27}$

The minimal clinically important difference in pain for participants with chronic low back pain was estimated at 2 points or more of the 10-point NRS, a difference of 20 points on the 100 -point ODI, and between 0.09 and 0.28 points on the EQ-5D-3L utility score between 0 and $1 .{ }^{28,29}$ No minimal clinically important differences are known for the other secondary outcomes.

All outcome measures were registered using web-based questionnaires, which were sent at baseline and 3-, 6-, 9-, and 12-month follow-up. Pain intensity, global perceived recovery, and health-related quality of life were also assessed at 3-week follow-up and 6-week follow-up.

\section{Sample Size Calculation}

A clinically relevant mean difference of 2 points or more on the $\mathrm{NRS}^{28}$ for pain intensity $(\mathrm{SD}, 4)$ was used for the sample 


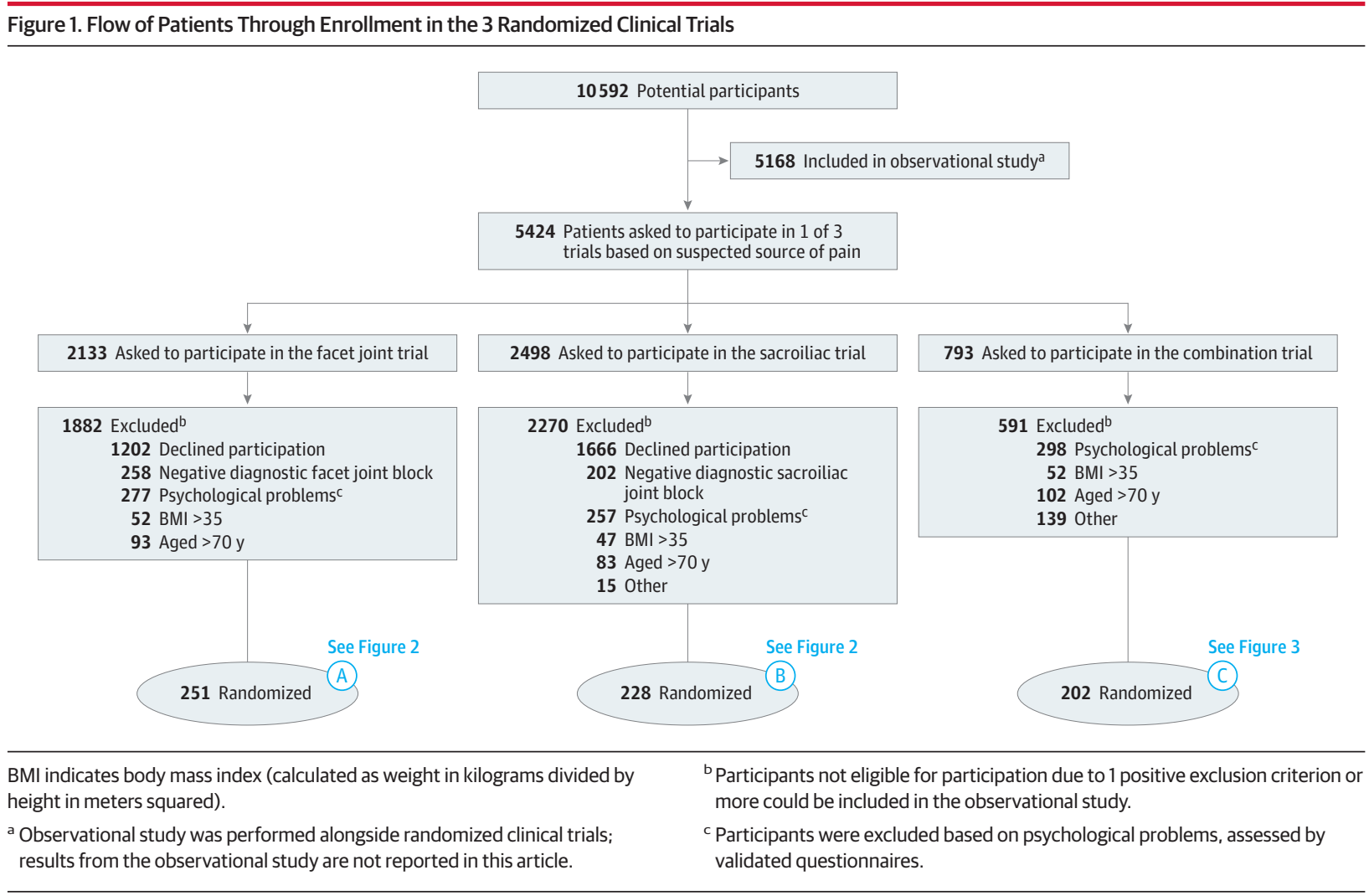

size calculation. With a power of 0.9, a 2-sided a of .05, and a correlation of 0.5 for repeated measurements, 85 participants per group were needed. Anticipating potential study withdrawal (20\%), a minimum of 204 participants per trial was needed.

\section{Statistical Analyses}

Effects were estimated using a maximum likelihood estimation for longitudinal mixed-effects model, under "missing at random" assumptions, including a term for pain clinic, if necessary, based on the likelihood ratio test. ${ }^{30}$ We used a generalized linear mixed model (logit link) for the post hoc analysis of treatment response for dichotomized outcomes. The same multilevel structure was used for both models. All analyses were conducted in accordance with the intentionto-treat principle.

Regression coefficients or odds ratios (ORs) with 95\% CIs were calculated; ORs were converted to relative risks (RRs) using the method of Zhang et $\mathrm{al}^{31}: \mathrm{RR}=\mathrm{OR} /[(1$ - prevalence in control group) + (prevalence in control group $\times \mathrm{OR})]$. We adjusted for the outcome parameter at baseline, and age, sex (self-reported), BMI, education, smoking, marital status, back pain complaint history, and participant expectations. The effect of interest was the time $\times$ treatment interaction. Regression coefficients can be interpreted as mean differences between interventions compared with baseline. Additionally, we calculated the number needed to treat and the unadjusted risk differences as absolute differences between groups. Data were compared between complete and incomplete cases to identify possible selective dropout.

Treatment success for the global perceived recovery was defined as "much recovery" or "complete recovery." In post hoc analyses, treatment success in pain reduction was defined as either more than $30 \%$ or 2 points reduction or more on the NRS pain scale.

No adjustments for multiple comparisons were made. Findings for the secondary outcomes should be interpreted as exploratory.

In 2 sensitivity analyses, participants marked as participants who had protocol violations, and participants who received radiofrequency denervation during follow-up were excluded from the analyses. Additionally, data were compared between complete and incomplete cases. We used MLwiN software (University of Bristol), version 2.22, for the effects models ( 2 -sided significance $P<.05$ ).

\section{Results}

In total, 251 patients were included in the facet joint trial, 228 patients in the sacroiliac joint trial, and 202 in the combination trial (Figure 1, Figure 2, and Figure 3). The 681 randomized participants had a mean age of 52.2 years, 421 participants were women $(61.8 \%)$, and the mean baseline pain intensity was 7.1 on the NRS scale. Another 5168 patients were included in the observational part of Mint study. 


\begin{tabular}{|l}
\hline 125 Randomized to intervention group \\
121 Received radiofrequency \\
denervation as randomized \\
3 Received sacroiliac joint \\
Palisade radiofrequency \\
treatment \\
1 Did not receive treatment \\
101 Completed exercise program \\
18 Did not complete exercise \\
program \\
6 Unknown completion
\end{tabular}

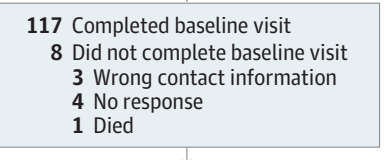

\begin{tabular}{|l|}
108 Completed 3-wk follow-up \\
17 Did not complete 3-wk follow-up \\
4 Wrong contact information \\
4 No response \\
1 Died \\
8 No treatment details
\end{tabular}

8 No treatment details

119 Completed 6-wk follow-up 6 Did not complete 6-wk follow-up 2 Wrong contact information 2 No response

1 Died

1 No treatment details

\begin{tabular}{|l|}
\hline 119 Completed 3-mo follow-up \\
6 Did not complete 3-mo follow-up \\
1 No internet \\
4 No response \\
1 Died \\
\hline
\end{tabular}

113 Completed 6-mo follow-up

12 Did not complete 6-mo follow-up 2 Unmotivated 9 No response 1 Died

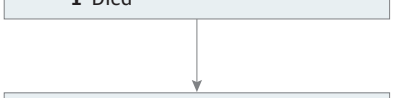

106 Completed 9-mo follow-up

19 Did not complete 9-mo follow-up

1 Unmotivated

1 No internet

3 No time

13 No response

1 Died

$\checkmark$

103 Completed 12-mo follow-up
22 Did not complete 12 -mo follow-up

3 No time

18 No response

1 Died

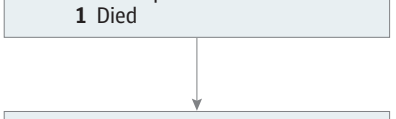

125 Included in intention-totreat analysis
126 Randomized to control group 92 Received exercise program as randomized

22 Did not complete exercise program

12 Unknown completion

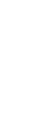

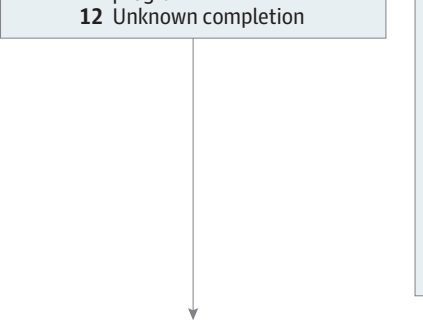
116 Completed baseline visit
10 Did not complete baseline visit 4 Wrong contact information 5 No response
1 Unsure about participating

$$
\downarrow
$$

101 Completed 3-wk follow-up

25 Did not complete 3-wk follow-up

5 Wrong contact information

9 No response

1 Comorbidity

10 No treatment details

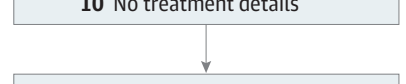

118 Completed 6-wk follow-up

8 Did not complete 6-wk follow-up

1 Wrong contact information

5 No response

1 Comorbidity

1 No treatment details

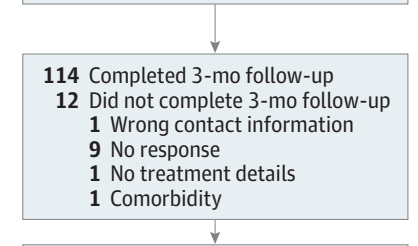

108 Completed 6-mo follow-up

18 Did not complete 6-mo follow-up

1 Wrong contact information

14 No response

1 Unsatisfied

1 No treatment details

1 Comorbidity

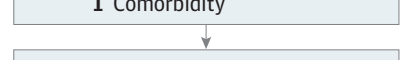

105 Completed 9-mo follow-up

21 Did not complete 9-mo follow-up

1 Wrong contact information

18 No response

1 No treatment details

1 Comorbidity

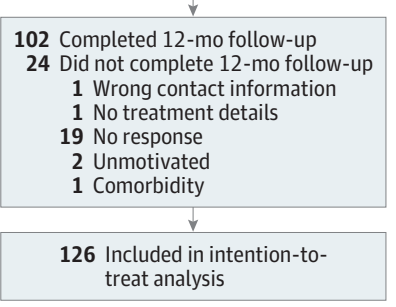

\section{Sacroiliac joint trial B \\ 228 Randomized}

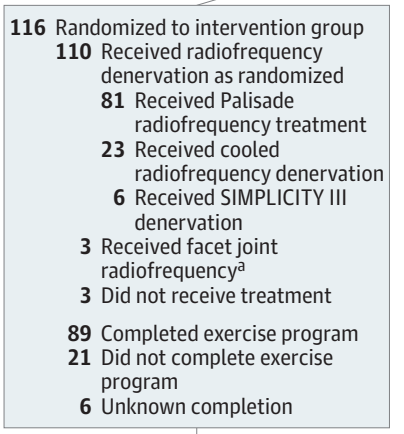

109 Completed baseline visit

7 Did not complete baseline visit 2 Wrong contact information 5 No response
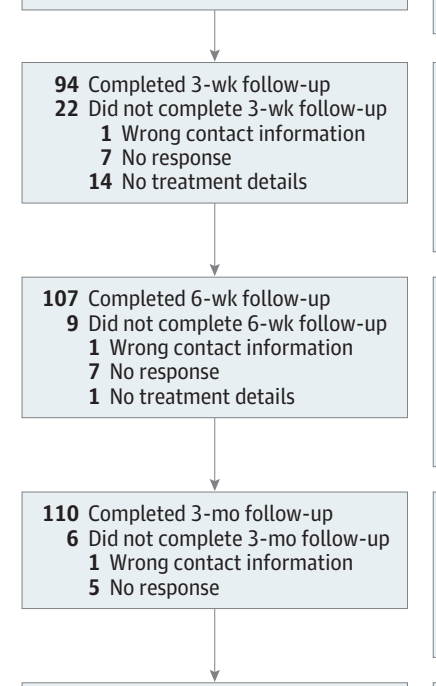

103 Completed 6-mo follow-up

13 Did not complete 6-mo follow-up 2 Wrong contact information 11 No response

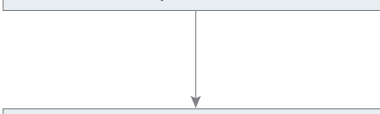

101 Completed 9-mo follow-up

15 Did not complete 9-mo follow-up

1 Wrong contact information

12 No response

2 Withdrew $^{\mathrm{b}}$

101 Completed 12-mo follow-up

15 Did not complete 12-mo follow-up

1 Wrong contact information

12 No response

2 Withdrew $^{\mathrm{b}}$

116 Included in intention-totreat analysis
112 Randomized to control group 69 Received exercise program as randomized
18 Did not complete exercise program
25 Unknown completion

\footnotetext{
a Participants received RF treatment other than their randomized assignment.

bStudy withdrawals were not cumulative.
} 


\section{Figure 3. Flow of Patients Through the Combination Trial}

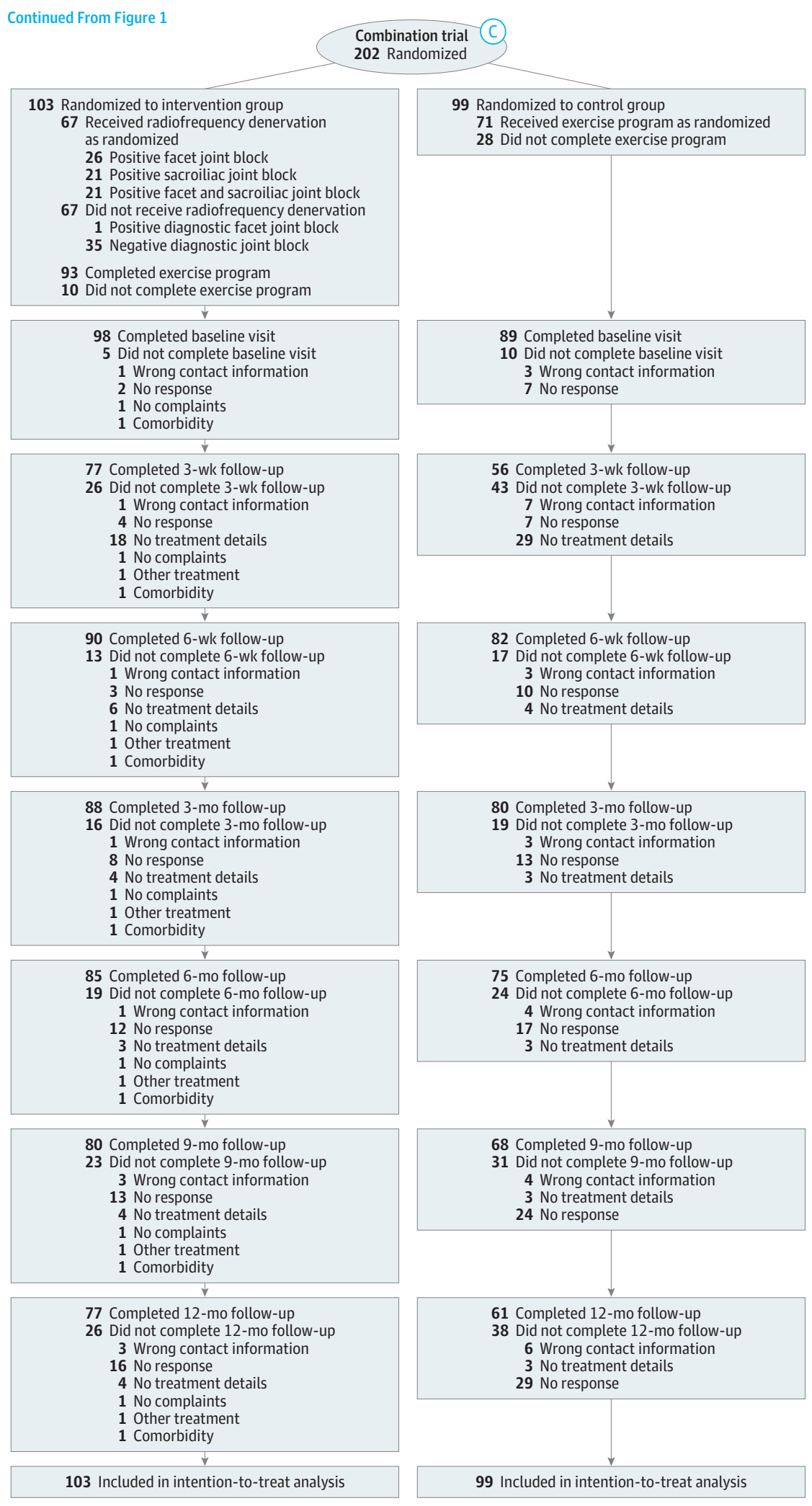




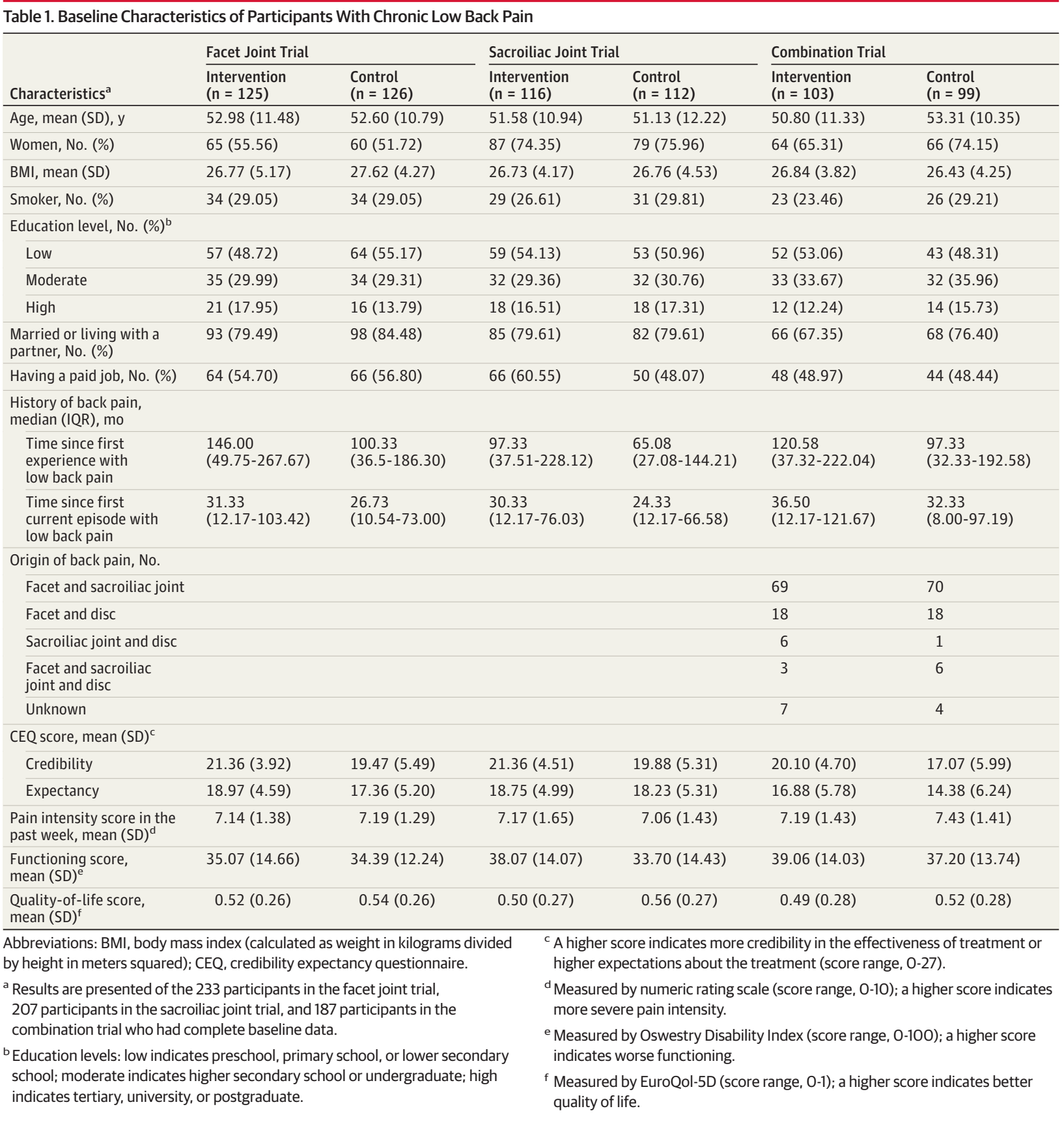

\section{Facet Joint Trial}

\section{Study Participants}

Between January 1, 2013, and June 3, 2014 (the inclusion period for the facet joint trial), 931 participants received a diagnostic facet joint block. Patients with a negative result for the diagnostic facet joint block $(n=258)$ were excluded. Patients with psychological problems $(n=277)$, older than 70 years ( $n=93)$, or with a BMI higher than $35(n=52)$ were followed up in the observational study. The inclusion criteria were met by 251 participants for the facet joint trial and were randomized to the intervention group $(\mathrm{n}=125)$ and control group $(n=126)$ (Figure 1 and Figure 2).
Baseline characteristics were comparable across groups (Table 1). However, participants in the intervention group had a first low back pain episode 12 years prior compared with 8 years prior in the control group.

Complete data on pain intensity, functional status, and global perceived recovery after 3 months was obtained from 233 participants (93\%). Complete outcome data on all follow-up points during the year were obtained from 179 participants (71\%). Participants with complete data were older, more often nonsmokers, were more likely to have a partner, had a higher BMI, and had low back pain complaints for a longer period (eTable 1 in Supplement 2). 


\begin{tabular}{|c|c|c|c|c|}
\hline Overall Effect & $\begin{array}{l}\text { Intervention Group, } \\
\text { Mean }(95 \% \mathrm{Cl})\end{array}$ & $\begin{array}{l}\text { Control Group, } \\
\text { Mean }(95 \% \mathrm{Cl})\end{array}$ & $\begin{array}{l}\text { Between-Group Difference, } \\
\text { Mean }(95 \% \mathrm{CI})^{\mathrm{C}}\end{array}$ & $P$ Value \\
\hline $\begin{array}{l}\text { Facet joint trial, } \\
\text { No. of participants }\end{array}$ & 125 & 126 & & \\
\hline Overall & & & $-0.08(-0.50$ to 0.34$)$ & .71 \\
\hline 3 wk & 5.17 (4.73 to 5.61$)$ & 5.92 (5.58 to 6.26$)$ & $-0.41(-1.02$ to 0.19$)$ & .18 \\
\hline 6 wk & 5.19 (4.76 to 5.61$)$ & 5.90 (5.53 to 6.26$)$ & $-0.38(-0.96$ to 0.20$)$ & .20 \\
\hline $3 \mathrm{mo}$ & 5.01 (4.59 to 5.43 ) & 5.44 (5.03 to 5.85$)$ & $-0.18(-0.76$ to 0.40$)$ & .55 \\
\hline $6 \mathrm{mo}$ & 4.61 (4.18 to 5.04$)$ & $4.84(4.38$ to 5.30$)$ & $-0.04(-0.63$ to 0.56$)$ & .91 \\
\hline $9 \mathrm{mo}$ & 4.66 (4.20 to 5.00$)$ & 4.73 (4.24 to 5.22$)$ & $0.19(-0.41$ to 0.80$)$ & .53 \\
\hline $12 \mathrm{mo}$ & 4.49 (4.00 to 4.97$)$ & 4.44 (3.94 to 4.94$)$ & $0.47(-0.14$ to 1.07$)$ & .13 \\
\hline $\begin{array}{l}\text { Sacroiliac joint trial, } \\
\text { No. of participants }\end{array}$ & 116 & 112 & & \\
\hline Overall & & & $-0.40(-0.83$ to 0.03$)$ & .07 \\
\hline $3 w k$ & 4.96 (4.51 to 5.40$)$ & $6.00(5.59$ to 6.41$)$ & $-0.96(-1.63$ to -0.29$)$ & .005 \\
\hline $6 w k$ & 5.22 (4.81 to 5.64$)$ & 5.69 (5.31 to 6.08$)$ & $-0.53(-1.17$ to 0.10$)$ & .10 \\
\hline $3 \mathrm{mo}$ & 4.77 (4.31 to 5.24$)$ & 5.45 (4.94 to 5.95$)$ & $-0.71(-1.35$ to -0.06$)$ & .03 \\
\hline $6 \mathrm{mo}$ & 4.50 (4.01 to 4.98$)$ & $4.78(4.24$ to 5.31$)$ & $-0.12(-0.77$ to 0.53$)$ & .73 \\
\hline $9 \mathrm{mo}$ & 5.03 (4.55 to 5.51$)$ & 4.97 (4.39 to 5.56$)$ & $0.16(-0.51$ to 0.83$)$ & .64 \\
\hline $12 \mathrm{mo}$ & 4.65 (4.16 to 5.13$)$ & 4.84 (4.30 to 5.38$)$ & $-0.07(-0.74$ to 0.60$)$ & .83 \\
\hline $\begin{array}{l}\text { Combination trial, } \\
\text { No. of participants }\end{array}$ & 103 & 99 & & \\
\hline Overall & & & $-0.21(-0.76$ to 0.35$)$ & .47 \\
\hline 3 wk & 5.45 (4.95 to 5.95$)$ & 6.40 (5.91 to 6.89$)$ & $-0.65(-1.47$ to 0.17$)$ & .12 \\
\hline 6 wk & 5.37 (4.89 to 5.85$)$ & 6.09 (5.65 to 6.52$)$ & $-0.40(-1.14$ to 0.34$)$ & .29 \\
\hline $3 \mathrm{mo}$ & 4.77 (4.25 to 5.30$)$ & 5.94 (5.42 to 6.45$)$ & $-0.99(-1.73$ to -0.25$)$ & .01 \\
\hline $6 \mathrm{mo}$ & $4.92(4.39$ to 5.44$)$ & 4.95 (4.35 to 5.54$)$ & $0.33(-0.53$ to 1.09$)$ & .39 \\
\hline $9 \mathrm{mo}$ & 5.01 (4.47 to 5.56$)$ & 5.25 (4.65 to 5.86$)$ & $-0.05(-0.82$ to 0.73$)$ & .90 \\
\hline $12 \mathrm{mo}$ & 4.85 (4.24 to 5.46$)$ & 4.38 (3.73 to 5.03$)$ & $0.69(-0.10$ to 1.49$)$ & .09 \\
\hline
\end{tabular}

Abbreviation: NNT, number needed to treat.

${ }^{a}$ Measured by numeric rating scale (score range, 0-10); a higher score indicates more severe symptoms.

${ }^{\mathrm{b}}$ The overall effect measures provide information over the total follow-up time of $12 \mathrm{mo}$, instead of the time $\times$ treatment effects.

c Values presented (for mean differences) are model estimates of linear mixed-effects models with a random intercept, and adjusted for outcome at baseline and age, sex, body mass index, education, smoking, marital status, back pain complaint history, and participant expectations. Regression coefficients can be interpreted as mean differences between interventions at a certain follow-up point compared with baseline.
Twelve participants in the control group received radiofrequency denervation within the first 3 months and were marked as participants who had protocol violations. Ten participants (8\%) in the intervention group and 11 participants (9\%) in the control group received psychological care during the 3-month intervention period.

No treatment-related adverse events were reported during the 1-year follow-up.

\section{Intention-to-Treat Analyses}

The mean difference for the primary outcome pain intensity at 3 months was -0.18 ( $95 \%$ CI, -0.76 to 0.40 ). Results on all other follow-up points are shown in Table 2 and Table 3 . The mean difference for functional status at 3 months was -2.45 (95\% CI, -5.53 to 1.03); the RR for global perceived recovery at 3 months was 1.35 (95\% CI, 0.81 to 2.05). Other follow-up points and secondary outcomes are shown in eTable 2 in Supplement 2.

\section{Post Hoc Analyses of Treatment Response}

No significant differences between the groups were found when success was defined as more than $30 \%$ or 2 points reduction or more in pain at 3 months (Table 4).

\section{Sensitivity Analyses}

When participants with protocol violations were excluded from the analysis, the interpretation of the outcomes remained similar (eTable 3 in Supplement 2). After 3 months of follow-up, 31 control group participants received radiofrequency denervation. The analyses were repeated excluding participants receiving the intervention after the 3-month intervention period; this did not alter the results either (eTable 4 in Supplement 2). The complete case analysis showed no significant between-group differences for pain intensity, functional status, and global perceived recovery at 3 months (eTable 5 in Supplement 2).

\section{Sacroiliac Joint Trial}

\section{Study Participants}

Between January 1, 2013, and July 1, 2014 (the inclusion period for the sacroiliac joint trial), 832 participants received a diagnostic sacroiliac joint block. Patients with a negative result for the diagnostic sacroiliac joint block $(n=202)$ were excluded. Patients with psychological problems $(n=257)$, older than 70 years $(n=83)$, or a BMI higher than $35(n=47)$, or other reasons for not participating in the trial $(n=15)$ were followed up in the observational study. The inclusion criteria were met by 228 participants for the sacroiliac joint trial and were randomized to the intervention group $(n=116)$ and the control group $(n=112)$ (Figure 1 and Figure 2 ).

Baseline characteristics were comparable across groups (Table 1). However, the first episode of low back pain in the intervention group was 97 months before inclusion compared with 65 months in the control group. 


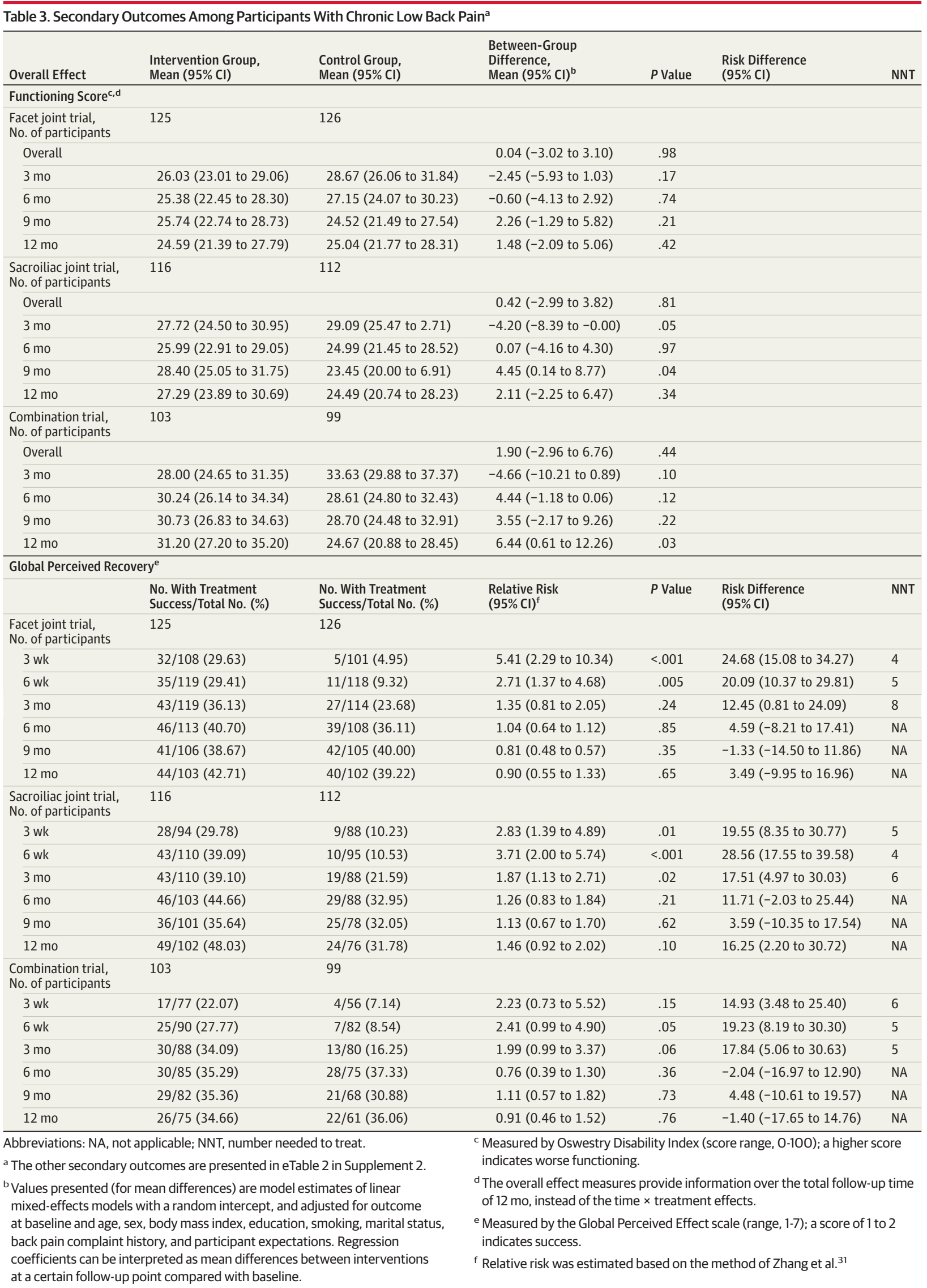




\begin{tabular}{|c|c|c|c|c|c|c|}
\hline & $\begin{array}{l}\text { Intervention Group, } \\
\text { No.With Treatment } \\
\text { Success/Total No. (\%) }\end{array}$ & $\begin{array}{l}\text { Control Group, } \\
\text { No. With Treatment } \\
\text { Success/Total No. (\%) }\end{array}$ & $\begin{array}{l}\text { Relative Risk } \\
(95 \% \mathrm{Cl})^{\mathrm{a}}\end{array}$ & $P$ Value & $\begin{array}{l}\text { Risk Difference } \\
(95 \% \mathrm{Cl})\end{array}$ & NNT \\
\hline \multicolumn{7}{|c|}{ Facet Joint Trial } \\
\hline \multicolumn{7}{|c|}{$\begin{array}{l}\text { Pain intensity } \\
\text { reduction }>30 \%\end{array}$} \\
\hline 3 wk & $40 / 102(39.22)$ & $27 / 100(27.00)$ & $1.33(0.80$ to 1.97$)$ & .25 & $12.22(-0.65$ to 25.08$)$ & NA \\
\hline 6 wk & $45 / 112(40.17)$ & $36 / 114(31.57)$ & $1.13(0.70$ to 1.63$)$ & .59 & $8.60(-3.86$ to 21.06$)$ & NA \\
\hline $3 \mathrm{mo}$ & $52 / 114(45.61)$ & $40 / 111(36.03)$ & $1.16(0.76$ to 1.60$)$ & .46 & $9.58(-3.20$ to 22.36$)$ & NA \\
\hline $6 \mathrm{mo}$ & $60 / 108(55.56)$ & $53 / 105(50.47)$ & $1.02(0.71$ to 1.33$)$ & .88 & $5.09(-8.31$ to 18.47$)$ & NA \\
\hline $9 \mathrm{mo}$ & $52 / 102(50.98)$ & $50 / 102(49.02)$ & 1.09 (0.75 to 1.42$)$ & .60 & $1.88(-11.76$ to 15.68$)$ & NA \\
\hline $12 \mathrm{mo}$ & $47 / 100(47.00)$ & $53 / 99(53.53)$ & $0.78(0.50$ to 1.09$)$ & .16 & $-6.53(-20.40$ to 7.33$)$ & NA \\
\hline \multicolumn{7}{|c|}{$\begin{array}{l}\text { Pain intensity } \\
\text { reduction } \geq 2 \text { points }\end{array}$} \\
\hline 3 wk & $56 / 102(54.90)$ & $44 / 100(44.00)$ & $1.17(0.81$ to 1.53$)$ & .36 & $10.90(-2.81$ to 24.61$)$ & NA \\
\hline 6 wk & $57 / 112(50.89)$ & $47 / 114(41.23)$ & 1.09 (0.74 to 1.46$)$ & .65 & $9.66(-3.27$ to 22.60$)$ & NA \\
\hline $3 \mathrm{mo}$ & $64 / 111(57.65)$ & $52 / 111(46.85)$ & 1.07 (0.75 to 1.39$)$ & .68 & $10.80(-2.25$ to 23.87$)$ & NA \\
\hline $6 \mathrm{mo}$ & $68 / 108(62.96)$ & $61 / 105(58.09)$ & $1.00(0.73$ to 1.25$)$ & .98 & $4.84(-8.25$ to 17.98$)$ & NA \\
\hline $9 \mathrm{mo}$ & $56 / 102(54.90)$ & $58 / 102(56.86)$ & $0.90(0.62$ to 1.17$)$ & .47 & $-1.96(-15.59$ to 11.66$)$ & NA \\
\hline $12 \mathrm{mo}$ & $55 / 100(55.00)$ & $55 / 99(55.56)$ & $0.76(0.49$ to 1.05$)$ & .11 & $-0.56(-14.37$ to 13.26$)$ & NA \\
\hline \multicolumn{7}{|c|}{ Sacroiliac Joint Trial } \\
\hline \multicolumn{7}{|c|}{$\begin{array}{l}\text { Pain intensity } \\
\text { reduction }>30 \%\end{array}$} \\
\hline 3 wk & $41 / 90(45.56)$ & $16 / 83(19.27)$ & 2.35 (1.45 to 3.32$)$ & .001 & 26.29 (12.94 to 39.62$)$ & 4 \\
\hline 6 wk & $43 / 104(41.35)$ & $25 / 91(27.47)$ & $1.49(0.94$ to 2.18$)$ & .08 & 13.88 (0.69 to 27.05$)$ & 7 \\
\hline $3 \mathrm{mo}$ & $48 / 105(45.71)$ & $29 / 84(34.52)$ & $1.33(0.87$ to 1.81$)$ & .16 & $11.19(-2.74$ to 25.13$)$ & NA \\
\hline $6 \mathrm{mo}$ & $50 / 99(50.51)$ & $42 / 85(49.41)$ & $1.01(0.69$ to 1.34$)$ & .94 & $1.10(-13.40$ to 15.58$)$ & NA \\
\hline $9 \mathrm{mo}$ & $39 / 98$ (39.79) & $33 / 76(43.42)$ & 0.88 (0.54 to 1.27$)$ & .53 & $-3.63(-18.39$ to 11.14$)$ & NA \\
\hline $12 \mathrm{mo}$ & $48 / 97(49.48)$ & $31 / 75(41.33)$ & 1.15 (0.75 to 1.56$)$ & .48 & 8.15 ( -6.79 to 23.09$)$ & NA \\
\hline \multicolumn{7}{|c|}{$\begin{array}{l}\text { Pain intensity } \\
\text { reduction } \geq 2 \text { points }\end{array}$} \\
\hline 3 wk & $56 / 90(62.22)$ & $30 / 83(36.14)$ & 1.68 (1.25 to 2.05$)$ & .002 & 26.08 (11.68 to 40.47$)$ & 4 \\
\hline 6 wk & $59 / 104(56.73)$ & $40 / 91(43.95)$ & $1.29(0.97$ to 1.59$)$ & .08 & $12.78(-1.18$ to 26.73$)$ & NA \\
\hline $3 \mathrm{mo}$ & $62 / 105(59.05)$ & $40 / 84(47.61)$ & 1.25 (0.94 to 1.52$)$ & .11 & $11.44(-2.80$ to 25.66$)$ & NA \\
\hline $6 \mathrm{mo}$ & $61 / 99(61.61)$ & $47 / 85(55.29)$ & $1.12(0.85$ to 1.35$)$ & .37 & $6.32(-7.94$ to 20.59$)$ & NA \\
\hline $9 \mathrm{mo}$ & $51 / 98(52.04)$ & $41 / 76(53.95)$ & $0.96(0.68$ to 1.22$)$ & .76 & $-1.91(-16.85$ to 13.04$)$ & NA \\
\hline $12 \mathrm{mo}$ & $57 / 97(58.76)$ & $41 / 75(54.67)$ & 1.04 (0.76 to 1.30$)$ & .77 & $4.09(-10.83$ to 19.03$)$ & NA \\
\hline \multicolumn{7}{|c|}{ Combination Trial } \\
\hline \multicolumn{7}{|c|}{$\begin{array}{l}\text { Pain intensity } \\
\text { reduction }>30 \%\end{array}$} \\
\hline 3 wk & $23 / 75(30.67)$ & $7 / 48(14.58)$ & 2.39 (1.08 to 4.16$)$ & .03 & 16.09 (1.64 to 30.53$)$ & 6 \\
\hline 6 wk & $32 / 88(36.36)$ & $21 / 72(29.17)$ & 1.16 (0.63 to 1.84$)$ & .60 & $7.19(-7.34$ to 21.73$)$ & NA \\
\hline $3 \mathrm{mo}$ & $43 / 86(50.00)$ & $19 / 72(26.38)$ & 1.92 (1.19 to 2.65$)$ & .01 & 23.62 (8.94 to 38.28$)$ & 4 \\
\hline $6 \mathrm{mo}$ & $36 / 82(43.90)$ & $38 / 68(55.88)$ & 0.77 (0.44 to 1.11$)$ & .19 & $-11.98(-27.94$ to 3.98$)$ & NA \\
\hline $9 \mathrm{mo}$ & $38 / 81(46.91)$ & $26 / 61(42.62)$ & 1.05 (0.62 to 1.52$)$ & .83 & 4.29 (-12.21 to 20.79$)$ & NA \\
\hline $12 \mathrm{mo}$ & $37 / 75$ (49.33) & $32 / 56(57.14)$ & $0.86(0.52$ to 1.21$)$ & .47 & $-7.81(-25.02$ to 9.40$)$ & NA \\
\hline \multicolumn{7}{|c|}{$\begin{array}{l}\text { Pain intensity } \\
\text { reduction } \geq 2 \text { points }\end{array}$} \\
\hline 3 wk & $32 / 75(42.67)$ & $12 / 48(25.00)$ & 1.67 (0.89 to 2.57$)$ & .10 & 17.67 (1.04 to 34.26$)$ & 5 \\
\hline 6 wk & $44 / 88(50.00)$ & $33 / 72(45.83)$ & $0.96(0.58$ to 1.37$)$ & .83 & $4.17(-11.38$ to 19.71$)$ & NA \\
\hline $3 \mathrm{mo}$ & $48 / 86(55.81)$ & $28 / 72(38.88)$ & $1.32(0.85$ to 1.79$)$ & .20 & 16.93 (1.53 to 32.32$)$ & 5 \\
\hline $6 \mathrm{mo}$ & $49 / 82(59.76)$ & $43 / 68(63.23)$ & $0.91(0.59$ to 1.19$)$ & .54 & $-3.47(-19.10$ to 12.14$)$ & NA \\
\hline $9 \mathrm{mo}$ & $48 / 81(59.25)$ & $34 / 61(55.73)$ & $0.98(0.62$ to 1.31$)$ & .91 & $3.52(-12.91$ to 19.95$)$ & NA \\
\hline $12 \mathrm{mo}$ & $41 / 75(54.67)$ & $37 / 56(66.07)$ & $0.80(0.50$ to 1.10$)$ & .21 & $-11.40(-28.16$ to 5.35$)$ & NA \\
\hline
\end{tabular}

Abbreviations: NA, not applicable; NNT, number needed to treat.

${ }^{a}$ Relative risk was estimated based on the method of Zhang et al. ${ }^{31}$ 
Complete data on pain intensity, functional status, and global perceived recovery after 3 months were obtained from 198 participants (87\%). Complete outcome data on all follow-up points during the year were obtained from 134 participants (59\%). The participants with complete data were older, more often nonsmokers, were more likely to have a partner, and had low back pain complaints for a longer period (eTable 1 in Supplement 2).

Seven participants in the control group received radiofrequency denervation within the first 3 months and were marked as participants who had protocol violations. Seven participants (6\%) in the intervention group and 6 participants (5\%) in the control group received psychological care during the 3-month intervention period.

There was 1 registered treatment-related complication (vasovagal reaction to treatment).

\section{Intention-to-Treat Analyses}

The mean difference for the primary outcome pain intensity at 3 months was -0.71 ( $95 \%$ CI, -1.35 to -0.06 ). Results on all other follow-up points are shown in Table 2 and Table 3 . The mean difference for functional status at 3 months was -4.20 (95\% CI, -8.39 to -0.002); the RR for global perceived recovery at 3 months was 1.87 (95\% CI, 1.13 to 2.71 ). Other follow-up points and secondary outcomes are shown in eTable 2 in Supplement 2.

\section{Post Hoc Analyses of Treatment Response}

No significant differences between the groups were found when success was defined as more than $30 \%$ or 2 points reduction or more in pain at 3 months (Table 4 ).

\section{Sensitivity Analyses}

When participants who had protocol violations were excluded from the analysis, the interpretation of the outcomes remained similar (eTable 3 in Supplement 2). After 3 months of follow-up, 41 control group participants received radiofrequency denervation. Excluding these from the analysis did not change the long-term results (eTable 4 in Supplement 2). The complete case analysis showed no significant between-group differences for the primary outcomes at 3 months than participants without complete data (eTable 5 in Supplement 2).

\section{Combination Trial}

Study Participants

Between January 1, 2013, and October 24, 2014 (the inclusion period for participants in this trial), 793 participants were eligible for this trial. The inclusion criteria were met by 202 participants, and those participants were randomly assigned to the intervention $(n=103)$ and control group $(n=99)$. All reasons for exclusions are presented in the flow charts (Figure 1 and Figure 3).

Baseline characteristics were comparable in both groups (Table 1).

Complete data on pain intensity, functional status, and global perceived recovery after 3 months were obtained from 168 participants (83\%). Complete data on all follow-up assessments were obtained from 89 participants (44\%) on the effect measures. Participants with complete data had low back pain complaints for a longer period, but were similar for all other demographic characteristics (eTable 1 in Supplement 2).

Two participants in the control group received radiofrequency denervation, and 2 participants did not receive any treatment. In the intervention group, 11 participants did not receive or it was unknown if they received the standardized exercise program. These 14 participants were considered participants who had protocol violations. Eight participants (8\%) in the intervention group and 10 participants (10\%) in the control group received psychological care during the 3-month intervention period.

In the intervention group, 35 participants had negative results for diagnostic blocks and did not receive radiofrequency denervation. These participants were still included in the intention-to-treat analyses. The diagnostic block had a positive result for 68 participants, of whom 25 received facet joint radiofrequency denervation, 21 sacroiliac joint radiofrequency denervation, 21 received a combination of radiofrequency denervation treatments (facet and sacroiliac joint radiofrequency denervation), and 1 participant did not receive radiofrequency denervation despite a positive result for the diagnostic block.

One complication was recorded during the 1-year follow-up in the intervention group: a hematoma, causing extra pain. The participant completely recovered.

\section{Intention-to-Treat Analyses}

The mean difference for the primary outcome pain intensity at 3 months was -0.99 ( $95 \% \mathrm{CI},-1.73$ to -0.25$)$. Results on all other follow-up points are shown in Table 2 and Table 3. The mean difference for functional status at 3 months was -4.66 (95\% CI, -10.21 to 0.89); the RR for global perceived recovery at 3 months was 1.99 (95\% CI, 0.99 to 3.36). Other follow-up points and secondary outcomes are shown in eTable 2 in Supplement 2.

\section{Post Hoc Analyses of Treatment Response}

When success was defined as 30\% pain reduction (RR, 1.92 [95\% CI, 1.19 to 2.65]), there was a statistically significant difference at 3 months favoring the intervention group (Table 4).

\section{Sensitivity Analyses}

Excluding participants who had protocol violations from the analysis slightly increased the contrast between the groups, as significantly more people in the intervention group recovered based on global perceived recovery after 3 months (RR, 2.07 [95\% CI, 1.02 to 3.43]) (eTable 3 in Supplement 2). After 3 months follow-up, 31 control group participants received radiofrequency denervation. The analyses were repeated without participants receiving the intervention after the 3-month intervention period; this resulted in only minor differences (eTable 4 in Supplement 2). The completecases analysis showed no significant between-group differences for the primary outcomes at 3 months (eTable 5 in Supplement 2). 


\section{Discussion}

In 3 trials, the effects of radiofrequency denervation for participants with chronic low back pain due to facet joints, sacroiliac joints, or a combination of the facet joints, sacroiliac joints, or intervertebral disks in addition to a standardized exercise program were compared with a standardized exercise program alone. The 2 trials assessing radiofrequency denervation for the sacroiliac joints and a combination of the facet joints, sacroiliac joints, or intervertebral disks showed a statistically significant but not clinically important improvement in pain intensity 3 months after the intervention. No clinically important or statistically significant differences between the groups were shown in the trial assessing radiofrequency denervation for facet joint pain. Only small or no effects were found for all secondary outcomes.

Based on this study, radiofrequency denervation is not recommended and should be performed only in a research setting. Patients with chronic low back pain who show no improvement in symptoms after conservative treatment have no clear alternative therapies that have been shown to be effective. Future research regarding the diagnosis and treatment for low back pain in participants with chronic low back pain is necessary and should focus on better participant selection (because there remains a possibility that radiofrequency denervation could be beneficial on a subset of participants) and improvement of the treatment techniques.

\section{Strengths and Limitations}

Strengths of these trials are the large sample sizes and stratified randomization that allowed for well-balanced study groups, and the use of outcome measures as recommended by the core outcome set for low back pain research. ${ }^{32}$ In addition to the primary time point at 3 months, a follow-up of 12 months was included.

This study has several limitations. First, different radiofrequency denervation techniques (cooled radiofrequency denervation, Palisade, and Simplicity III) were used in the sacroiliac joint trial. ${ }^{33-36}$ However, the groups were too small for a subgroup analysis. Second, because the aim of the study was to provide evidence of the added value of radiofrequency denervation in a multidisciplinary setting, as done in daily practice, participants and clinicians were not blinded. Evidence suggests that treatment effects for subjective outcomes may be overestimated when outcome assessors (ie, participants, if outcomes are self-reported) are not blinded. ${ }^{37}$ However, the magnitude of this bias is unknown. The lack of blinding was a significant limitation of the trials, and it is possible that radiofrequency denervation could even be harmful, but the lack of blinding may have made the treatment effect seem null. Also, the short-term differences in global perceived recovery for facet joint and sacroiliac joint radiofrequency denervation in absence of a difference in functional status might be the result of a nonspecific effect due to the nonblinded study design.

Third, a reference standard for diagnosing facet joint or sacroiliac joint pain is not available. ${ }^{14}$ In this pragmatic study, diagnostic tests that are commonly applied in clinical practice were used. Controversy concerning the ideal threshold value of pain reduction in the diagnostic blocks exists. A 50\% cutoff was most frequently used in previous studies ${ }^{38}$ and in clinical practice. Performing 2 or more independent diagnostic blocks will decrease the false-positive rate, but increase the number of false-negative blocks. ${ }^{38}$ Furthermore, a clinical trial showed that multiple blocks are not cost-effective. ${ }^{38}$

Fourth, the generalizability of the results might be reduced by the large number of people excluded for psychological problems. In the Netherlands, participants visiting a pain clinic often have long-lasting persistent low back pain. A large number of these participants have psychological problems. These participants were excluded from this study because in daily practice they are not considered candidates for radiofrequency denervation and will be referred to psychological treatment.

Fifth, in all 3 trials, some control group participants received radiofrequency denervation after the 3-month intervention period ( $25 \%$ in the facet joint trial, $35 \%$ in sacroiliac joint trial, and $31 \%$ in the combination trial) and some intervention group participants received a second radiofrequency denervation ( $8 \%$ in the facet joint trial, $17 \%$ in the sacroiliac joint trial, and $15 \%$ in the combination trial). This could have influenced the long-term outcomes. However, sensitivity analyses without these participants showed similar results.

Sixth, in the sacroiliac joint trial, there was a higher dropout in the control group. This could potentially have biased the long-term results.

Seventh, in the combination trial, not all participants in the intervention group received radiofrequency denervation, because they did not respond to the diagnostic block or provocative discography.

Eighth, more missing data were found in the combination trial compared with the other 2 trials. This is a potential limitation, but because of the relatively large number of dropouts at 12 months, the complete case analysis might also be biased. Although we did not define differences between the complete-case analysis and the intention-to-treat analysis using all data, it is possible that completers are different from noncompleters, which could have biased the results of the complete-case analyses.

Ninth, we assessed multiple outcomes and made no adjustment for multiple comparisons, which could have resulted in some statistically significant findings by chance.

\section{Comparison With the Literature}

Recent systematic reviews have evaluated the association of radiofrequency denervation with isolated pain sources and showed evidence of low to moderate quality for associations of facet joint radiofrequency with small positive effects on pain and functional status compared with placebo or steroid injections. ${ }^{9-11}$ There is very low to moderate quality evidence and conflicting evidence for sacroiliac joint radiofrequency denervation and radiofrequency denervation in the intervertebral disk. ${ }^{5,9-11}$ In the trials included in these reviews, participants had a baseline pain score of 1 point lower compared with this trial, and the radiofrequency denervation groups decreased more (to 3.3 of 10) than the placebo groups (to 5.0 of 10). In the Mint study, participants in both groups decreased 
in pain, but both groups continued to have a higher pain level compared with other similar trials.

\section{Conclusions}

In 3 randomized clinical trials of participants with chronic low back pain originating in the facet joints, sacroiliac joints, or a combination of facet joints, sacroiliac joints, or intervertebral disks, radiofrequency denervation combined with a standardized exercise program resulted in either no improvement or no clinically important improvement in chronic low back pain compared with a standardized exercise program alone. The findings do not support the use of radiofrequency denervation to treat chronic low back pain from these sources.

\section{ARTICLE INFORMATION}

Accepted for Publication: June 6, 2017.

Author Affiliations: Department of Anesthesiology, Erasmus University Medical Centre, Rotterdam, the Netherlands (Juch, Groeneweg, Huygen); Department of Health Sciences, Faculty of Earth and Life Sciences, Vrije Universiteit Amsterdam, Amsterdam, the Netherlands (Maas, Ostelo, van Dongen, van Tulder); The EMGO+ Institute for Health and Care Research, Amsterdam, the Netherlands (Maas, Ostelo, van Dongen, van Tulder); Department of Epidemiology and Biostatistics, Vrije Universiteit Medical Centre Amsterdam, Amsterdam, the Netherlands (Ostelo); Department of Anesthesiology, Rijnstate hospital, Velp, the Netherlands (Kallewaard); Department of General Practice, Erasmus University Medical Centre, Rotterdam, the Netherlands (Koes, Verhagen).

Author Contributions: Drs Maas and Juch had full access to all of the data in the study and take responsibility for the integrity of the data and the accuracy of the data analysis. Drs Juch and Maas are shared first author, listed in alphabetical order. Concept and design: Juch, Maas, Ostelo, Groeneweg, Kallewaard, Koes, Verhagen, Huygen, van Tulder.

Acquisition, analysis, or interpretation of data: Juch, Maas, Koes, van Dongen, Huygen, van Tulder. Drafting of the manuscript: Juch, Maas, Ostelo, Groeneweg, Koes, Verhagen, Huygen, van Tulder. Critical revision of the manuscript for important intellectual content: All authors.

Statistical analysis: Juch, Maas, van Dongen. Obtained funding: Koes, Huygen, van Tulder. Administrative, technical, or material support: Juch, Maas, Kallewaard, Huygen.

Supervision: Ostelo, Groeneweg, Huygen, van Tulder.

Conflict of Interest Disclosures: All authors have completed and submitted the ICMJE Form for Disclosure of Potential Conflicts of Interest. Dr Ostelo reports receiving grant funding from the Netherlands Organisation for Scientific Research and Scientific Association Physiotherapy. Dr van Tulder reports receiving funding to his institution from professional organizations (eg, the Royal Dutch Association for Physiotherapy; the Netherlands National Chiropractic Association and the European Chiropractic Union); travel expenses by the organizing professional organizations when speaking at conferences; and honoraria for reviewing grant proposals from Swedish and Canadian governmental grant agencies. He has not received any honoraria or travel expenses from the industry. No other disclosures were reported.

Funding/Support: This study was funded by grant 171202013 from the Netherlands Organization for Health Research and Development, by the Dutch
Society for Anesthesiology, and the Dutch health insurance companies.

Role of the Funder/Sponsor: The funders played no role in the design and conduct of the study; collection, management, analysis, and interpretation of the data; and preparation, review, or approval of the manuscript or decision to submit the manuscript for publication.

Additional Contributions: We thank Merel van Raamt, PT, and Robert van Cingel, PhD (both from Sports Medical Centre Papendal [SMCP]), for their help in developing the exercise program. SMCP received financial support from the research grant for the development of the protocol. We also thank all participants, physiotherapists, and everyone working on the Mint study at the participating pain clinics. The participating pain clinics received reimbursement from the research grant for their extra study-related administrative tasks.

Additional Information: The following were in charge of participant recruitment and treatment per clinic: Bernard Lo, MD (Diakonessenhuis Utrecht/Zeist); Harmen Pelleboer, MD (Medisch Centrum Alkmaar); Jasper Kal, MD, PhD, FIPP (Onze Lieve Vrouwe Gasthuis Amsterdam); Dennis Harhangi, MD (Havenziekenhuis Rotterdam); Renate Munnikes, MD, FIPP (Maasstad ziekenhuis Rotterdam); Willem-Jan Hofsté, MD (St Antonius ziekenhuis Nieuwegein); Katja Bürger, MD (Alrijne ziekenhuis Leiderdorp); Michel Wagemans, MD (Reinier de Graaf Gasthuis Delft); Mettje Hanje, MD (Medisch Spectrum Twente Enschede); Michel Terheggen, MD (Rijnstate ziekenhuis Velp); Gilbert Tjiang, MD (Amphia ziekenhuis Breda); Maurice Giezeman, MD (Isala klinieken, Zwolle); Joep Scholten, MD (Gelre ziekenhuis Apeldoorn); Eric van den Bosch, MD (Medisch Centrum Leeuwarden); Antal van der Gaag, MD (Catharina ziekenhuis Eindhoven); Hans Aukes, MD (Albert Schweitzer ziekenhuis Sliedrecht).

\section{REFERENCES}

1. Martin BI, Deyo RA, Mirza SK, et al. Expenditures and health status among adults with back and neck problems. JAMA. 2008;299(6):656-664.

2. Vos $T$, Flaxman $A D$, Naghavi $M$, et al. Years lived with disability (YLDs) for 1160 sequelae of 289 diseases and injuries 1990-2010: a systematic analysis for the Global Burden of Disease Study 2010 [correction appears in Lancet. 2013;381(9867):628]. Lancet. 2012;380(9859): 2163-2196

3. Katz JN. Lumbar disc disorders and low-back pain: socioeconomic factors and consequences. J Bone Joint Surg Am. 2006;88(suppl 2):21-24.

4. Dieleman JL, Baral R, Birger M, et al. US spending on personal health care and public health, 1996-2013. JAMA. 2016;316(24):2627-2646.
5. van Zundert J, Hartrick C, Lataster A, Huygen F, Mekhail N, van Kleef MPJ. Evidence-Based Interventional Pain Practice: According to Clinical Diagnoses. Oxford, UK: Wiley-Blackwell; 2011.

6. Bogduk $N$. The anatomical basis for spinal pain syndromes. J Manipulative Physiol Ther. 1995;18(9): 603-605.

7. Manchikanti L, Hirsch JA, Pampati V, Boswell MV. Utilization of facet joint and sacroiliac joint interventions in Medicare population from 2000 to 2014: explosive growth continues! Curr Pain Headache Rep. 2016;20(10):58.

8. Koes BW, van Tulder M, Lin C-WC, Macedo LG, McAuley J, Maher C. An updated overview of clinical guidelines for the management of non-specific low back pain in primary care. Eur Spine J. 2010;19(12):2075-2094.

9. Maas ET, Ostelo RW, Niemisto L, et al. Radiofrequency denervation for chronic low back pain. Cochrane Database Syst Rev. 2015;10(10): CD008572.

10. Henschke N, Kuijpers T, Rubinstein SM, et al. Injection therapy and denervation procedures for chronic low-back pain: a systematic review. Eur Spine J. 2010;19(9):1425-1449.

11. Maas ET, Juch JN, Groeneweg JG, et al. Cost-effectiveness of minimal interventional procedures for chronic mechanical low back pain: design of four randomised controlled trials with an economic evaluation. BMC Musculoskelet Disord. 2012;13:260

12. Szadek KM, van der Wurff $P$, van Tulder MW, Zuurmond WW, Perez RSGM. Diagnostic validity of criteria for sacroiliac joint pain: a systematic review. J Pain. 2009;10(4):354-368.

13. Hancock MJ, Maher CG, Latimer J, et al. Systematic review of tests to identify the disc SIJ or facet joint as the source of low back pain. Eur Spine J. 2007;16(10):1539-1550.

14. Bogduk N. Practice Guidelines for Spinal Diagnostic and Treatment Procedures. Hinsdale, IL: International Spine Intervention Society; 2004.

15. Kallewaard JW, Terheggen MA, Groen GJ, et al. 15: Discogenic low back pain. Pain Pract. 2010;10 (6):560-579.

16. Devilly GJ, Borkovec TD. Psychometric properties of the credibility/expectancy questionnaire. J Behav Ther Exp Psychiatry. 2000; 31(2):73-86.

17. Bombardier C. Outcome assessments in the evaluation of treatment of spinal disorders: summary and general recommendations. Spine (Phila Pa 1976). 2000;25(24):3100-3103.

18. Hoeijenbos $M$, Bekkering $T$, Lamers $L$, Hendriks E, van Tulder M, Koopmanschap M. Cost-effectiveness of an active implementation 
strategy for the Dutch physiotherapy guideline for low back pain. Health Policy. 2005;75(1):85-98.

19. Cohen SP, Hurley RW, Buckenmaier CC III, Kurihara C, Morlando B, Dragovich A. Randomized placebo-controlled study evaluating lateral branch radiofrequency denervation for sacroiliac joint pain. Anesthesiology. 2008;109(2):279-288.

20. Cosman ER Jr, Gonzalez CD. Bipolar radiofrequency lesion geometry: implications for palisade treatment of sacroiliac joint pain. Pain Pract. 2011;11(1):3-22.

21. Schmidt PC, Pino CA, Vorenkamp KE. Sacroiliac joint radiofrequency ablation with a multilesion probe: a case series of 60 patients. Anesth Analg. 2014;119(2):460-462.

22. Gauci CA, Jankowiak B. Manual of RF Techniques: A Practical Manual of Radiofrequency Procedures in Chronic Pain Management. Seattle, WA: CoMedical; 2011.

23. Downie WW, Leatham PA, Rhind VM, Wright V, Branco JA, Anderson JA. Studies with pain rating scales. Ann Rheum Dis. 1978;37(4):378-381.

24. Fairbank JC, Pynsent PB. The Oswestry Disability Index. Spine (Phila Pa 1976). 2000;25(22): 2940-2952.

25. Brooks R. EuroQol: the current state of play. Health Policy. 1996;37(1):53-72.
26. Hays RD, Morales LS. The RAND-36 measure of health-related quality of life. Ann Med. 2001;33(5): 350-357.

27. Lousberg R, Van Breukelen GJP, Groenman NH Schmidt AJM, Arntz A, Winter FAM. Psychometric properties of the Multidimensional Pain Inventory, Dutch Language Version (MPI-DLV). Behav Res Ther. 1999;37(2):167-182

28. Ostelo RWJG, Deyo RA, Stratford P, et al. Interpreting change scores for pain and functional status in low back pain: towards international consensus regarding minimal important change. Spine (Phila Pa 1976). 2008;33(1):90-94.

29. van der Roer N, Ostelo RW, Bekkering GE, van Tulder MW, de Vet HC. Minimal clinically important change for pain intensity, functional status, and general health status in patients with nonspecific low back pain. Spine (Phila Pa 1976). 2006;31(5):578-582.

30. Twisk JWR. Applied Multilevel Analysis: A Practical Guide for medical researchers. Cambridge, UK: Cambridge Univ Press; 2006.

31. Zhang J, Yu KF. What's the relative risk? a method of correcting the odds ratio in cohort studies of common outcomes. JAMA. 1998;280 (19):1690-1691.

32. Chiarotto A, Deyo RA, Terwee CB, et al. Core outcome domains for clinical trials in non-specific low back pain. Eur Spine J. 2015;24(6):1127-1142.
33. Ferrante FM, King LF, Roche EA, et al. Radiofrequency sacroiliac joint denervation for sacroiliac syndrome. Reg Anesth Pain Med. 2001;26 (2):137-142.

34. Patel N, Gross A, Brown L, Gekht G. A randomized, placebo-controlled study to assess the efficacy of lateral branch neurotomy for chronic sacroiliac joint pain. Pain Med. 2012;13(3):383-398.

35. Burnham RS, Yasui Y. An alternate method of radiofrequency neurotomy of the sacroiliac joint: a pilot study of the effect on pain, function, and satisfaction. Reg Anesth Pain Med. 2007;32(1):12-19.

36. van Tilburg CW, Schuurmans FA, Stronks DL, Groeneweg JG, Huygen FJ. Randomized sham-controlled double-blind multicenter clinical trial to ascertain the effect of percutaneous radiofrequency treatment for sacroiliac joint pain: three-month results. Clin J Pain. 2016;32(1):921-926.

37. Kahan BC, Cro S, Doré CJ, et al. Reducing bias in open-label trials where blinded outcome assessment is not feasible: strategies from two randomised trials. Trials. 2014;15(1):456.

38. Cohen SP, Huang JHY, Brummett C. Facet joint pain-advances in patient selection and treatment. Nat Rev Rheumatol. 2013;9(2):101-116. 


\section{Cost-effectiveness of minimal interventional procedures for patients with chronic low back pain}

Version 1.8 (Augustus 2014) 
PROTOCOL TITLE: 'Cost-effectiveness of minimal interventional procedures for patients with chronic low back pain'

\begin{tabular}{|c|c|}
\hline Protocol ID & $\begin{array}{l}\text { ABR } 39578 \\
\text { ZonMW } 171202013\end{array}$ \\
\hline Short title & Minimal interventional procedures \\
\hline Version & 1.8 \\
\hline Date & Augustus 2014 \\
\hline $\begin{array}{l}\text { Coordinating investigator/project } \\
\text { leader }\end{array}$ & $\begin{array}{l}\text { Prof.dr. F.J.P.M. Huygen f.huygen@erasmusmc.nl } \\
\text { anaesthesiologist/pain specialist }\end{array}$ \\
\hline $\begin{array}{l}\text { Principal investigators (in Dutch: } \\
\text { hoofdonderzoeker/uitvoerder) } \\
\text { Multicenter research: per site }\end{array}$ & $\begin{array}{l}\text { Prof.dr. M.W. van Tulder maurits.van.tulder@ vu.nl } \\
\text { Department of Health Sciences } \\
\text { EMGO + Institute for Health and Care Research } \\
\text { VU University Amsterdam } \\
\text { Dr. R. Ostelo r.ostelo@ vumc.nl } \\
\text { Research coordinator VU Amsterdam } \\
\text { Dr. J.G. Groeneweg j.groeneweg@erasmusmc.nl } \\
\text { Research coordinator Center for Pain Medicine } \\
\text { Erasmus MC }\end{array}$ \\
\hline $\begin{array}{l}\text { Sponsor (in Dutch: } \\
\text { verrichter/opdrachtgever) }\end{array}$ & ZonMW \\
\hline Independent physician(s) & $\begin{array}{l}\text { Drs. Maaike Dirckx } \\
\text { m.dirckx@erasmusmc.nI }\end{array}$ \\
\hline Laboratory sites & Not Applicable \\
\hline Pharmacy & Not Applicable \\
\hline
\end{tabular}


PROTOCOL SIGNATURE SHEET

\begin{tabular}{|l|l|l|}
\hline Name & Signature & Date \\
\hline Sponsor or legal representative: & Erasmus MC & \\
For non-commercial research, & $\begin{array}{l}\text { Head of Department } \\
\text { Anaesthesiology } \\
\text { Prof.dr. R.J. Stolker }\end{array}$ & \\
\hline $\begin{array}{l}\text { Coordinating Investigator/Project } \\
\text { leader/Principal Investigator: }\end{array}$ & $\begin{array}{l}\text { Prof.dr. F.J.P.M. Huygen } \\
\text { Center for Pain Medicine } \\
\text { Dept of Anaesthesiology } \\
\text { Erasmus MC }\end{array}$ & \\
\hline & & \\
\hline
\end{tabular}




\section{TABLE OF CONTENTS}

1. INTRODUCTION AND RATIONALE 9

2. OBJECTIVES 11

3. STUDY DESIGN 12

4. STUDY POPULATION 13

4.1 Population (base) 13

4.2 Inclusion criteria 13

4.3 Exclusion criteria 13

4.4 Sample size calculation 13

5. TREATMENT OF SUBJECTS 15

5.1 Investigational product/treatment 15

5.2 Use of co-intervention (if applicable) 15

5.3 Escape medication (if applicable) 15

6. INVESTIGATIONAL MEDICINAL PRODUCT 16

7. METHODS 17

7.1 Study parameters/endpoints 17

7.1.1 Main study parameter/endpoint 17

7.1.2 Secondary study parameters/endpoints 17

7.1.3 Other study parameters 18

7.2 Randomisation, blinding and treatment allocation $\quad 19$

7.2 Study procedures 20

7.3 Withdrawal of individual subjects 21

7.4 Replacement of individual subjects after withdrawal 21

7.5 Follow-up of subjects withdrawn from treatment 21

7.6 Premature termination of the study 21

8. SAFETY REPORTING 23

8.1 Section $10 \mathrm{WMO}$ event 23

8.2 Adverse and serious adverse events 23

8.2.1 Suspected unexpected serious adverse reactions (SUSAR) 23

8.2.2 Annual safety report 24

8.3 Follow-up of adverse events 24

8.4 Data Safety Monitoring Board (DSMB) 24

9. STATISTICAL ANALYSIS25

9.1 Descriptive statistics 25

9.2 Univariate analysis 25

9.3 Multivariate analysis25

9.4 Interim analysis 26

10.ETHICAL CONSIDERATIONS 27

10.1 Regulation statement 27

10.2 Recruitment and consent 27

10.3 Objection by minors or incapacitated subjects (if applicable) 27

10.4 Benefits and risks assessment, group relatedness 27 
10.5 Compensation for injury 28

10.6 Incentives (if applicable) 28

11.ADMINISTRATIVE ASPECTS AND PUBLICATION 29

11.1 Handling and storage of data and documents 29

11.2 Amendments 29

11.3 Annual progress report 29

11.4 End of study report 30

11.5 Public disclosure and publication policy30

12.REFERENCES 31 


\section{LIST OF ABBREVIATIONS AND RELEVANT DEFINITIONS}

ABR ABR form, General Assessment and Registration form, is the application form that is required for submission to the accredited Ethics Committee (In Dutch, ABR = Algemene Beoordeling en Registratie)

AE Adverse Event

AR Adverse Reaction

CA Competent Authority

CCMO Central Committee on Research Involving Human Subjects; in Dutch: Centrale Commissie Mensgebonden Onderzoek

CV Curriculum Vitae

DSMB Data Safety Monitoring Board

EU European Union

EudraCT European drug regulatory affairs Clinical Trials

GCP Good Clinical Practice

IB Investigator's Brochure

IC Informed Consent

IMP Investigational Medicinal Product

IMPD Investigational Medicinal Product Dossier

METC Medical research ethics committee (MREC); in Dutch: medisch ethische toetsing commissie (METC)

(S)AE (Serious) Adverse Event

SPC Summary of Product Characteristics (in Dutch: officiële productinfomatie IB1-tekst)

Sponsor The sponsor is the party that commissions the organisation or performance of the research, for example a pharmaceutical company, academic hospital, scientific organisation or investigator. A party that provides funding for a study but does not commission it is not regarded as the sponsor, but referred to as a subsidising party.

SUSAR Suspected Unexpected Serious Adverse Reaction

Wbp Personal Data Protection Act (in Dutch: Wet Bescherming Persoonsgevens)

WMO Medical Research Involving Human Subjects Act (in Dutch: Wet Medischwetenschappelijk Onderzoek met Mensen 


\section{SUMMARY}

Rationale: Low back pain is a common complaint associated with high costs. Minimal interventional procedures are frequently applied in pain clinics in a subgroup of patients with chronic low back pain, namely in patients with pain resulting from single sources: facet, discus, sacroiliac joint or a combination of these. There is no general accepted definition and/or classification of these kinds of complaints. The terminology, which is used in the reimbursement system (DBC system) of the Dutch Anaesthesiology Society, is a classification of mechanical, neurologic and sympathic. Mechanical low back pain is defined as pain resulting from single sources: facet, discus, sacroiliac joint or a combination of these. In the proposal we use the terminology in this way. These minimal interventional procedures are nowadays performed in pain clinics in a multidisciplinary setting for diagnosis and therapy. Treatment with minimal interventional procedures is used as a part of a multidisciplinairy pain programme. A recent systematic review issued by the Dutch Health Insurance Council (CVZ 26/3/2011) showed that the effectiveness of minimal interventional procedures for the total group of chronic low back pain is unclear and the cost-effectiveness unknown. Based on these studies CVZ has decided not to include these procedures in our public health insurance. Despite the fact that the evidence for effectiveness of minimal interventional procedures also for specific subgroups like mechanical low back pain is limited, these procedures are, based on a risk benefit balance, recommended in the practical anaesthesiology guidelines for pain treatment and frequently applied in daily practice.

Objective: The aim of this study is to evaluate whether a multidisciplinary pain programme with minimal interventional procedures is effective and cost-effective compared with the multidisciplinary pain programme alone for patients with mechanical low back pain who did not respond to conservative primary care and were referred to a pain clinic.

Study design: We will conduct three clinical and economic evaluations from a societal perspective in which the single entities of mechanical low back pain and a mix of the single entities will be studied. Besides, we will perform an observational study of the total turnover of not eligible patients in pain clinics. Outcome measures are pain intensity, recovery, functional status and costs. Both a cost-effectiveness and cost-utility analysis will be performed.

Study population: We will include patients with mechanical low back pain who are referred by a general practitioner or medical specialist to participating pain clinics. 
Intervention: In the diagnostic phase, patients will be selected by making use of diagnostic criteria as described in the Guideline low back pain (NVA, NVvN et al. 2011).

Based on signs and symptoms, patients with suspicion of a single entity, namely pain arising from the facet joints or sacroiliac joint will receive a test block with local anaesthetics.

Patients with the suspicion of pain arising from a disc will receive a provocative discography. If patients answer yes to the question 'is there a $50 \%$ or more reduction in pain?' 30 minutes after the test block, or have a positive discography; they will be randomised to a group who receives a minimal interventional treatment + a multidisciplinary pain programme versus patients receiving the multidisciplinary pain programme alone.

Patients randomised to minimal interventional procedures will be treated according to the Guideline low back pain (NVA, NVvN et al. 2011).

Besides these three randomized trials for subgroups of patients, all patients referred to the participating pain clinics and who give informed consent will be part of an observational study. The observational data will inform us about the proportion of patients with facet joint pain, disc pain, SI pain and a combination of these, the proportion of patients with a positive block within these four groups, and the clinical outcomes of patients with a negative block.

Main study parameters/endpoints: The primary outcome measure will be measuring pain intensity with the NRS, at 3 months after the intervention.

\section{Nature and extent of the burden and risks associated with participation, benefit and group relatedness:}

Participating in this trial means that difference in pain and perceived improvement in functioning will be measured at 3 and 6 weeks after the intervention; patients have to fill in web based questionnaires (see 7.1. for the questionnaires) at baseline, 3, 6, 9, and 12 months; all are referred to a multidisciplinary pain programme, and they are randomised to receive minimal interventional procedures or no additional treatment. The multidisciplinary pain program is standard care, which means that patients will not be withheld from standard care. 


\section{INTRODUCTION AND RATIONALE}

In the Netherlands the majority of patients with low back pain is successfully treated in primary care. Approximately $20 \%$ of the patients, however, still have symptoms after 3 months and 5\% after 1 year. In The Netherlands, costs of low back pain are enormous: $€ 3.4$ billion in 2007 (Lambeek, van Mechelen et al. 2010). Patients with chronic low back pain are responsible for the majority of the high costs.

Mechanical low back pain is defined as pain resulting from single sources: facet, discus, sacroiliac joint or a combination of these. In the proposal we use the terminology in this way.

When primary care treatment has not been successful in alleviating symptoms, patients may be referred to medical specialists. Minimal interventional procedures are commonly used by anaesthesiologists in a subgroup of patients with mechanical low back pain arising from structures like facet joints, discus and sacroiliac joint or combinations of these. In The Netherlands there are more than 75 certified pain clinics that use these procedures. Indications and treatment algorithms are described in the evidence based Guideline low back pain (NVA, NVvN et al. 2011). Although these procedures are commonly used, strong evidence for their effectiveness is lacking and economic evaluations have not been performed. This multidisciplinary clinical guideline has currently been developed with support of the Dutch Society of Medical Specialists.

There is consensus among anaesthesiologists, as reflected by recommendations in this guideline, that minimal interventional procedures are effective for patients with intervertebral disc, facet joint and sacroiliac joint pain or mixed forms of these. This seems to be in contrast with recently performed systematic reviews and multidisciplinary international clinical guidelines, which concluded that there is no strong evidence that supports the effectiveness of minimal interventional procedures in patients with chronic low back pain. The main reason is that randomised controlled trials with a low risk of bias and an adequate sample size are lacking. A recent systematic review issued by the Dutch Health Insurance Council (CVZ $26 / 3 / 2011$ ) showed that the effectiveness of minimal interventional procedures for the total group of chronic low back pain is unclear and the cost-effectiveness unknown. Based on this lack of evidence, the Dutch Health Insurance Council (CVZ) has decided to advise the Ministry of Health in The Netherlands not to reimburse minimal interventional procedures for low back pain within the Dutch public health insurance system. The anaesthesiologists claim that they are only treating a subgroup of these patients, namely patients with mechanical low back pain. It is important for care providers to evaluate the effectiveness and cost-effectiveness of minimal interventional procedures in this subgroup of patients.

Health insurance companies often have contracts with hospitals agreeing to reimburse treatment for patients with a specific health problem at specified costs without specifying the care that will be delivered. The use of diagnostic and therapeutic interventions is at the discretion of the medical specialists. For health 
insurance companies it is important to know whether the care that is reimbursed is effective and cost-effective.

The aim of his project will be to provide the lacking information. The Dutch Association of Anaesthesiologists, the Dutch Spine Society, the Dutch Health Insurance Council (CVZ) and the VUmc and Erasmus MC have all explicitly acknowledged the importance of this project. 


\section{OBJECTIVES}

Primary Objective: The main objective of this project is to evaluate the effectiveness and cost-effectiveness of minimal interventional procedures as an add-on to a multidisciplinary pain programme for patients with chronic mechanical low back pain who are referred to a pain programme/pain clinic.

The primary outcome measure will be measuring pain intensity with the NRS at 3 months after the intervention. 


\section{STUDY DESIGN}

Economic evaluation alongside a clinical study with four subgroups for patients with mechanical low back pain who did not respond to conservative primary care and were referred to a pain clinic.

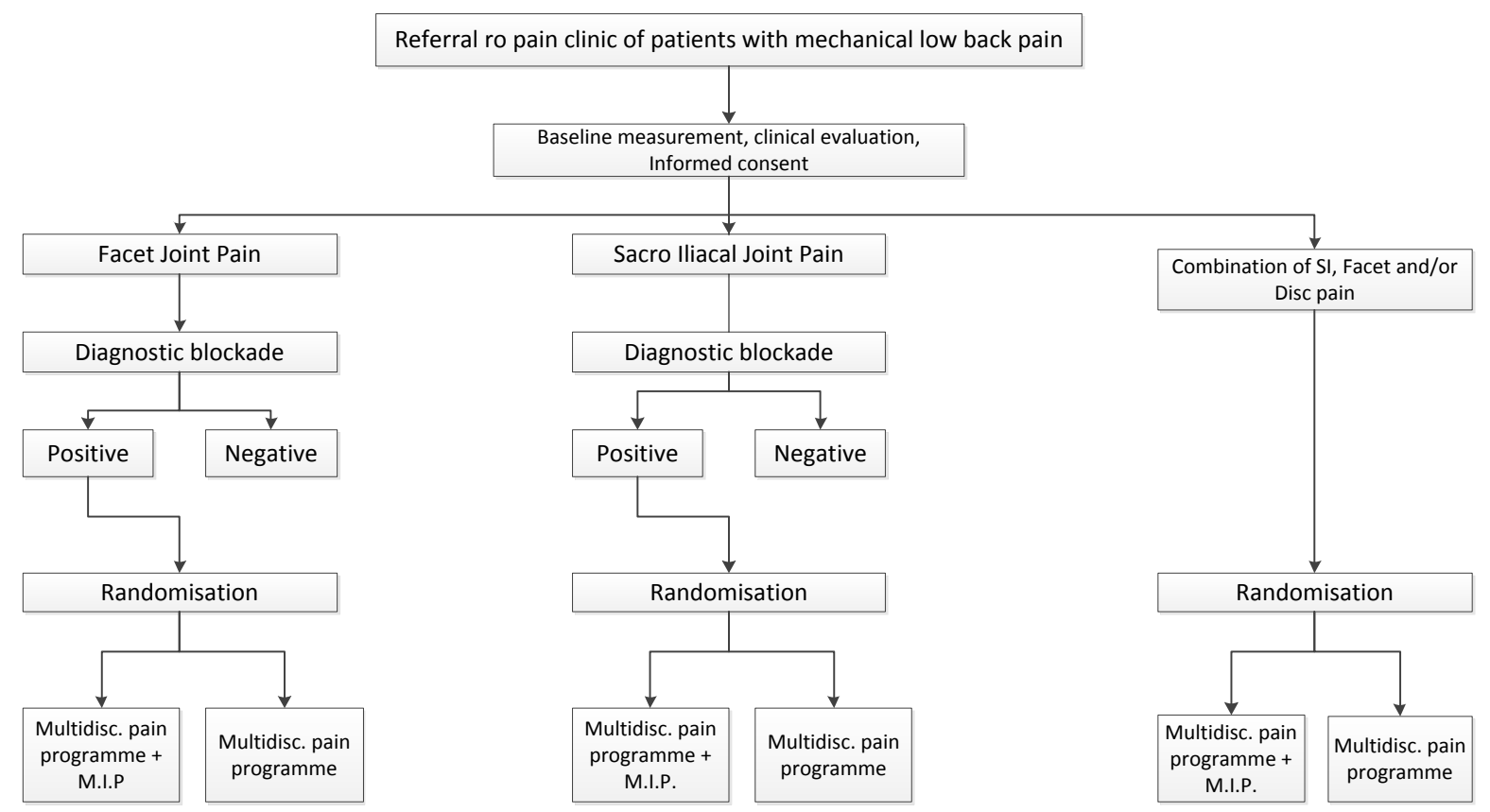

Follow - up measurements after 3 and 6 weeks: difference in pain and perceived improvement.

Follow up measurements after 3, 6, 9 and 12 months: difference in pain, perceived improvement, recovery, pain function, quality of life and patient satisfaction.

An observational study will be done alongside these trials

\footnotetext{
${ }^{*}$ Abbreviations: multidisc. pain program: multidisciplinary pain programme; M.I.P.: minimal interventional procedures
} 


\section{STUDY POPULATION}

\subsection{Population (base)}

Patients are recruited at the departments of Anaesthesiology, i.c. the pain clinics of the participating hospitals. In this study all patients who are referred to a pain programme/pain clinic with mechanical low back pain will be invited to participate. General practitioners and medical specialists who referred patients to the pain clinics will be informed about participation of their patients in the study.

\subsection{Inclusion criteria}

Chronic (more than 3 months) mechanical low back pain symptoms, age between 18 and 70 years, no improvement of symptoms after at least three months of conservative treatment according to the Dutch guidelines for non-specific low back pain (GP care (advise to stay active and pain medication) and exercise therapy) in primary care. Patients must report pain on a NRS scale of 6 or higher.

Patients must answer 'yes' on the question 'is there a $50 \%$ or more reduction in pain?', 30 minutes after the test block, or the disc provocation test must be positive.

\subsection{Exclusion criteria}

Patients with severe psychiatric or severe psychological problems, pregnant women, and patients who are not able to complete the questionnaires.

Anticoagulant drug therapy and/or disturbed coagulation BMI > 35. Involved in a work related legal dispute and /or liability claim.

Patients with less than $50 \%$ reduction in pain after the test block, or a negative disc provocation test. Patients that underwent instrumented surgery in the area to be investigated a laminectomy or a spondylodesis.

\subsection{Sample size calculation}

Using a power of .9 , alpha .05 and a correlation of .5 for repeated measurements, a total of 85 patients per group are needed to detect a clinically relevant mean difference of 2 points on the Numerical Rating Scale (SD 4). Anticipating potential study withdrawal (20\%) 102 patients per group or 204 patients per randomized comparison are needed. In total we will need to include 612 patients in this study.

The primary outcome measure is the difference in pain intensity, measured with the numeric rating scale 3 months after the intervention. Since the intervention is directed at pain reduction, it may be expected that the effects of the minimal invasive procedures will show after a short period. A long term follow up period of 12 months is chosen to evaluate whether these effects persist, and also to create a time horizon that is long enough for the economic evaluation. 
Because our primary outcome measure is the pain difference after 3 months, repeated measurements are not relevant for the sample size calculation.

The difference of 2 points in the NRS is based on a review by Ostelo et al. (Ostelo, Deyo et al. 2008), that found a Minimal Important Change of the NRS of 2 points.

Since these minimal interventional procedures have not been studied before, no SD can be found in the literature. This is in fact one of the reasons for these studies. The SD of 4 was chosen with an 'educated guess'. It may be arbitrary, but in any case it is conservative, and makes sure that we will include enough patients to find clinically relevant effects. 


\section{TREATMENT OF SUBJECTS}

\subsection{Investigational product/treatment}

The selection of adequate patients in the diagnostic phase, as well as the invasive treatment of patients is usual care, as described in the Guideline low back pain (NVA, NVvN et al. 2011).

Based on signs and symptoms, patients with suspicion of a single entity, namely pain arising from the facet joints or sacroiliac joint will receive a test block with local anaesthetics. If patients answer 'yes' to the question 'is there a $50 \%$ or more reduction in pain?' 30 minutes after the test block, patients will be scheduled to receive a minimal interventional treatment.

Patients with suspicion of pain arising from the intervertebral disc will receive as test a provocative discography. If this test is positive than they will be scheduled to receive a minimal interventional treatment.

The minimal interventional procedures will take place according to a pre-specified approach:

1) Patients with facet joint pain will receive radiofrequency denervation of the first ramus dorsalis at $L 3, L 4, L 5$ and $S 1$.

2) Patients with intervertebral disc pain will receive a denervation of the involved discus.

3) Patients with sacroiliac joint pain will receive radiofrequency denervation of the ramus dorsalis at L5, S1, S2 and S3.

4) Patients with a combination of the single entities will be randomised after the clinical diagnosis to a group who receives minimal interventional treatments (i.e. a combination of the interventions mentioned under 1,2 and 3) and a multidisciplinary pain programme.

\subsection{Use of co-intervention (if applicable)}

Any co intervention will be measured and included in the cost effectiveness analysis.

\subsection{Escape medication (if applicable)}

Not applicable 
6. INVESTIGATIONAL MEDICINAL PRODUCT

Not applicable 


\section{METHODS}

\subsection{Study parameters/endpoints}

\subsubsection{Main study parameter/endpoint}

The primary outcome will be measuring pain intensity with the NRS at 3 months after the intervention.

\subsubsection{Secondary study parameters/endpoints}

\begin{tabular}{|c|c|c|c|c|c|c|c|}
\hline \multirow[t]{2}{*}{ Outcome measures } & \multicolumn{4}{|c|}{ Follow-up } & \multirow[b]{2}{*}{$\begin{array}{c}6 \\
\text { months }\end{array}$} & \multirow[b]{2}{*}{$\begin{array}{c}9 \\
\text { months }\end{array}$} & \multirow[b]{2}{*}{$\begin{array}{c}12 \\
\text { months }\end{array}$} \\
\hline & Baseline & $\begin{array}{c}3 \\
\text { weeks }\end{array}$ & $\begin{array}{c}6 \\
\text { weeks }\end{array}$ & $\begin{array}{c}3 \\
\text { months }\end{array}$ & & & \\
\hline \multicolumn{8}{|l|}{ Primary outcomes RCT } \\
\hline Pain Intensity (NRS) & $x$ & $x$ & $x$ & $x$ & $x$ & $x$ & $x$ \\
\hline \multicolumn{8}{|l|}{ Secondary outcomes } \\
\hline Global perceived recovery (NRS) & $x$ & $x$ & $x$ & $\mathrm{x}$ & $\mathrm{x}$ & $\mathrm{x}$ & $\mathrm{x}$ \\
\hline Quality of life (EQ-5D) & $x$ & $x$ & $x$ & $x$ & $x$ & $x$ & $x$ \\
\hline Patient satisfaction (NRS) & $x$ & & & $x$ & $x$ & $x$ & $x$ \\
\hline Functional Status (ODI) & $x$ & & & $x$ & $x$ & $x$ & $x$ \\
\hline General health (Rand-36) & $x$ & & & $x$ & $x$ & $x$ & $x$ \\
\hline Chronic pain experience (MPI) & $x$ & & & $x$ & $x$ & $x$ & $x$ \\
\hline \multicolumn{8}{|l|}{ Others } \\
\hline Demographic data & $x$ & & & & & & \\
\hline Pain expectation (CEQ) & $x$ & & & & & & \\
\hline Pain coping strategies (PCI) & $x$ & & & & & & \\
\hline Pain cognition (PCL) & $x$ & & & & & & \\
\hline Depression etc. (4DSQ) & $x$ & & & & & & \\
\hline Pain acceptance (CPAQ) & $x$ & & & & & & \\
\hline Anxiety, depression (HADS) & $x$ & & & & & & \\
\hline \multicolumn{8}{|l|}{ Economic evaluation } \\
\hline Costs (diaries) & & & & monthly & & & \\
\hline
\end{tabular}

Follow-up will be 12 months. All patients participating in the trial will complete questionnaires at baseline and after 3, 6, 9, and 12 months. (The difference in pain intensity and the global-perceived improvement in functioning and quality of life will also be measured at 3 and 6 weeks after the intervention). We will ask patients to complete web-based questionnaires. If patients do not have access to the internet or prefer hard copies, we will provide these. Study subjects included in the study will receive up to two (e-mail) reminders to fill out the questionnaires. If patients still not respond the investigators will try to contact the patients by telephone once. If the patient then refuses to fill out the questionnaires the investigators will ask if by telephone they can ask the following at the three month measure points: Pain 
Intensity (NRS), Global perceived recovery (NRS) and Patient satisfaction (NRS). Patients who refuse, will be considered lost to follow up. The core set of primary outcomes recommended for low back pain research (Bombardier 2000) will be used: global perceived recovery (7-point scale), functional status (Oswestry Disability Index (ODI)), and pain intensity (leg and back) (11-point NRS). Also general health (Rand-36), quality of life (EuroQol-5D) and patient satisfaction (NRS) are measured. The Multidimensional Pain Inventory (MPI) will be used to assess a number of dimensions of the chronic pain experience, including pain intensity, emotional distress, cognitive and functional adaptation, and social support. Patient expectation will be measured at baseline, using the CEQ. Pain cognition and coping will be measured with the Pain Cognition List and the Pain Coping Inventory. Furthermore, psychological questionnaires will be used at baseline to be able to exclude patients with severe psychiatric or psychological complaints: the 4 Dimensional Symptoms Questionnaire (4DSQ), the Chronic Pain Acceptance Questionnaire (CPAQ) and the Hospital Anxiety Depression Scale (HADS). Amongst patients that have completed the full year of follow up, dining vouchers will be distributed by means of a raffle.

\subsubsection{Other study parameters}

\section{Economic evaluation: General considerations}

Four economic evaluations will be performed alongside the four randomized trials. The aim of the economic evaluation is to determine and compare the total rehabilitation-related costs for patients in both trial arms, and to relate these costs to the effects of these two groups. The economic evaluations will be performed according to the intention-to-treat principle and from a societal perspective.

\section{Economic evaluation: Costs}

- Costs indicators, the following costs are considered in this study:

- Costs of minimal interventional procedures

- Costs of the rehabilitation programme

- Other health care costs including the costs of physiotherapy (during follow up and in the control group), manual therapy, additional visits to other health care providers (e.g. GPs, medical specialist), prescription of medication, professional home care and hospitalisation.

- Patient and family costs include out-of-pocket expenses (i.e., over the counter medication) and costs of paid and unpaid help.

- Costs due to loss of production due to LBP-related work absenteeism (paid jobs and unpaid jobs).

- Measurement of volumes:

- Number of treatment sessions during the intervention period will be registered by the therapist on standardised forms. 
- All other health care costs, patient and family costs and costs due to production loss will be registered by means of cost questionnaires to be administered by the patients (Goossens, Rutten-van Molken et al. 2000). These cost questionnaires measure resources consumed on a monthly basis. Patients will receive the first questionnaire at baseline; the following diaries at the 3 weeks follow up measure, the following at the 6-week follow-up, etc. We will ask patients to complete webbased cost questionnaires. If patients do not have access to the Internet or prefer hard copies, we will provide these.

- Sources of cost prices

Costs will be valued using the guidelines published in the updated handbook for economic evaluation in the Netherlands (Hakkaart van Roijen, Tan et al. 2010). If not available then the real cost prices are calculated through the bottom-up method. Visits to other health care professionals (e.g. chiropractor) will be estimated on the basis of fees and prices charged by the professional organisation. The costs of medication will estimated on the basis of prices charged by the Royal Society for Pharmacy. Costs of production losses due to LBP will be estimated for both paid and unpaid labour. For paid labour the costs will be calculated using both the human capital approach and the friction cost approach (Koopmanschap and Rutten 1996). For unpaid labour, the indirect costs will be estimated as the costs of production losses due to ongoing or renewed complaints in back and/or leg, e.g. voluntary work and household work, using shadow prices.

\section{Imaging}

It is standard care, in performing the minimal interventional treatments as described under 5.1, to make and save radiographic images of the needle positions. Images saved in the Facet RCT will be submitted to an expert panel to assess correct needle placement. Retrospectively we will submit all available (anonymized) images taken in the Facet RF RCT to a panel, and have them judged twice, with a 1.5 month interval. Both times we will ask the panel to judge the images as 'correct', 'incorrect' or 'unsure' - needle placement.

Out of this we want to determine an inter- and intra- observer reliability. If the reliability is high, we will determine whether 'correct placement', indeed shows a higher pain reduction (NRS) after 3 months.

\subsection{Randomisation, blinding and treatment allocation}

Central randomisation will be performed by a computer-generated list of random numbers. The outcome of the randomisation will be automatically reported to the local nurse who entered a positive diagnostic test in the datamanagement system. Randomisation will be stratified for clinics.

In this pragmatic trial patients and care providers will not be blinded. Because all outcome measures are self-reported, the outcome measurement is also not blinded. 
Data analysis will be conducted blinded for treatment allocation and blinding will only be finished after the final analyses have been concluded.

To evaluate whether lack of blinding is associated with bias, expectations and preferences of patients will be measured before randomisation and after treatment allocation and patient satisfaction after treatment and during follow-up.

\subsection{Study procedures}

The selection of adequate patients in the diagnostic phase, as well as the invasive treatment of patients is usual care, described in the Guideline low back pain (NVA, NVvN et al. 2011).

On entry in the pain clinic every patient will be asked to fill the set of primary and secondary outcomes.

Eligible patients will be informed about the trial and have two weeks time to react. Patients will be included when an informed consent has been given.

Based on signs and symptoms, patients with suspicion on a single entity, namely pain arising from the facet joints or sacroiliac joint will receive a test block with local anaesthetics. If patients answer 'yes' to the question: 'is there a $50 \%$ or more reduction in pain?' 30 minutes after the test block, patients are randomized in one of the study groups. Patients with the suspicion of pain arising from the intervertebral disc will receive a provocative discography.

Patients with pain suspected to arise from multiple entities, will be randomized prior to the test block and provocative discography. The patients will follow an intention to treat protocol.

Patients will be randomised to a group who receives a multidisciplinary pain programme with a minimal interventional treatment or a group receiving a multidisciplinary pain programme alone.

All patients will receive the same standard multidisciplinary pain programme according to the guideline of the Royal Dutch Society for Physical Therapy (Bekkering, Hendriks et al. 2005). Referral and coordination will take place by the anaesthesiologist; a physiotherapist will be involved, and a psychologist if necessary. The treatment will focus on activation mobilisation and consist of graded activity.

If patients in the non-interventional study groups have not improved or recovered after three months, they will not receive interventional procedures but will go back to the GP or medical specialist that had referred them to the pain clinic. We will also closely monitor and register additional care in this group.

Apart from the standard set of outcomes for low back pain research, participants in the study will fill in an economic evaluation and a monthly cost diary.

All questionnaires will be repeated at baseline, 3, 6, 9 and 12 months. 
Besides these four randomized trials for subgroups of patients, all patients referred to the participating pain clinics and who give informed consent will be part of an observational study. The observational data will inform us about the proportion of patients with facet joint pain, disc pain, SI pain and a combination of these, the proportion of patients with a positive block within these four groups, and the clinical outcomes of patients with a negative block.

Participating in this trial means that difference in pain and perceived improvement in functioning will be measured at 3 and 6 weeks after the intervention; patients have to fill in web based questionnaires (see 7.1.2. for the questionnaires) at baseline, 3 , 6,9 , and 12 months; all are referred to a multidisciplinary pain programme, and they are randomised to receive the minimal interventional procedures or no additional treatment.

\subsection{Withdrawal of individual subjects}

Subjects can leave the study at any time for any reason if they wish to do so without any consequences. The treating physician can decide to withdraw a subject from the study for urgent medical reasons.

\subsection{Replacement of individual subjects after withdrawal}

Until the sample size for the study has been reached, candidates can participate. Patients will not be replaced. No specific conditions apply for replacing an individual subject after withdrawal. When a patient withdraws him/herself (or is withdrawn by the investigator) he/she can be treated for his/her medical condition outside the study.

\subsection{Follow-up of subjects withdrawn from treatment}

After withdrawal patients will be asked to keep filling in the questionnaires, and an intention to treat analysis will be performed.

\subsection{Premature termination of the study}

Premature termination of the study is possible under the following circumstances:

A) If no positive decision is obtained with regard to the research or if the judgement of the competent medical research ethics committee that has assessed the research is irrevocably revoked;

B) In the event that Section 13i, clause 5 of the Medical Research Involving Human Subjects Act applies, if the Central Committee or the Minister of Health, Welfare and Sport has made an irrevocable objection to the performance of the research with medicinal products (only applicable for medicinal products);

C) If a reasonable case can be made for terminating the research in the interests of the subjects' health; 
D) If it transpires that continuation of the research cannot serve any scientific purpose, and this is confirmed by the medical research ethics committee that has issued a positive decision on the research;

E) If one of the two parties has been declared insolvent, or if a petition has been filed for liquidation of one of the two parties;

F) If one of the two parties fails to comply with the obligations arising from the agreement and, provided compliance is not permanently impossible, this compliance has not taken place within thirty days after the defaulting party has received a written request to comply, unless failure to comply is out of reasonable proportion to the premature termination of the research. 


\section{SAFETY REPORTING}

\subsection{Section 10 WMO event}

In accordance to section 10, subsection 1, of the WMO, the investigator will inform the subjects and the reviewing accredited METC if anything occurs, on the basis of which it appears that the disadvantages of participation may be significantly greater than was foreseen in the research proposal. The study will be suspended pending further review by the accredited METC, except insofar as suspension would jeopardise the subjects' health. The investigator will take care that all subjects are kept informed.

\subsection{Adverse and serious adverse events}

Adverse events are defined as any undesirable experience occurring to a subject during the study, whether or not considered related to [the investigational product / the experimental treatment]. All adverse events reported spontaneously by the subject or observed by the investigator or his staff will be recorded.

A serious adverse event is any untoward medical occurrence or effect that at any dose:

- $\quad$ results in death;

- $\quad$ is life threatening (at the time of the event);

- $\quad$ requires hospitalisation or prolongation of existing inpatients' hospitalisation;

- $\quad$ results in persistent or significant disability or incapacity;

- $\quad$ is a congenital anomaly or birth defect;

- $\quad$ is a new event of the trial likely to affect the safety of the subjects, such as an unexpected outcome of an adverse reaction, lack of efficacy of an IMP used for the treatment of a life threatening disease, major safety finding from a newly completed animal study, etc.

All SAEs will be reported through the web portal ToetsingOnline to the accredited METC that approved the protocol, within 15 days after the sponsor has first knowledge of the serious adverse reactions.

SAEs that result in death or are life threatening should be reported expedited. The expedited reporting will occur not later than 7 days after the responsible investigator has first knowledge of the adverse reaction. This is for a preliminary report with another 8 days for completion of the report.

\subsubsection{Suspected unexpected serious adverse reactions (SUSAR)}

Not applicable 


\subsubsection{Annual safety report}

Not applicable

\subsection{Follow-up of adverse events}

All adverse events will be followed until they have abated, or until a stable situation has been reached. Depending on the event, follow up may require additional tests or medical procedures as indicated, and/or referral to the general physician or a medical specialist.

\subsection{Data Safety Monitoring Board (DSMB)}

A data safety monitoring board (DSMB) will not be assembled for this study. All adverse events, serious or not, unanticipated or not, will be reported to the appropriate ethics and regulatory agencies in accordance with reporting requirements. 


\section{STATISTICAL ANALYSIS}

\subsection{Descriptive statistics}

All patients will be given a distinctive number; data will be analysed anonymously. Baseline comparability was performed by descriptive statistics to examine if randomisation was successful.

\subsection{Univariate analysis}

An intention-to-treat analysis will be conducted for each follow-up moment. Baseline data (demographics, pain expectation and the psychological variables) will be analysed for comparing the difference between the interventiongroup and the controlgroup for each RCT. 95\%-confidence intervals will be calculated for the difference of percentages (Chi-square distribution) and means (t-distribution) for dichotomous and continuous outcome variables, respectively.

\subsection{Multivariate analysis}

To compare changes in pain between the interventiongroup and the controlgroup for each RCT after three months multilevel analyses will be performed.

In case of unequal distributions of prognostic factors, multivariate analysis techniques will be used to correct for these between-group differences in prognosis.

Change scores for the primary and secondary outcomes will be calculated by substracting the baseline scores from the post-treatment scores (after 3 and 6 weeks, 3, 6, 9, and 12 months) and compare those for the intervention and the controlgroup using a t-test.

\section{Economic evaluation}

For the economic evaluation of each RCT, multivariate analyses will be performed as well. Costs and QALYS will be compared for the intervention- and the controlgroup (with costs/QALYS as dependent variable and group as independent variable)

Cost-effectiveness and a cost-utility analysis will be performed. Cost-effectiveness ratios will be calculated by dividing the difference between the mean costs of the two treatment groups by the difference in the mean effects of the two treatment groups. Ratio's will include the clinical effect measures of the trial, i.e., general perceived recovery, functional status, pain intensity. Cost-utility will be based on the EuroQol and expressed in costs per QALY. Cost-effectiveness and cost-utility ratios will be estimated using bootstrapping techniques and acceptability curves and net 
monetary benefit will also be estimated. Sensitivity analysis on the most important cost drivers will be performed in order to assess the robustness of the results.

- Patient outcome analysis

The primary effect measures will also be used in the economic evaluation:

1) general improvement, 2) functional status, 3) pain intensity, and 4) work absenteeism. Utilities will be measures using the EuroQol-5D. Overall utility scores for population-based quality of life can be obtained and will be expressed as QALY's. QALY's will be calculated by multiplying the utility of a health state by the time spent in this health state using the Dutch valuation tariff (Lamers, Stalmeier et al. 2005).

\subsection{Interim analysis}

Not applicable 


\section{ETHICAL CONSIDERATIONS}

\subsection{Regulation statement}

The study will be conducted according to the principles of the Declaration of Helsinki (WORLD MEDICAL ASSOCIATION DECLARATION OF HELSINKI - Ethical Principles for Medical Research Involving Human Subjects; Adopted by the 18th WMA General Assembly, Helsinki, Finland, June 1964, and amended by the: 29th WMA General Assembly, Tokyo, Japan, October 1975, 35th WMA General Assembly, Venice, Italy, October 1983, 41st WMA General Assembly, Hong Kong, September 1989, 48th WMA General Assembly, Somerset West, Republic of South Africa, October 1996, 52nd WMA General Assembly, Edinburgh, Scotland, October 2000, 53rd WMA General Assembly, Washington 2002 (Note of Clarification on paragraph 29 added), 55th WMA General Assembly, Tokyo 2004 (Note of Clarification on Paragraph 30 added) and 59th WMA General Assembly, Seoul, October 2008) and in accordance with the Medical Research Involving Human Subjects Act (WMO).

\subsection{Recruitment and consent}

Patients are recruited at the departments of Anaesthesiology, i.c. the pain clinics of the participating hospitals. In this pragmatic trial, all patients who are referred to a pain programme/pain clinic with mechanical low back pain will be invited to participate. General practitioners and medical specialists who referred patients to the pain clinics will be informed about participation of their patients in the study. Patients who meet the criteria are informed of the purpose and procedures of the study; each patient receives a general brochure concerning scientific research involving human subjects (in Dutch: medisch-wetenschappelijk onderzoek met mensen) and a patient information letter (section E1 of the protocol). After giving informed consent by means of an informed consent patients are enrolled in the study.

\subsection{Objection by minors or incapacitated subjects (if applicable)}

Not applicable

\subsection{Benefits and risks assessment, group relatedness}

Minimal interventional procedures provide alternatives for patients with mechanical back pain who did not improve on primary care treatment. No major complications have been reported on these procedures. 


\subsection{Compensation for injury}

The sponsor/investigator has a liability insurance which is in accordance with article 7 , subsection 6 of the WMO.

The sponsor (also) has an insurance which is in accordance with the legal requirements in the Netherlands (Article $7 \mathrm{WMO}$ and the Measure regarding Compulsory Insurance for Clinical Research in Humans of 23th June 2003). This insurance provides cover for damage to research subjects through injury or death caused by the study.

1. $€ 450.000$,-- (i.e. four hundred and fifty thousand Euro) for death or injury for each subject who participates in the Research;

2. $€ 3.500 .000$,-- (i.e. three million five hundred thousand Euro) for death or injury for all subjects who participate in the Research;

3. $€ 5.000 .000$,-- (i.e. five million Euro) for the total damage incurred by the organisation for all damage disclosed by scientific research for the Sponsor as 'verrichter' in the meaning of said Act in each year of insurance coverage.

The insurance applies to the damage that becomes apparent during the study or within 4 years after the end of the study.

\subsection{Incentives (if applicable)}

Not applicable 


\section{ADMINISTRATIVE ASPECTS AND PUBLICATION}

\subsection{Handling and storage of data and documents}

Web based questionnaires will be used to assess questionnaires, and an online data management system will be used for the management of these questionnaires. This software is installed on the computers of the Erasmus MC MGZ and VU University EMGO department, so that backup and access protection have been arranged.

The patients will receive an email notification when a questionnaire is due. The database itself is safeguarded with tokens and passwords. The trial coordinator of the Erasmus MC controls the patient tracking programme that enables her to send out emails, and check whether all questionnaires have been completed. Only the research coordinators of the VUmc and the Erasmus MC have access to all data. If the patients do not have access to the internet or prefer hard copies, we will provide these. The data from measurements and questionnaires will be stored in the Promise database.

The researchers at the VUmc and the Erasmus MC will only receive the data, and these will be processed without knowing the treatment group. The coding and randomisation will take place using a computer based list, safeguarded by the statistician of the Center for Pain Medicine of the Erasmus MC. The patient records will be coded by a code for the center that included the patient, and a number, starting with 1 for the first patient.

\subsection{Amendments}

Amendments are changes made to the research after a favourable opinion by the accredited METC has been given. All amendments will be notified to the METC that gave a favourable opinion.

All substantial amendments will be notified to the METC and to the competent authority.

Non-substantial amendments will not be notified to the accredited METC and the competent authority, but will be recorded and filed by the sponsor.

\subsection{Annual progress report}

The sponsor/investigator will submit a summary of the progress of the trial to the accredited METC once a year. Information will be provided on the date of inclusion of the first subject, numbers of subjects included and numbers of subjects that have completed the trial, serious adverse events/ serious adverse reactions, other problems, and amendments. 


\subsection{End of study report}

The investigator will notify the accredited METC of the end of the study within a period of 8 weeks. The end of the study is defined as the last patient's last visit. In case the study is ended prematurely, the investigator will notify the accredited METC, including the reasons for the premature termination.

Within one year after the end of the study, the investigator/sponsor will submit a final study report with the results of the study, including any publications/abstracts of the study, to the accredited METC.

\subsection{Public disclosure and publication policy}

The principal investigator is free to publish. 


\section{REFERENCES}

Bekkering, G. E., H. J. M. Hendriks, et al. (2005) "KNGF Guideline low back Pain."

Bombardier, C. (2000). "Outcome assessments in the evaluation of treatment of spinal disorders: summary and general recommendations." Spine (Phila Pa 1976) 25(24): 3100-3103.

Goossens, M. E., M. P. Rutten-van Molken, et al. (2000). "The cost diary: a method to measure direct and indirect costs in cost-effectiveness research." $\underline{\mathrm{J} \text { Clin Epidemiol }}$ 53(7): 688-695.

Hakkaart van Roijen, L., S. S. Tan, et al. (2010). Handleiding voor kostenonderzoek, CVZ.

Koopmanschap, M. A. and F. F. Rutten (1996). "A practical guide for calculating indirect costs of disease." Pharmacoeconomics 10(5): 460-466.

Lambeek, L. C., W. van Mechelen, et al. (2010). "Randomised controlled trial of integrated care to reduce disability from chronic low back pain in working and private life." BMJ 340: $c 1035$.

Lamers, L. M., P. F. Stalmeier, et al. (2005). "[Measuring the quality of life in economic evaluations: the Dutch EQ-5D tariff]." Ned Tijdschr Geneeskd 149(28): 1574-1578.

NVA, NVvN, et al. (2011). Guideline Low Back Pain. N. V. v. A. (NVA), N. V. v. N. (NVvN) and N. O. V. (NOV).

Ostelo, R. W., R. A. Deyo, et al. (2008). "Interpreting change scores for pain and functional status in low back pain: towards international consensus regarding minimal important change." Spine 33(1): 90-94. 


\section{Supplementary Online Content}

Juch JNS, Maas ET, Ostelo RWJG, et al. Effect of radiofrequency denervation on pain intensity among patients with chronic low back pain: the Mint randomized clinical trials. JAMA. doi:10.1001/jama.2017.7918

eAppendix. Description Radiofrequency Denervation Intervention

eTable 1. Baseline Characteristics of Completers vs Noncompleters

eTable 2. Treatment Effects for Secondary Outcomes Based on Intention-to-Treat Analyses

eTable 3. As-Treated Analysis for Pain Intensity, Functional Status, and Global Perceived Recovery, Without Protocol Violators Based on Intention-to-Treat Analyses

eTable 4. Treatment Effects for Pain Intensity, Functional Status, and Global Perceived Recovery Based on an As-Treated After 3 Months

eTable 5. Treatment Effects for Complete Cases for Pain Intensity, Functional Status, and Global Perceived Recovery Based on Intention-to-Treat Analyses

eReferences.

This supplementary material has been provided by the authors to give readers additional information about their work. 


\section{eAppendix. Description radiofrequency denervation intervention.}

Radiofrequency denervation of the facet joints:

A C-arm image intensifier was positioned in a slightly $\left(10-15^{\circ}\right)$ oblique position, with the patient in prone position. A 22 G SMK needle with a 10-mm active curved tip was introduced at each entry point. The position of the cannula was checked on the lateral and AP projection. The depth was adjusted until the tip of the cannula was at the level of a line connecting the posterior aspects of the intervertebral foramen. Sensory stimulation $(50 \mathrm{~Hz})$ was positive when the patient felt paresthesia, and motor stimulation $(2 \mathrm{~Hz})$ was positive with visible muscle stimulation but no leg contractions. Once the position of the electrode was satisfactory, $1-2 \mathrm{ml}$ per level $\mathrm{ml} 2 \%$ lidocaine was injected and a $90^{\circ} \mathrm{C} 90$ seconds RF lesion was made of the medial ramus dorsalis of L3-4, L4-5, and L5-S1.

\section{Radiofrequency denervation of the sacroiliac joints:}

The choice of technique for radiofrequency denervation was left to the discretion of the physician. Participants received either the Cooled RF technique (SInergy, Kimberly Clark Health Care, Roswell GA, USA); Bipolar Palisade Technique; or SIMPLICITY III Probe technique (Neurotherm, St Paul MN, USA).

For the Cooled RF technique1: Under fluoroscopy, 25G needles were placed along the lateral wall of each foramen, with the tip at the opening. An Epsilon® ruler was used together with the reference needles as landmarks for the lesions. Using the introducer, stylet and probe provided by the manufacturer, radiofrequency lesions were made (at 
02:30, 04:00 and 05:30 for S1 and S2 and 02:30, 04:00 for S3 on the right side, inversely on the left) at a temperature of $60^{\circ} \mathrm{C}$ for 2.5 minutes per lesion.

The Palisade Technique ${ }^{2}$ : was carried out by drawing a cranial-caudal line between the lateral aspect of the sacral foramina and the sacroiliac joint line. Under lateral fluoroscopic view six $20 \mathrm{G}$ needles with $10 \mathrm{~mm}$ active tips were placed parallel to each other $10 \mathrm{~mm}$ apart and perpendicular to the sacrum. Stimulations to $2.0 \mathrm{~V}$ were done to be sure there was no motor response. Then eight lesions $\left(90^{\circ} \mathrm{C}, 180\right.$ seconds per lesion) were made using adjacent parings of the cannulas. The maximum allowed temperature drop between cannulas was $30^{\circ} \mathrm{C}$.

The SIMPLICITY III probe ${ }^{3}$ : was inserted at the lateral, inferior border of the sacrum, $10 \mathrm{~mm}$ below the $\mathrm{S} 4$ foramen under fluoroscopic view. The electrode probe was advanced in a cephalad direction along the sacrum, lateral of the foramina, medial to the sacroiliac joint and ventral to the ileum. The correct position of the electrodes was checked and the $\mathrm{RF}$ lesion $\left(85^{\circ} \mathrm{C}\right.$ for 90 seconds per step) was made.

In all three techniques RF lesion of the ramus dorsalis of L5/S1 was carried out monopolar. ${ }^{4}$ All lesion sites were anesthetized using $2 \%$ lidocaine.

\section{Radiofrequency denervation in the combination trial:}

As opposed to the other two trials, participants of the combination trial were randomized before a diagnostic block was done. Patients were only treated with a radiofrequency denervation when randomized to the intervention group and a positive diagnostic block of the facet joint or sacroiliac joint, or a positive provocative discography. ${ }^{5}$ If none of the diagnostic tests were positive, the participant would receive the standardized exercise 
program only. The facet joint and sacroiliac joint radiofrequency denervation were performed as described above. The treatment of the intervertebral disc could be done by one of two radiofrequency denervation techniques: Intradiscal Electrothermal Therapy or Biacuplasty.

Intradiscal Electrothermal Therapy: Using fluoroscopic control, with the patient prone on the operating table, a needle was passed into the injured disc via the side. With the needle placed alongside the internal aspect of the posterior annulus, the catheter containing the heating coil was manipulated inside the disc. The temperature inside the disc was raised to $90^{\circ} \mathrm{C}$ in 12 minutes, and maintained at $90^{\circ} \mathrm{C}$ for another four minutes.

Biacuplasty: Two internally cooled $17 \mathrm{G}$ needles were inserted at the level of the annulus fibrosis. Two RF currents were inserted to generate a bipolar configuration. The ideal temperature profile is $55 / 60^{\circ} \mathrm{C}$ in the inner posterior disc decreasing to $45^{\circ} \mathrm{C}$ for 12 to 16 minutes in the peripheral edge of the posterior disc. 
eTable 1. Baseline Characteristics of Completers vs Non-completers

\begin{tabular}{|c|c|c|c|c|c|c|}
\hline Characteristics* & $\begin{array}{c}\text { Intervention } \\
\text { Randomized: } \\
\mathrm{N}=125 \\
\text { Complete } \\
\text { baseline: } \\
\mathrm{N}=117\end{array}$ & $\begin{array}{c}\text { Intervention } \\
\text { Complete } \\
\mathrm{N}=78 \\
\text { Complete } \\
\text { baseline: } \\
\mathrm{N}=78 \\
\end{array}$ & $\begin{array}{c}\text { Intervention } \\
\text { Incomplete } \\
\mathrm{N}=47 \\
\text { Complete } \\
\text { baseline: } \\
\mathrm{N}=39 \\
\end{array}$ & $\begin{array}{c}\text { Control } \\
\text { Randomized: } \\
\mathrm{N}=126 \\
\text { Complete } \\
\text { baseline: } \\
\mathrm{N}=116 \\
\end{array}$ & $\begin{array}{c}\text { Control } \\
\text { Complete } \\
\mathrm{N}=88 \\
\text { Complete } \\
\text { baseline: } \\
\mathrm{N}=88 \\
\end{array}$ & $\begin{array}{c}\text { Control } \\
\text { Incomplete } \\
\mathrm{N}=38 \\
\text { Complete } \\
\text { baseline: } \mathrm{N}=28\end{array}$ \\
\hline \multicolumn{7}{|c|}{ FACET JOINT TRIAL } \\
\hline Age in years (SD) & $52.98(11.48)$ & $54.45(10.90)$ & $50.10(12.01)$ & $52.60(10.79)$ & $53.20(10.48)$ & $50.71(11.79)$ \\
\hline Female (N (\%)) & $65(55.56 \%)$ & $45(57.69 \%)$ & $19(48.71 \%)$ & $60(51.72 \%)$ & $48(54.54 \%)$ & $16(57.14 \%)$ \\
\hline BMI (SD) & $26.77(5.17)$ & $27.23(5.70)$ & $25.85(3.76)$ & $27.62(4.27)$ & $27.94(4.32)$ & $26.62(4.07)$ \\
\hline Smoker (N (\%)) & $34(29.05 \%)$ & $16(20.51 \%)$ & $18(46.15 \%)$ & $34(29.05 \%)$ & $22(25.00 \%)$ & $12(42.85 \%)$ \\
\hline \multicolumn{7}{|l|}{ Education§ } \\
\hline Low (N (\%)) & $57(48.72 \%)$ & $40(51.28 \%)$ & $18(48.61 \%)$ & $64(55.17 \%)$ & $48(54.54 \%)$ & $17(60.71 \%)$ \\
\hline Moderate (N (\%)) & $35(29.99 \%)$ & $22(28.21 \%)$ & $13(33.33 \%)$ & $34(29.31 \%)$ & $27(30.68 \%)$ & $8(28.57 \%)$ \\
\hline High $(\mathrm{N}(\%))$ & $21(17.95 \%)$ & $16(20.51 \%)$ & $6(15.38 \%)$ & $16(13.79 \%)$ & $13(14.77 \%)$ & $3(10.71 \%)$ \\
\hline \multicolumn{7}{|l|}{$\begin{array}{l}\text { History of back pain } \\
\text { complaints }\end{array}$} \\
\hline $\begin{array}{c}\text { Time since first experience } \\
\text { with low back pain in months } \\
\text { (median (IQR)) }\end{array}$ & $\begin{array}{c}146.00 \\
(49.75-267.67)\end{array}$ & $\begin{array}{l}158.17 \\
(42.29- \\
304.17)\end{array}$ & $\begin{array}{l}146.00 \\
(54.73- \\
220.00)\end{array}$ & $\begin{array}{c}100.33 \\
(36.5-186.30)\end{array}$ & $\begin{array}{l}115.58 \\
(36.50- \\
186.30)\end{array}$ & $\begin{array}{c}83.75 \\
(49.73- \\
220.63)\end{array}$ \\
\hline $\begin{array}{l}\text { Time since current episode } \\
\text { with low back pain in months } \\
\text { (median (IQR)) }\end{array}$ & $\begin{array}{c}31.33 \\
(12.17-103.42)\end{array}$ & $\begin{array}{c}29.33 \\
(12.17-83.58)\end{array}$ & $\begin{array}{c}36.50 \\
(8.33-130.63)\end{array}$ & $\begin{array}{c}26.73 \\
(10.54-73.00)\end{array}$ & $\begin{array}{c}30.33 \\
(12.17- \\
77.57) \\
\end{array}$ & $\begin{array}{c}19.75 \\
(7.25-70.20)\end{array}$ \\
\hline $\begin{array}{l}\text { Married or living with a } \\
\text { partner }(\mathrm{N}(\%))\end{array}$ & $\begin{array}{c}93 \\
(79.49 \%)\end{array}$ & $\begin{array}{c}68 \\
(87.17 \%)\end{array}$ & $\begin{array}{c}25 \\
(64.10 \%)\end{array}$ & $\begin{array}{c}98 \\
(84.48 \%)\end{array}$ & $\begin{array}{c}76 \\
(86.36 \%)\end{array}$ & $\begin{array}{c}22 \\
(78.57 \%)\end{array}$ \\
\hline \multicolumn{7}{|l|}{ Expectations (CEQ) $^{\text {a }}$} \\
\hline Credibility (0-27) & $21.36(3.92)$ & $21.84(3.38)$ & $20.36(4.76)$ & $19.47(5.49)$ & $19.19(5.87)$ & $20.32(4.08)$ \\
\hline Expectancy (0-27) & $18.97(4.59)$ & $19.35(4.35)$ & $18.18(5.02)$ & $17.36(5.20)$ & $16.85(5.62)$ & $18.96(3.16)$ \\
\hline
\end{tabular}

(C) 2017 American Medical Association. All rights reserved. 


\begin{tabular}{|c|c|c|c|c|c|c|}
\hline Characteristics* & $\begin{array}{c}\text { Intervention } \\
\text { Randomized: } \\
\mathrm{N}=125 \\
\text { Complete } \\
\text { baseline: } \\
\mathrm{N}=117\end{array}$ & $\begin{array}{c}\text { Intervention } \\
\text { Complete } \\
\mathrm{N}=78 \\
\text { Complete } \\
\text { baseline: } \\
\mathrm{N}=78\end{array}$ & $\begin{array}{c}\text { Intervention } \\
\text { Incomplete } \\
\mathrm{N}=47 \\
\text { Complete } \\
\text { baseline: } \\
\mathrm{N}=39\end{array}$ & $\begin{array}{c}\text { Control } \\
\text { Randomized: } \\
\mathrm{N}=126 \\
\text { Complete } \\
\text { baseline: } \\
\mathrm{N}=116 \\
\end{array}$ & $\begin{array}{l}\text { Control } \\
\text { Complete } \\
\mathrm{N}=88 \\
\text { Complete } \\
\text { baseline: } \\
\mathrm{N}=88 \\
\end{array}$ & $\begin{array}{c}\text { Control } \\
\text { Incomplete } \\
\mathrm{N}=38 \\
\text { Complete } \\
\text { baseline: } \mathrm{N}=28\end{array}$ \\
\hline $\begin{array}{c}\text { Mean (SD) Pain intensity in } \\
\text { the past week } \\
\text { (NRS 0-10) }{ }^{b}\end{array}$ & $7.14(1.38)$ & $6.99(1.48)$ & $7.44(1.11)$ & 7. 19 (1.29) & $7.14(1.27)$ & $7.36(1.39)$ \\
\hline $\begin{array}{l}\text { Mean (SD) Functioning } \\
\quad(\text { ODI } 0-100)^{c}\end{array}$ & $35.07(14.66)$ & $35.02(14.02)$ & $35.18(16.07)$ & $34.39(12.24)$ & $33.88(11.52)$ & $36.00(14.36)$ \\
\hline $\begin{array}{l}\text { Mean (SD) Quality of life } \\
\text { (EQ-5D 0-1) }\end{array}$ & $0.52(0.26)$ & $0.55(0.24)$ & $0.46(0.29)$ & $0.54(0.26)$ & $0.55(0.26)$ & $0.52(0.25)$ \\
\hline \multicolumn{7}{|c|}{ SACROILIAC JOINT TRIAL } \\
\hline Age in years (SD) & $51.58(10.94)$ & $53.10(10.46)$ & $48.56(11.37)$ & $51.13(12.22)$ & $53.33(11.62)$ & $48.83(12.52)$ \\
\hline Female $(\mathrm{N}(\%))$ & $87(74.35 \%)$ & $63(82.89 \%)$ & $24(77.42 \%)$ & $79(75.96 \%)$ & $42(73.68 \%)$ & $37(78.09 \%)$ \\
\hline BMI (SD) & $26.73(4.17)$ & $26.79(4.16)$ & $26.57(4.25)$ & $26.76(4.53)$ & $26.89(4.70)$ & $26.61(4.36)$ \\
\hline Smoker (N (\%)) & $29(26.61 \%)$ & $19(25.00 \%)$ & $10(32.26 \%)$ & $31(29.81 \%)$ & $18(31.57 \%)$ & $13(30.95 \%)$ \\
\hline \multicolumn{7}{|l|}{ Education§ } \\
\hline Low (N (\%)) & $59(54.13 \%)$ & $45(59.51 \%)$ & $14(45.16 \%)$ & $53(50.96 \%)$ & $30(52.63 \%)$ & $23(54.76 \%)$ \\
\hline Moderate (N (\%)) & $32(29.36 \%)$ & $20(26.31 \%)$ & $12(38.7 \%)$ & $32(30.76 \%)$ & $21(36.84 \%)$ & $11(26.19 \%)$ \\
\hline High (N (\%)) & $18(16.51 \%)$ & $12(15.78 \%)$ & $6(19.35 \%)$ & $18(17.31 \%)$ & $6(10.52 \%)$ & $12(28.57 \%)$ \\
\hline \multicolumn{7}{|l|}{$\begin{array}{l}\text { History of back pain } \\
\text { complaints }\end{array}$} \\
\hline $\begin{array}{l}\text { Time since first experience } \\
\text { with low back pain in months } \\
\text { (median (IQR)) }\end{array}$ & $\begin{array}{c}97.33 \\
(37.51-228.12)\end{array}$ & $\begin{array}{c}109.50 \\
(41.02-243.33)\end{array}$ & $\begin{array}{r}79.08 \\
(36.50- \\
164.43)\end{array}$ & $\begin{array}{c}65.08 \\
(27.08-144.21)\end{array}$ & $\begin{array}{r}60.83 \\
(27.83- \\
121.67) \\
\end{array}$ & $\begin{array}{c}103.33 \\
(24.33-219.00)\end{array}$ \\
\hline
\end{tabular}

(C) 2017 American Medical Association. All rights reserved. 


\begin{tabular}{|c|c|c|c|c|c|c|}
\hline Characteristics* & $\begin{array}{c}\text { Intervention } \\
\text { Randomized: } \\
\mathrm{N}=125 \\
\text { Complete } \\
\text { baseline: } \\
\mathrm{N}=117 \\
\end{array}$ & $\begin{array}{c}\text { Intervention } \\
\text { Complete } \\
\mathrm{N}=78 \\
\text { Complete } \\
\text { baseline: } \\
\mathrm{N}=78\end{array}$ & $\begin{array}{c}\text { Intervention } \\
\text { Incomplete } \\
\mathrm{N}=47 \\
\text { Complete } \\
\text { baseline: } \\
\mathrm{N}=39\end{array}$ & $\begin{array}{c}\text { Control } \\
\text { Randomized: } \\
\mathrm{N}=126 \\
\text { Complete } \\
\text { baseline: } \\
\mathrm{N}=116\end{array}$ & $\begin{array}{c}\text { Control } \\
\text { Complete } \\
\mathrm{N}=88 \\
\text { Complete } \\
\text { baseline: } \\
\mathrm{N}=88 \\
\end{array}$ & $\begin{array}{c}\text { Control } \\
\text { Incomplete } \\
\mathrm{N}=38 \\
\text { Complete } \\
\text { baseline: } \mathrm{N}=28\end{array}$ \\
\hline $\begin{array}{c}\text { Time since current episode } \\
\text { with low back pain in months } \\
\text { (median (IQR)) }\end{array}$ & $\begin{array}{c}30.33 \\
(12.17-76.03)\end{array}$ & $\begin{array}{c}26.33 \\
(10.00-79.08)\end{array}$ & $\begin{array}{c}34.75 \\
(13.52- \\
77.55) \\
\end{array}$ & $\begin{array}{c}24.33 \\
(12.17-66.58)\end{array}$ & $\begin{array}{c}20.17 \\
(9.50-53.17)\end{array}$ & $\begin{array}{c}36.50 \\
(16.17-73.00)\end{array}$ \\
\hline $\begin{array}{l}\text { Married or living with a } \\
\text { partner }(\mathrm{N}(\%))\end{array}$ & $85(79.61 \%)$ & $64(84.21 \%)$ & $21(67.74 \%)$ & $82(79.61 \%)$ & $49(85.96 \%)$ & $33(78.57 \%)$ \\
\hline Expectations (CEQ) $^{\mathrm{a}}$ & & & & & & \\
\hline Credibility (0-27) & $21.36(4.51)$ & $21.18(4.51)$ & $21.77(4.56)$ & $19.88(5.31)$ & $20.05(5.60)$ & $19.64(4.94)$ \\
\hline Expectancy (0-27) & $18.75(4.99)$ & $18.86(4.82)$ & $18.48(5.47)$ & $18.23(5.31)$ & $18.51(5.09)$ & $17.88(5.64)$ \\
\hline $\begin{array}{l}\text { Mean (SD) Pain intensity in } \\
\text { the past week (NRS 0-10) }\end{array}$ & $7.17(1.65)$ & $7.09(1.78)$ & $7.34(1.310)$ & $7.06(1.43)$ & $7.12(1.68)$ & $6.98(1.035)$ \\
\hline $\begin{array}{l}\text { Mean (SD) Functioning } \\
\quad\left(\text { ODI 0-100) }{ }^{c}\right.\end{array}$ & $38.07(14.07)$ & $38.26(14.97)$ & $37.63(11.81)$ & $33.70(14.43)$ & $34.46(14.23)$ & $32.70(14.79)$ \\
\hline $\begin{array}{l}\text { Mean (SD) Quality of life } \\
\left(\text { EQ-5D 0-1) }{ }^{\text {d }}\right.\end{array}$ & $0.50(0.27)$ & $0.50(0.28)$ & $0.47(0.26)$ & $0.56(0.27)$ & $0.54(0.27)$ & $0.60(0.26)$ \\
\hline \multicolumn{7}{|c|}{ COMBINATION TRIAL } \\
\hline Age in years (SD) & $50.80(11.33)$ & $51.02(11.51)$ & $50.39(11.56)$ & $53.31(10.35)$ & $54.65(11.00)$ & $52.92(9.66)$ \\
\hline Female N (\%) & $64(65.31 \%)$ & $48(80.00 \%)$ & $27(72.93 \%)$ & $66(74.15 \%)$ & $35(76.10 \%)$ & $38(71.71 \%)$ \\
\hline $\mathrm{BMI}(\mathrm{SD})$ & $26.84(3.82)$ & $26.70(3.92)$ & $27.06(3.69)$ & $26.43(4.25)$ & $26.29(3.60)$ & $26.57(4.86)$ \\
\hline Smoker N (\%) & $23(23.46 \%)$ & $12(20.00 \%)$ & $11(28.94 \%)$ & $26(29.21 \%)$ & $11(23.91 \%)$ & $15(34.88 \%)$ \\
\hline \multicolumn{7}{|l|}{ Education§ } \\
\hline Low N (\%) & $52(53.06 \%)$ & $32(53.33 \%)$ & $19(50.00 \%)$ & $43(48.31 \%)$ & $21(45.65 \%)$ & $21(48.84 \%)$ \\
\hline Moderate N (\%) & $33(33.67 \%)$ & $18(30.00 \%)$ & $12(31.58 \%)$ & $32(35.96 \%)$ & $17(36.56 \%)$ & $13(30.23 \%)$ \\
\hline High N (\%) & $12(12.24 \%)$ & $8(13.33 \%)$ & $4(10.53 \%)$ & $14(15.73 \%)$ & $6(13.04 \%)$ & $8(18.60 \%)$ \\
\hline
\end{tabular}

(C) 2017 American Medical Association. All rights reserved. 


\begin{tabular}{|c|c|c|c|c|c|c|}
\hline Characteristics* & $\begin{array}{c}\text { Intervention } \\
\text { Randomized: } \\
\mathrm{N}=125 \\
\text { Complete } \\
\text { baseline: } \\
\mathrm{N}=117\end{array}$ & $\begin{array}{c}\text { Intervention } \\
\text { Complete } \\
\mathrm{N}=78 \\
\text { Complete } \\
\text { baseline: } \\
\mathrm{N}=78\end{array}$ & $\begin{array}{c}\text { Intervention } \\
\text { Incomplete } \\
\mathrm{N}=47 \\
\text { Complete } \\
\text { baseline: } \\
\mathrm{N}=39\end{array}$ & $\begin{array}{c}\text { Control } \\
\text { Randomized: } \\
\mathrm{N}=126 \\
\text { Complete } \\
\text { baseline: } \\
\mathrm{N}=116\end{array}$ & $\begin{array}{c}\text { Control } \\
\text { Complete } \\
\mathrm{N}=88 \\
\text { Complete } \\
\text { baseline: } \\
\mathrm{N}=88\end{array}$ & $\begin{array}{c}\text { Control } \\
\text { Incomplete } \\
\mathrm{N}=38 \\
\text { Complete } \\
\text { baseline: } \mathrm{N}=28\end{array}$ \\
\hline \multicolumn{7}{|l|}{$\begin{array}{l}\text { History of back pain } \\
\text { complaints }\end{array}$} \\
\hline $\begin{array}{c}\text { Time since first experience } \\
\text { with low back pain in months } \\
\text { median (IQR) }\end{array}$ & $\begin{array}{l}120.58 \\
(37.32- \\
222.04)\end{array}$ & $\begin{array}{l}124.92 \\
(55.46- \\
240.29)\end{array}$ & $\begin{array}{c}76.03 \\
(30.83- \\
124.71)\end{array}$ & $\begin{array}{c}97.33 \\
(32.33- \\
192.58) \\
\end{array}$ & $\begin{array}{l}121.67 \\
(34.42- \\
231.17)\end{array}$ & $\begin{array}{c}85.17 \\
(27.83- \\
176.37) \\
\end{array}$ \\
\hline $\begin{array}{l}\text { Time since current episode } \\
\text { with low back pain in months } \\
\text { median (IQR) }\end{array}$ & $\begin{array}{c}36.50 \\
(12.17-121.67)\end{array}$ & $\begin{array}{c}36.50 \\
(14.18-119.63)\end{array}$ & $\begin{array}{l}36.50 \\
(11.88- \\
121.67) \\
\end{array}$ & $\begin{array}{c}32.33 \\
(8.00-97.19)\end{array}$ & $\begin{array}{c}32.33 \\
(11.08-21.67)\end{array}$ & $\begin{array}{c}32.33 \\
(8.00-96.77)\end{array}$ \\
\hline $\begin{array}{l}\text { Married or living with a } \\
\text { partner } \mathrm{N}(\%)\end{array}$ & $66(67.35 \%)$ & $43(71.67 \%)$ & $23(60.53 \%)$ & $68(76.40 \%)$ & $36(78.26 \%)$ & $32(74.42 \%)$ \\
\hline \multicolumn{7}{|l|}{ Expectations (CEQ) $^{\mathrm{a}}$} \\
\hline Credibility (0-27) & $20.10(4.70)$ & $20.45(4.10)$ & $19.54(5.55)$ & $17.07(5.99)$ & $16.33(5.95)$ & $17.90(5.99)$ \\
\hline Expectancy (0-27) & $16.88(5.78)$ & $17.57(5.85)$ & $15.75(5.55)$ & $14.38(6.24)$ & $13.38(6.42)$ & $15.50(5.92)$ \\
\hline $\begin{array}{l}\text { Mean (SD) Pain intensity in } \\
\text { the past week (NRS 0-10) }\end{array}$ & $7.19(1.43)$ & $7.30(1.28)$ & $7.03(1.65)$ & $7.43(1.41)$ & $4.47(1.25)$ & $7.39(1.58)$ \\
\hline $\begin{array}{l}\text { Mean (SD) Functioning } \\
\left(^{\text {ODI } 0-100)^{c}}\right.\end{array}$ & $39.06(14.03)$ & $38.00(13.12)$ & $40.74(15.38)$ & $37.20(13.74)$ & $37.16(15.57)$ & $37.25(11.54)$ \\
\hline $\begin{array}{l}\text { Mean (SD) Quality of life } \\
\text { (EQ-5D 0-1) }^{\text {d }}\end{array}$ & $0.49(0.28)$ & $0.50(0.28)$ & $0.47(0.28)$ & $0.52(0.28)$ & $0.54(0.28)$ & $0.49(0.29)$ \\
\hline
\end{tabular}

Abbreviations: SD, Standard Deviation; N, number; BMI, Body Mass Index; IQR, interquartile range; CEQ, credibility expectancy questionnaire; NRS, Numeric Rating Scale, ODI: Oswestry Disability Index; EQ-5D, EuroQol-5D

$\S$ Low $=$ pre-school, primary school, lower secondary school; moderate= higher secondary school, undergraduate; high=tertiary, university, or postgraduate 
${ }^{a}$ A higher score indicates more credibility in the effectiveness of the treatment, or higher expectations about the treatment ${ }^{\mathrm{b}}$ A higher score indicates more severe pain intensity ${ }^{c}$ A higher score indicates worse functioning ${ }^{\mathrm{d}}$ A higher score indicates better quality of life 
eTable2. Treatment Effects for Secondary Outcomes Based on Intention-to-Treat Analyses

\begin{tabular}{|c|c|c|c|c|}
\hline Facet Joint Trial & $\begin{array}{l}\text { Mean Intervention } \\
\text { group }(95 \% \mathrm{CI}) \\
\mathrm{N}=125\end{array}$ & $\begin{array}{l}\text { Mean Control } \\
\text { group }(95 \% \mathrm{CI}) \\
\mathrm{N}=126\end{array}$ & $\begin{array}{l}\text { Mean difference } \\
(95 \% \mathrm{CI})\end{array}$ & $\begin{array}{l}P \\
\text { value }\end{array}$ \\
\hline \multicolumn{5}{|l|}{ EQ5D Utilities**** } \\
\hline Overall effect & & & $0.01(-0.03$ to 0.04$)$ & 0.75 \\
\hline Baseline (SD) & $0.52(0.47$ to 0.57$)$ & 0.54 (0.49 to 0.59$)$ & & \\
\hline 3 weeks & $0.69(0.64$ to 0.73$)$ & 0.64 (0.59 to 0.68$)$ & $0.05(-0.01$ to 0.10$)$ & 0.08 \\
\hline 6 weeks & 0.69 (0.66 to 0.73$)$ & 0.67 (0.63 to 0.70$)$ & $0.03(-0.03$ to 0.08$)$ & 0.32 \\
\hline 3 months & $0.68(0.64$ to 0.73$)$ & $0.69(0.65$ to 0.73$)$ & $-0.01(-0.06$ to 0.05$)$ & 0.85 \\
\hline 6 months & 0.73 (0.70 to 0.77$)$ & 0.71 (0.67 to 0.76$)$ & $0.02(-0.03$ to 0.07$)$ & 0.42 \\
\hline 9 months & $0.72(0.68$ to 0.76$)$ & 0.75 (0.71 to 0.78$)$ & $-0.05(-0.10$ to 0.01$)$ & 0.11 \\
\hline 12 months & 0.73 (0.69 to 0.73$)$ & 0.73 (0.69 to 0.77$)$ & $-0.03(-0.08$ to 0.03$)$ & 0.37 \\
\hline \multicolumn{5}{|c|}{\begin{tabular}{|l} 
Patient satisfaction** \\
\end{tabular}} \\
\hline Overall effect & & & $-0.01(-0.30$ to 0.28$)$ & 0.96 \\
\hline 3 months & $2.95(2.70$ to 3.20$)$ & 3.26 (3.00 to 3.52$)$ & $-0.18(-0.54$ to 0.18$)$ & 0.34 \\
\hline 6 months & $2.96(2.74$ to 3.17$)$ & $3.06(2.81$ to 3.31$)$ & $0.01(-0.35$ to 0.38$)$ & 0.94 \\
\hline
\end{tabular}




\begin{tabular}{|c|c|c|c|c|}
\hline 9 months & 2.88 (2.63 to 3.12$)$ & 3.13 (2.83 to 3.42$)$ & $-0.02(-0.39$ to 0.35$)$ & 0.91 \\
\hline 12 months & 2.88 (2.60 to 3.16$)$ & 3.01 (2.73 to 3.29$)$ & $0.19(-0.19$ to 0.56$)$ & 0.32 \\
\hline \multicolumn{5}{|c|}{ MPI Pain severity** } \\
\hline Overall effect & & & $0.05(-0.21$ to 0.32$)$ & 0.7 \\
\hline Baseline & 3.87 (3.68 to 4.06$)$ & $3.85(3.70$ to 4.00$)$ & & \\
\hline 3 months & $2.96(2.71$ to 3.21$)$ & $3.20(2.96$ to 3.44$)$ & $-0.15(-0.48$ to 0.18$)$ & 0.36 \\
\hline 6 months & 2.73 (2.48 to 2.98$)$ & 2.84 (2.58 to 3.11$)$ & $-0.03(-0.37$ to 0.31$)$ & 0.86 \\
\hline 9 months & 2.73 (2.45 to 3.02$)$ & 2.68 (2.40 to 2.97 ) & $0.16(-0.18$ to 0.50$)$ & 0.36 \\
\hline 12 months & 2.65 (2.34 to 2.95$)$ & 2.58 (2.30 to 2.85$)$ & $0.27(-0.07$ to 0.61$)$ & 0.12 \\
\hline \multicolumn{5}{|c|}{ MPI interference** } \\
\hline Overall effect & & & $-0.06(-0.31$ to 0.19$)$ & 0.63 \\
\hline Baseline & 3.30 (3.07 to 3.52 ) & 3.12 (2.91 to 3.34$)$ & & \\
\hline 3 months & 2.62 (2.37 to 2.87 ) & 2.74 (2.48 to 2.99$)$ & $-0.15(-0.44$ to 0.14$)$ & 0.32 \\
\hline 6 months & 2.59 (2.33 to 2.85$)$ & 2.572 .31 to 2.84 ) & $-0.02(-0.31$ to 0.27$)$ & 0.88 \\
\hline 9 months & 2.38 (2.08 to 2.67$)$ & 2.43 (2.14 to 2.72 ) & $-0.06(-0.36$ to 0.24$)$ & 0.70 \\
\hline
\end{tabular}




\begin{tabular}{|c|c|c|c|c|}
\hline 12 months & $2.40(2.10$ to 2.70$)$ & $2.42(2.12$ to 2.71$)$ & $-0.01(-0.31$ to 0.29$)$ & 0.93 \\
\hline \multicolumn{5}{|c|}{ MPI Life control** } \\
\hline Overall effect & & & $0.00(-0.20$ to 0.20$)$ & 0.98 \\
\hline Baseline & $3.92(3.72$ to 4.12$)$ & 4.18 (4.02 to 4.34$)$ & & \\
\hline 3 months & $4.26(4.06$ to 4.45$)$ & 4.17 (3.99 to 4.35$)$ & $0.17(-0.08$ to 0.41$)$ & 0.18 \\
\hline 6 months & 4.13 (3.91 to 4.34$)$ & 4.32 (4.13 to 4.52$)$ & $-0.15(-0.41$ to 0.10$)$ & 0.23 \\
\hline 9 months & 4.26 (4.05 to 4.46$)$ & 4.31 (4.11 to 4.51$)$ & $-0.00(-0.25$ to 0.25$)$ & 0.99 \\
\hline 12 months & 4.28 (4.07 to 4.48$)$ & 4.32 (4.11 to 4.54$)$ & $-0.02(-0.28$ to 0.23$)$ & 0.86 \\
\hline \multicolumn{5}{|l|}{$\begin{array}{l}\text { MPI Affective } \\
\text { distress** }\end{array}$} \\
\hline Overall effect & & & $0.03(-0.10$ to 0.16$)$ & 0.69 \\
\hline Baseline & $2.71(2.56$ to 2.86$)$ & $2.60(2.46$ to 2.73$)$ & & \\
\hline 3 months & $2.56(2.43$ to 2.69$)$ & 2.46 (2.33 to 2.60$)$ & $0.07(-0.11$ to 0.24$)$ & 0.46 \\
\hline 6 months & 2.55 (2.41 to 2.69$)$ & 2.52 (2.38 to 2.67$)$ & $-0.03(-0.20$ to 0.15$)$ & 0.78 \\
\hline 9 months & 2.49 (2.34 to 2.63$)$ & 2.43 (2.29 to 2.56$)$ & $0.06(-0.12$ to 0.24$)$ & 0.51 \\
\hline 12 months & 2.47 (2.34 to 2.61$)$ & 2.48 (2.35 to 2.60$)$ & $-0.00(-0.19$ to 0.18$)$ & 0.97 \\
\hline MPI Support** & & & & \\
\hline
\end{tabular}




\begin{tabular}{|c|c|c|c|c|}
\hline Overall effect & & & $0.06(-0.14$ to 0.26$)$ & 0.56 \\
\hline Baseline & $4.60(4.41$ to 4.80$)$ & $4.42(4.20$ to 4.64$)$ & & \\
\hline 3 months & 4.43 (4.22 to 4.64$)$ & 4.35 (4.10 to 4.60$)$ & $-0.03(-0.29$ to 0.24$)$ & 0.85 \\
\hline 6 months & 4.34 (4.09 to 4.58$)$ & $4.22(3.95$ to 4.51$)$ & $0.02(-0.25$ to 0.29$)$ & 0.88 \\
\hline 9 months & $4.36(4.10$ to 4.63$)$ & $4.17(3.89$ to 4.45$)$ & $0.12(-0.15$ to 0.39$)$ & 0.38 \\
\hline 12 months & $4.37(4.12$ to 4.62$)$ & 4.15 (3.83 to 4.46$)$ & $0.15(-0.13$ to 0.42$)$ & 0.3 \\
\hline $\begin{array}{l}\text { RAND-36 Physic } \\
\text { health*** }\end{array}$ & & & & \\
\hline Overall effect & & & $-0.42(-4.11$ to 3.26$)$ & 0.82 \\
\hline Baseline & $\begin{array}{l}46.20 \text { (42.68 to } \\
49.71)\end{array}$ & $\begin{array}{l}47.20(44.09 \text { to } \\
50.30))\end{array}$ & & \\
\hline 3 months & $\begin{array}{l}57.67 \text { (53.80 to } \\
61.54)\end{array}$ & $\begin{array}{l}53.79 \text { (49.91 to } \\
57.67)\end{array}$ & $3.41(-0.89$ to 7.71$)$ & 0.12 \\
\hline 6 months & $\begin{array}{l}57.68(53.80 \text { to } \\
61.56)\end{array}$ & $\begin{array}{l}56.85(52.99 \text { to } \\
60.71)\end{array}$ & $0.21(-4.15$ to 4.56$)$ & 0.93 \\
\hline 9 months & $\begin{array}{l}56.89(52.68 \text { to } \\
60.09)\end{array}$ & $\begin{array}{l}58.70(54.93 \text { to } \\
62.47)\end{array}$ & $-2.07(-6.47$ to 2.32$)$ & 0.35 \\
\hline 12 months & $\begin{array}{l}57.30(52.79 \text { to } \\
61.82)\end{array}$ & $\begin{array}{l}58.87 \text { (54.88 to } \\
62.86)\end{array}$ & $-4.02(-8.45$ to 0.40$)$ & 0.07 \\
\hline \multicolumn{5}{|l|}{$\begin{array}{l}\text { RAND-36 mental } \\
\text { health**** }\end{array}$} \\
\hline Overall effect & & & $-0.69(-3.35$ to 1.96$)$ & 0.61 \\
\hline
\end{tabular}




\begin{tabular}{|c|c|c|c|c|}
\hline Baseline & $\begin{array}{l}73.68(70.85 \text { to } \\
76.50)\end{array}$ & $\begin{array}{l}75.24 \text { (72.52 to } \\
77.97)\end{array}$ & & \\
\hline 3 months & $\begin{array}{l}75.42(72.27 \text { to } \\
78.58)\end{array}$ & $\begin{array}{l}75.96(73.01 \text { to } \\
78.92)\end{array}$ & $-0.66(-3.91$ to 2.60$)$ & 0.69 \\
\hline 6 months & $\begin{array}{l}77.36 \text { (74.28 to } \\
80.43)\end{array}$ & $\begin{array}{l}77.46(74.46 \text { to } \\
80.46)\end{array}$ & $-0.18(-3.49$ to 3.14$)$ & 0.92 \\
\hline 9 months & $\begin{array}{l}76.75(73.51 \text { to } \\
80.00)\end{array}$ & $\begin{array}{l}77.15(74.00 \text { to } \\
80.30)\end{array}$ & $-1.68(-5.03$ to 1.67$)$ & 0.33 \\
\hline 12 months & $\begin{array}{l}77.98 \text { (74.84 to } \\
81.12)\end{array}$ & $\begin{array}{l}76.84 \text { (73.79 to } \\
80.09)\end{array}$ & $-0.26(-3.64$ to 3.13$)$ & 0.88 \\
\hline $\begin{array}{l}\text { SACROILIAC } \\
\text { JOINT TRIAL }\end{array}$ & $\begin{array}{l}\text { Mean Intervention } \\
\text { group (95\% CI) } \\
\text { N=116 }\end{array}$ & $\begin{array}{l}\text { Mean Control } \\
\text { group }(95 \% \mathrm{CI}) \\
\mathrm{N}=112\end{array}$ & $\begin{array}{l}\text { Mean difference } \\
(95 \% \mathrm{CI})\end{array}$ & $\begin{array}{l}\text { P- } \\
\text { value }\end{array}$ \\
\hline \multicolumn{5}{|c|}{ EQ5D Utilities*** } \\
\hline Overall effect & & & $0.02(-0.02$ to 0.06$)$ & 0.27 \\
\hline Baseline & $0.50(0.44$ to 0.55$)$ & $0.56(0.51$ to 0.62$)$ & & \\
\hline 3 weeks & 0.73 (0.69 to 0.76$)$ & $0.62(0.57$ to 0.68$)$ & 0.10 (0.03 to 0.16$)$ & 0.002 \\
\hline 6 weeks & 0.69 (0.64 to 0.73$)$ & $0.66(0.61$ to 0.71$)$ & $0.04(-0.02$ to 0.09$)$ & 0.22 \\
\hline 3 months & $0.68(0.64$ to 0.73$)$ & $0.66(0.60$ to 0.71$)$ & $0.05(-0.01$ to 0.11$)$ & 0.11 \\
\hline 6 months & 0.74 (0.70 to 0.78$)$ & \begin{tabular}{|l}
$0.73(0.69$ to 0.78$)$ \\
\end{tabular} & $0.001(-0.06$ to 0.06$)$ & 0.98 \\
\hline 9 months & $0.68(0.63$ to 0.73$)$ & $0.73(0.69$ to 0.78$)$ & $-0.05(-0.11$ to 0.02$)$ & 0.15 \\
\hline
\end{tabular}




\begin{tabular}{|c|c|c|c|c|}
\hline 12 months & $0.70(0.65$ to 0.74$)$ & 0.73 (0.68 to 0.78$)$ & $-0.02(-0.09$ to 0.04$)$ & 0.52 \\
\hline \multicolumn{5}{|l|}{$\begin{array}{l}\text { NRS patient } \\
\text { satisfaction** }\end{array}$} \\
\hline Overall effect & & & \begin{tabular}{|l}
$-0.21(-0.54$ to 0.13$)$ \\
\end{tabular} & 0.23 \\
\hline 3 months & 2.94 (2.67 to 3.20$)$ & 3.42 (3.09 to 3.75$)$ & $-0.54(-0.96$ to -0.13$)$ & 0.01 \\
\hline 6 months & 2.86 (2.59 to 3.13$)$ & 2.97 (2.66 to 3.27$)$ & $-0.05(-0.46$ to 0.37$)$ & 0.83 \\
\hline 9 months & $3.05(2.75$ to 3.35$)$ & 3.14 (2.79 to 3.49$)$ & $-0.06(-0.49$ to 0.36$)$ & 0.78 \\
\hline 12 months & 3.03 (2.74 to 3.32$)$ & 3.25 (2.92 to 3.59$)$ & $-0.16(-0.59$ to 0.26$)$ & 0.45 \\
\hline \multicolumn{5}{|c|}{ MPI Pain severity** } \\
\hline Overall effect & & & $-0.06(-0.38$ to 0.25$)$ & 0.70 \\
\hline Baseline & $3.99(3.80$ to 4.18$)$ & 3.76 (3.54 to 3.98$)$ & & \\
\hline 3 months & $2.90(2.61$ to 3.18$)$ & 3.17 (2.85 to 3.48$)$ & $-0.42(-0.46$ to -0.38$)$ & $\begin{array}{l}<0.000 \\
1\end{array}$ \\
\hline 6 months & 2.71 (2.43 to 2.99$)$ & 2.74 (2.42 to 3.06$)$ & $-0.07(-0.46$ to 0.33$)$ & 0.73 \\
\hline 9 months & 3.01 (2.74 to 3.28$)$ & 2.76 (2.43 to 3.08$)$ & $0.18(-0.23$ to 0.59$)$ & 0.39 \\
\hline 12 months & 2.87 (2.57 to 3.15$)$ & 2.71 (2.37 to 3.05$)$ & $0.13(-0.29$ to 0.54$)$ & 0.54 \\
\hline \multicolumn{5}{|c|}{ MPI interference** } \\
\hline Overall effect & & & $-0.04(-0.31$ to 0.23$)$ & 0.77 \\
\hline
\end{tabular}




\begin{tabular}{|c|c|c|c|c|}
\hline Baseline & 3.60 (3.37 to 3.84$)$ & 3.32 (3.05 to 3.57$)$ & & \\
\hline 3 months & 3.19 (2.95 to 3.44$)$ & 2.96 (2.67 to 3.25$)$ & $-0.10(-0.43$ to 0.24$)$ & 0.57 \\
\hline 6 months & 2.86 (2.60 to 3.13$)$ & $2.83(2.50$ to 3.13$)$ & $-0.09(-0.43$ to 0.24$)$ & 0.59 \\
\hline 9 months & $2.85(2.56$ to 3.15$)$ & 2.68 (2.35 to 3.02$)$ & $-0.02(-0.37$ to 0.32$)$ & 0.89 \\
\hline 12 months & $2.92(2.62$ to 3.22$)$ & 2.69 (2.37 to 3.01$)$ & $0.10(-0.25$ to 0.45$)$ & 0.59 \\
\hline \multicolumn{5}{|c|}{ MPI Life control** } \\
\hline Overall effect & & & $0.07(-0.12$ to 0.27$)$ & 0.47 \\
\hline Baseline & $4.11(3.91$ to 4.31$)$ & $4.22(4.04$ to 4.40$)$ & & \\
\hline 3 months & $4.32(4.12$ to 4.53$)$ & 4.23 (3.99 to 4.46$)$ & \begin{tabular}{|l|}
$0.22(-0.03$ to 0.48$)$ \\
\end{tabular} & 0.08 \\
\hline 6 months & $4.42(4.24$ to 4.60$)$ & 4.35 (4.14 to 4.57$)$ & $0.04(-0.21$ to 0.30$)$ & 0.74 \\
\hline 9 months & $4.28(4.07$ to 4.50$)$ & 4.40 (4.14 to 4.66$)$ & $-0.06(-0.32$ to 0.20$)$ & 0.65 \\
\hline 12 months & $4.39(4.17$ to 4.60$)$ & 4.37 (4.09 to 4.65$)$ & $0.06(-0.21$ to 0.32$)$ & 0.66 \\
\hline \multicolumn{5}{|l|}{$\begin{array}{l}\text { MPI Affective } \\
\text { distress** }\end{array}$} \\
\hline Overall effect & & & $0.07(-0.07$ to 0.20$)$ & 0.32 \\
\hline Baseline & $2.75(2.59$ to 2.91$)$ & $2.66(2.50$ to 2.82$)$ & & \\
\hline
\end{tabular}




\begin{tabular}{|c|c|c|c|c|}
\hline 3 months & 2.54 (2.39 to 2.68$)$ & 2.44 (2.28 to 2.59$)$ & $0.08(-0.12$ to 0.27$)$ & 0.44 \\
\hline 6 months & 2.54 (2.42 to 2.73$)$ & $2.58(2.42$ to 2.73$)$ & $-0.03(-0.22$ to 0.17$)$ & 0.79 \\
\hline 9 months & 2.62 (2.45 to 2.80$)$ & 2.44 (2.29 to 2.59$)$ & $0.19(-0.01$ to 0.39$)$ & 0.07 \\
\hline 12 months & 2.45 (2.30 to 2.60$)$ & 2.41 (2.25 to 2.56$)$ & $0.05(-0.15$ to 0.25$)$ & 0.62 \\
\hline \multicolumn{5}{|l|}{ MPI Support** } \\
\hline Overall effect & & & $-0.00(-0.25$ to 0.24$)$ & 0.99 \\
\hline Baseline & 4.95 (4.67 to 5.23 ) & 4.89 (4.64 to 5.13$)$ & & \\
\hline 3 months & 4.88 (4.60 to 5.16 ) & 4.69 (4.37 to 5.01$)$ & $0.01(-0.31$ to 0.33$)$ & 0.97 \\
\hline 6 months & 4.74 (4.44 to 5.03$)$ & 4.83 (4.51 to 5.14$)$ & $-0.09(-0.42$ to 0.24$)$ & 0.59 \\
\hline 9 months & 4.83 (4.51 to 5.15$)$ & 4.76 (4.44 to 5.07$)$ & $-0.00(-0.34$ to 0.33$)$ & 0.98 \\
\hline 12 months & 4.74 (4.42 to 5.06$)$ & $4.79(4.43$ to 5.16$)$ & $0.10(-0.24$ to 0.44$)$ & 0.57 \\
\hline \multicolumn{5}{|c|}{$\begin{array}{l}\text { RAND-36 Physical } \\
\text { health**** }\end{array}$} \\
\hline Overall effect & & & $-1.22(-5.19$ to 2.75$)$ & 0.55 \\
\hline Baseline & $\begin{array}{l}45.50 \text { (42.14 to } \\
48.87)\end{array}$ & $\begin{array}{l}48.50(44.60 \text { to } \\
52.40)\end{array}$ & & \\
\hline 3 months & $\begin{array}{l}53.91(50.09 \text { to } \\
57.73)\end{array}$ & $\begin{array}{l}54.37 \text { (49.76 to } \\
58.98)\end{array}$ & $2.21(-2.82$ to 7.24$)$ & 0.39 \\
\hline
\end{tabular}




\begin{tabular}{|c|c|c|c|c|}
\hline 6 months & $\begin{array}{l}57.04 \text { (52.98 to } \\
51.10)\end{array}$ & \begin{tabular}{|l}
$59.48(55.21$ to \\
$63.76)$
\end{tabular} & $-1.80(-6.88$ to 3.27$)$ & 0.49 \\
\hline 9 months & $\begin{array}{l}55.30(51.10 \text { to } \\
59.50)\end{array}$ & $\begin{array}{l}60.52(56.16 \text { to } \\
64.88)\end{array}$ & $-4.35(-9.54$ to 0.85$)$ & 0.10 \\
\hline 12 months & $\begin{array}{l}56.98(52.50 \text { to } \\
61.46)\end{array}$ & $\begin{array}{l}59.80(55.25 \text { to } \\
64.34)\end{array}$ & $-1.48(-6.73$ to 3.77$)$ & 0.58 \\
\hline \multicolumn{5}{|l|}{$\begin{array}{l}\text { RAND-36 mental } \\
\text { health**** }\end{array}$} \\
\hline Overall effect & & & 0.038 (-175 to 1.82$)$ & 0.97 \\
\hline Baseline & $\begin{array}{l}76.40(73.53 \text { to } \\
79.28)\end{array}$ & $\begin{array}{l}76.76(73.99 \text { to } \\
79.53)\end{array}$ & & \\
\hline 3 months & $\begin{array}{l}76.87(73.89 \text { to } \\
79.86)\end{array}$ & \begin{tabular}{|l}
76.78 (73.36 to \\
$80.21)$
\end{tabular} & $0.79(-2.09$ to 3.67$)$ & 0.59 \\
\hline 6 months & $\begin{array}{l}62.77(61.51 \text { to } \\
64.03)\end{array}$ & \begin{tabular}{|l}
$63.03(61.21$ to \\
$64.86)$
\end{tabular} & $-0.64(-3.56$ to 2.29$)$ & 0.67 \\
\hline 9 months & $\begin{array}{l}62.84(61.39 \text { to } \\
64.39)\end{array}$ & \begin{tabular}{|l}
$62.86(60.96$ to \\
$64.75)$
\end{tabular} & 0.03 (-2.99 to 3.04$)$ & 0.98 \\
\hline 12 months & $\begin{array}{l}62.64(60.99 \text { to } \\
64.30)\end{array}$ & $\begin{array}{l}62.43(60.57 \text { to } \\
64.30)\end{array}$ & $-0.06(-3.12$ to 3.01$)$ & 0.97 \\
\hline $\begin{array}{l}\text { COMBINATION } \\
\text { TRIAL }\end{array}$ & $\begin{array}{l}\text { Mean Intervention } \\
\text { group }(95 \% \mathrm{CI}) \\
\mathrm{N}=103\end{array}$ & \begin{tabular}{|l} 
Mean Control \\
group $(95 \% \mathrm{CI})$ \\
$\mathrm{N}=99$
\end{tabular} & $\begin{array}{l}\text { Mean difference } \\
(95 \% \mathrm{CI})\end{array}$ & $\begin{array}{l}\text { P- } \\
\text { value }\end{array}$ \\
\hline \multicolumn{5}{|l|}{ EQ5D Utilities*** } \\
\hline Overall effect & & & $0.04(-0.01$ to 0.09$)$ & 0.12 \\
\hline Baseline & $0.48(0.43$ to 0.54$)$ & $0.52(0.45$ to 0.58$)$ & & \\
\hline 3 weeks & $0.64(0.57$ to 0.70$)$ & $0.60(0.53$ to 0.67$)$ & $0.06(-0.02$ to 0.14$)$ & 0.15 \\
\hline
\end{tabular}




\begin{tabular}{|c|c|c|c|c|}
\hline 6 weeks & 0.70 (0.66 to 0.75$)$ & 0.57 (0.51 to 0.64$)$ & 0.14 (0.07 to 0.22$)$ & 0 \\
\hline 3 months & $0.69(0.64$ to 0.74$)$ & 0.63 (0.57 to 0.69$)$ & 0.09 (0.01 to 0.16$)$ & 0.02 \\
\hline 6 months & $0.69(0.64$ to 0.72$)$ & $0.69(0.63$ to 0.74$)$ & $0.01(-0.06$ to 0.09$)$ & 0.74 \\
\hline 9 months & $0.65(0.59$ to 0.72$)$ & $0.70(0.64$ to 0.76$)$ & $-0.02(-0.06$ to 0.09$)$ & 0.62 \\
\hline 12 months & 0.64 (0.58 to 0.70$)$ & 0.74 (0.69 to 0.80$)$ & $-0.07(-0.15$ to 0.01$)$ & 0.08 \\
\hline \multicolumn{5}{|c|}{ Patient satisfaction** } \\
\hline Overall effect & & & $-0.17(-0.56$ to 0.22$)$ & 0.39 \\
\hline 3 months & 2.98 (2.73 to 3.22$)$ & 3.48 (3.17 to 3.78 ) & $-0.52(-0.97$ to -0.07$)$ & 0.02 \\
\hline 6 months & $3.05(2.73$ to 3.36$)$ & $3.13(2.84$ to 3.43$)$ & \begin{tabular}{|l|}
$-0.056(-0.51$ to \\
$0.40)$
\end{tabular} & 0.81 \\
\hline 9 months & 3.16 (2.84 to 3.47$)$ & 3.29 (2.94 to 3.63$)$ & $-0.13(-0.59$ to 0.34$)$ & 0.60 \\
\hline 12 months & $3.32(2.96$ to 3.68$)$ & 3.08 (2.73 to 3.43$)$ & $0.10(-0.37$ to 0.58$)$ & 0.67 \\
\hline \multicolumn{5}{|c|}{ MPI Pain severity** } \\
\hline Overall effect & & & $0.02(-0.34$ to 0.38$)$ & 0.91 \\
\hline Baseline & $4.00(3.82$ to 4.18$)$ & $3.96(3.74$ to 4.19$)$ & & \\
\hline 3 months & 2.99 (2.70 to 3.28$)$ & $3.42(3.10$ to 3.74$)$ & $-0.50(-0.94$ to -0.05$)$ & 0.02 \\
\hline
\end{tabular}




\begin{tabular}{|c|c|c|c|c|}
\hline 6 months & $3.06(2.72$ to 3.40$)$ & 2.90 (2.58 to 3.23$)$ & $0.26(-0.18$ to 0.71$)$ & 0.24 \\
\hline 9 months & $3.09(2.75$ to 3.43$)$ & 3.05 (2.68 to 3.42$)$ & \begin{tabular}{|l}
$0.10(-0.35$ to 0.55$)$ \\
\end{tabular} & 0.67 \\
\hline 12 months & $3.07(2.73$ to 3.41$)$ & 2.61 (2.22 to 2.99$)$ & 0.68 (0.22 to 1.15$)$ & 0 \\
\hline \multicolumn{5}{|c|}{ MPI interference** } \\
\hline Overall effect & & & $0.09(-0.24$ to 0.43$)$ & 0.58 \\
\hline Baseline & 3.35 (3.09 to 3.61$)$ & 3.25 (2.97 to 3.53$)$ & & \\
\hline 3 months & 2.84 (2.56 to 3.13$)$ & $2.92(2.57$ to 3.26$)$ & $-0.18(-0.58$ to 0.21$)$ & 0.36 \\
\hline 6 months & $2.80(2.46$ to 3.15$)$ & 2.57 (2.27 to 2.88$)$ & $0.30(-0.10$ to 0.70$)$ & 0.14 \\
\hline 9 months & 2.78 (2.45 to 3.11$)$ & 2.77 (2.39 to 3.16$)$ & $0.01(-0.40$ to 0.43$)$ & 0.95 \\
\hline 12 months & 2.87 (2.52 to 3.23$)$ & 2.45 (2.06 to 2.82$)$ & $0.31(-0.11$ to 0.73$)$ & 0.15 \\
\hline \multicolumn{5}{|c|}{ MPI Life control** } \\
\hline Overall effect & & & $0.09(-0.17$ to 0.34$)$ & 0.49 \\
\hline Baseline & $3.98(3.76$ to 4.21$)$ & 4.09 (3.91 to 4.27$)$ & & \\
\hline 3 months & $4.15(3.90$ to 4.39$)$ & 3.97 (3.75 to 4.19$)$ & \begin{tabular}{|l}
$0.28(-0.05$ to 0.61$)$ \\
\end{tabular} & 0.09 \\
\hline 6 months & $4.16(3.92$ to 4.41$)$ & 4.10 (3.86 to 4.34$)$ & $0.10(-0.23$ to 0.44$)$ & 0.54 \\
\hline
\end{tabular}




\begin{tabular}{|c|c|c|c|c|}
\hline 9 months & 4.06 (3.77 to 4.36$)$ & 4.09 (3.81 to 4.38$)$ & $-0.02(-0.36$ to 0.32$)$ & 0.91 \\
\hline 12 months & 4.07 (3.78 to 4.35$)$ & 4.25 (3.96 to 4.54$)$ & $-0.05(-0.40$ to 0.30$)$ & 0.77 \\
\hline \multicolumn{5}{|l|}{$\begin{array}{l}\text { MPI Affective } \\
\text { distress** }\end{array}$} \\
\hline Overall effect & & & $0.03(-0.15$ to 0.21$)$ & 0.74 \\
\hline Baseline & 2.66 (2.49 to 2.83$)$ & 2.62 (2.47 to 2.78$)$ & & \\
\hline 3 months & 2.53 (2.36 to 2.70$)$ & $2.68(2.48$ to 2.88$)$ & $-0.20(-0.43$ to 0.04$)$ & 0.10 \\
\hline 6 months & 2.58 (2.40 to 2.76 ) & 2.48 (2.30 to 2.66$)$ & $0.11(-0.13$ to 0.35$)$ & 0.36 \\
\hline 9 months & 2.67 (2.49 to 2.85$)$ & 2.61 (2.43 to 2.80$)$ & $0.09(-0.16$ to 0.33$)$ & 0.49 \\
\hline 12 months & 2.57 (2.38 to 2.76$)$ & 2.43 (2.24 to 2.62 ) & $0.17(-0.08$ to 0.42$)$ & 0.19 \\
\hline \multicolumn{5}{|l|}{ MPI Support** } \\
\hline Overall effect & & & $0.13(-0.15$ to 0.40$)$ & 0.36 \\
\hline Baseline & 4.56 (4.26 to 4.86$)$ & 4.67 (4.44 to 4.90$)$ & & \\
\hline 3 months & 4.48 (4.16 to 4.81$)$ & $4.54(4.25$ to 4.83$)$ & $0.05(-0.30$ to 0.41$)$ & 0.76 \\
\hline 6 months & 4.36 (4.00 to 4.72$)$ & 4.35 (4.03 to 4.67$)$ & $0.17(-0.18$ to 0.53$)$ & 0.34 \\
\hline 9 months & 4.47 (4.10 to 4.83$)$ & 4.40 (4.08 to 4.72$)$ & $0.16(-0.20$ to 0.53$)$ & 0.38 \\
\hline
\end{tabular}




\begin{tabular}{|c|c|c|c|c|}
\hline 12 months & 4.56 (4.20 to 4.92$)$ & 4.51 (4.18 to 4.85$)$ & $0.11(-0.27$ to 0.49$)$ & 0.57 \\
\hline \multicolumn{5}{|c|}{$\begin{array}{l}\text { RAND-36 Physical } \\
\text { health*** }\end{array}$} \\
\hline Overall effect & & & $-2.44(-7.20$ to 2.33$)$ & 0.32 \\
\hline Baseline & $\begin{array}{l}\text { 45.61 (41.93 to } \\
49.29)\end{array}$ & $\begin{array}{l}\text { 48.35 (44.39 to } \\
52.31)\end{array}$ & & \\
\hline 3 months & \begin{tabular}{|l}
$54.66(50.49$ to \\
$58.82)$
\end{tabular} & $\begin{array}{l}50.06 \text { (45.39 to } \\
54.73)\end{array}$ & $4.20(-1.49$ to 9.89$)$ & 0.15 \\
\hline 6 months & $\begin{array}{l}52.87 \text { (48.00 to } \\
57.72)\end{array}$ & $\begin{array}{l}57.73(53.20 \text { to } \\
62.27)\end{array}$ & $\begin{array}{l}-5.39(-11.18 \text { to } \\
0.39)\end{array}$ & 0.07 \\
\hline 9 months & $\begin{array}{l}52.87 \text { (48.02 to } \\
57.71)\end{array}$ & $\begin{array}{l}54.69 \text { (49.40 to } \\
59.99)\end{array}$ & $-2.20(-8.11$ to 3.70$)$ & 0.46 \\
\hline 12 months & $\begin{array}{l}52.73(47.62 \text { to } \\
55.00)\end{array}$ & $\begin{array}{l}62.25(57.51 \text { to } \\
66.98)\end{array}$ & $\begin{array}{l}-8.72(-14.77 \text { to }- \\
2.67)\end{array}$ & 0.00 \\
\hline \multicolumn{5}{|l|}{$\begin{array}{l}\text { RAND-36 mental } \\
\text { health*** }\end{array}$} \\
\hline Overall effect & & & $-0.23(-4.16$ to 3.56$)$ & 0.88 \\
\hline Baseline & $\begin{array}{l}72.49 \text { (69.34 to } \\
75.64)\end{array}$ & $\begin{array}{l}77.55 \text { (74.97 to } \\
80.13)\end{array}$ & & \\
\hline 3 months & $\begin{array}{l}74.02(70.40 \text { to } \\
77.65)\end{array}$ & $\begin{array}{l}74.84(71.18 \text { to } \\
78.49)\end{array}$ & $1.57(-3.02$ to 6.17$)$ & 0.5 \\
\hline 6 months & $\begin{array}{l}73.04 \text { (69.41 to } \\
76.66)\end{array}$ & $\begin{array}{l}76.32(72.63 \text { to } \\
80.00)\end{array}$ & $-0.82(-5.48$ to 3.84$)$ & 0.73 \\
\hline 9 months & $\begin{array}{l}74.00 \text { (70.10 to } \\
77.90)\end{array}$ & $\begin{array}{l}76.18 \text { (72.74 to } \\
79.62)\end{array}$ & $-0.46(-5.20$ to 4.28$)$ & 0.85 \\
\hline 12 months & $\begin{array}{l}72.96 \text { (68.54 to } \\
77.37)\end{array}$ & $\begin{array}{l}76.53 \text { (72.66 to } \\
80.40)\end{array}$ & $-1.94(-6.79$ to 2.91$)$ & 0.43 \\
\hline
\end{tabular}


Values presented are model estimates of linear mixed-effects models with a random intercept, and adjusted for outcome at baseline and age, gender, BMI, education, smoking, marital status, back pain complaint history, patient expectations and baseline values. Regression coefficients can be interpreted as mean differences between interventions at a certain follow-up moment compared to baseline. Abbreviation: EQ5D; Utility scores based on the EuroQol5D; MPI, Multidimensional Pain Inventory; RAND36, Research and Development 36 item health survey. ** Higher score indicates less satisfaction or severe symptoms on the MPI. Range for patient satisfaction, 1-7, for MPI 0-6. *** Higher score indicates more quality of life. Range for EQ5D utility: 0-1; for RAND36: 0-100. 
eTable 3. As Treated Analysis for Pain Intensity, Functional Status, and Global Perceived Recovery, Without Protocol Violators Based on Intention-to-Treat Analyses

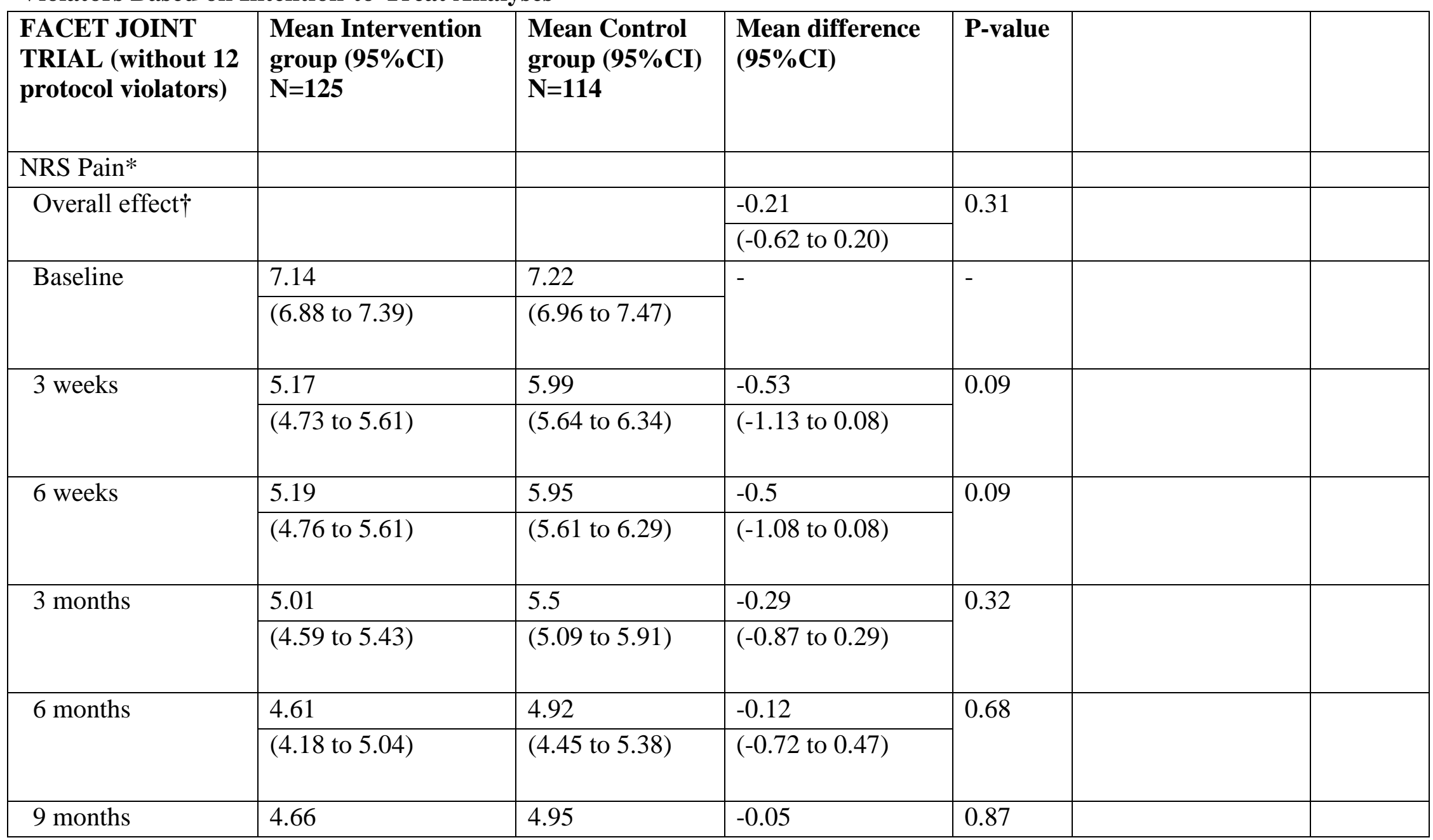




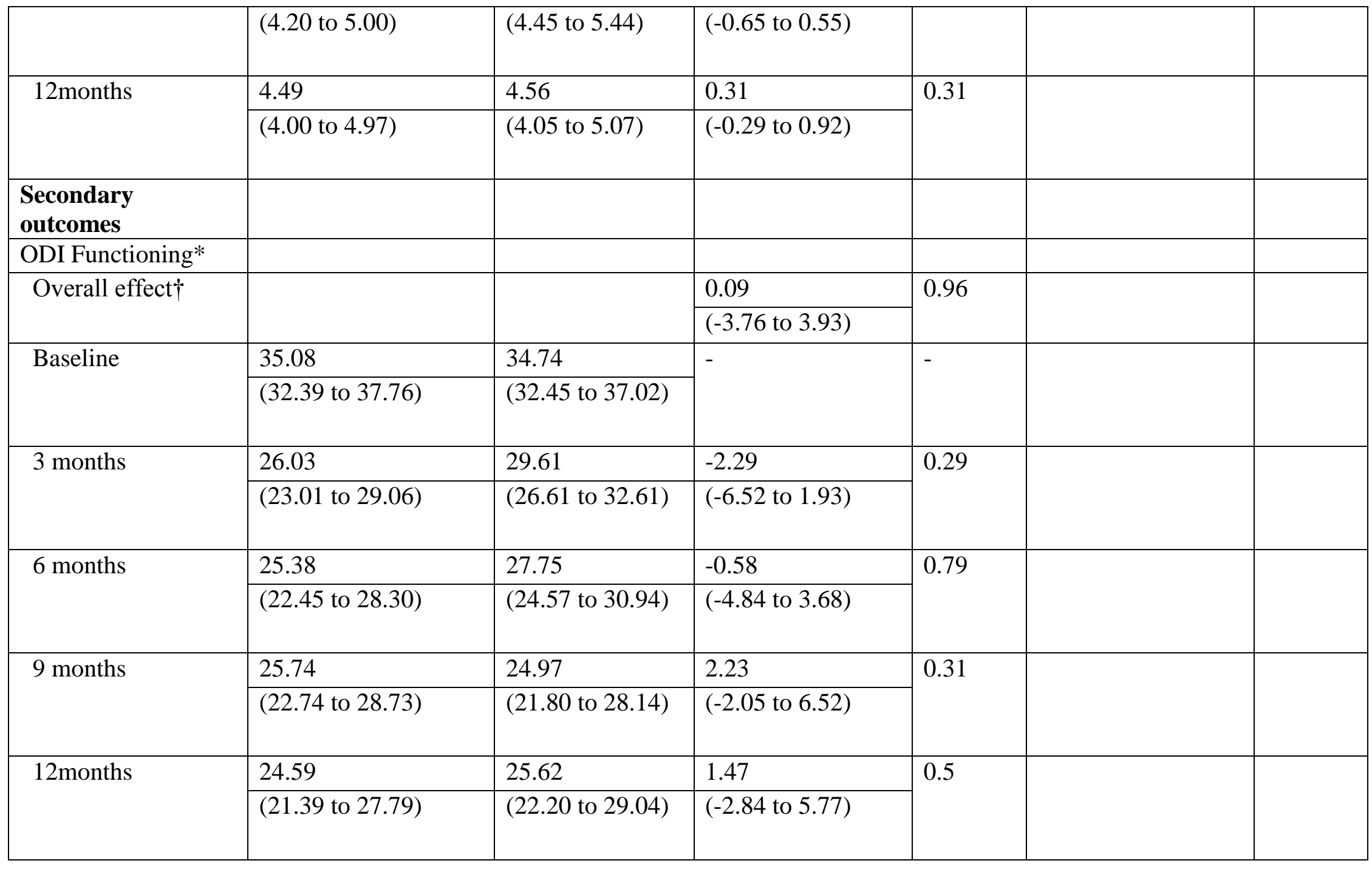




\begin{tabular}{|c|c|c|c|c|c|c|}
\hline & $\begin{array}{l}\text { Success } \mathbf{n} / \mathbf{N}(\%) \\
\text { Intervention group }\end{array}$ & $\begin{array}{l}\text { Success n/N (\%) } \\
\text { Control group }\end{array}$ & $\operatorname{RR}(95 \% \mathrm{CI})^{\S}$ & P-value & $\begin{array}{l}\text { Risk difference } \\
(95 \% \mathrm{CI})\end{array}$ & NNT \\
\hline \multicolumn{7}{|l|}{ GPR Success } \\
\hline \multirow[t]{2}{*}{3 weeks } & \multirow[t]{2}{*}{$32 / 108(29.63)$} & \multirow[t]{2}{*}{$3 / 92(3.26)$} & 8.71 & \multirow[t]{2}{*}{0.0001} & 29.37 & \multirow[t]{2}{*}{4} \\
\hline & & & (3.09 to 17.85 ) & & (17.02 to 35.72$)$ & \\
\hline \multirow[t]{2}{*}{6 weeks } & \multirow[t]{2}{*}{$35 / 119(29.41)$} & \multirow[t]{2}{*}{$7 / 108(6.48)$} & 4.24 & \multirow[t]{2}{*}{0.0004} & 22.93 & \multirow[t]{2}{*}{5} \\
\hline & & & (2.00 to 7.58$)$ & & (13.52 to 32.34$)$ & \\
\hline \multirow[t]{2}{*}{3 months } & \multirow[t]{2}{*}{$43 / 119(36.13)$} & \multirow[t]{2}{*}{ 23/104 (22.12) } & 1.56 & \multirow[t]{2}{*}{0.09} & 14.01 & \multirow[t]{2}{*}{ NA } \\
\hline & & & (0.93 to 2.34$)$ & & (2.27 to 25.77$)$ & \\
\hline \multirow[t]{2}{*}{6 months } & \multirow[t]{2}{*}{$46 / 113(40.71)$} & \multirow[t]{2}{*}{ 33/99 (33.33) } & 1.18 & \multirow[t]{2}{*}{0.46} & 7.38 & \multirow[t]{2}{*}{ NA } \\
\hline & & & (0.74 to 1.69$)$ & & (-5.60 to 20.35$)$ & \\
\hline \multirow[t]{2}{*}{9 months } & \multirow[t]{2}{*}{$41 / 106(38.68)$} & \multirow[t]{2}{*}{$36 / 96(37.50)$} & 0.91 & \multirow[t]{2}{*}{0.69} & 1.18 & \multirow[t]{2}{*}{ NA } \\
\hline & & & $(0.55$ to 0.82$)$ & & $(-12.23$ to 14.59$)$ & \\
\hline \multirow[t]{2}{*}{12 months } & \multirow[t]{2}{*}{$44 / 103$ (42.72) } & \multirow[t]{2}{*}{$36 / 95(37.89)$} & 0.99 & \multirow[t]{2}{*}{0.96} & 4.83 & \multirow[t]{2}{*}{ NA } \\
\hline & & & (0.61 to 1.44$)$ & & $(-8.83$ to 18.48$)$ & \\
\hline $\begin{array}{l}\text { SACROILIAC } \\
\text { JOINT TRIAL } \\
\text { (without } 7 \text { protocol } \\
\text { violators) }\end{array}$ & $\begin{array}{l}\text { Mean Intervention } \\
\text { group }(95 \% \mathrm{CI}) \\
\mathbf{N}=116\end{array}$ & $\begin{array}{l}\text { Mean Control } \\
\text { group }(95 \% \mathrm{CI}) \\
\mathrm{N}=105\end{array}$ & $\begin{array}{l}\text { Treatment effect } \\
(95 \% \text { CI })\end{array}$ & P-value & & \\
\hline
\end{tabular}

(C) 2017 American Medical Association. All rights reserved. 


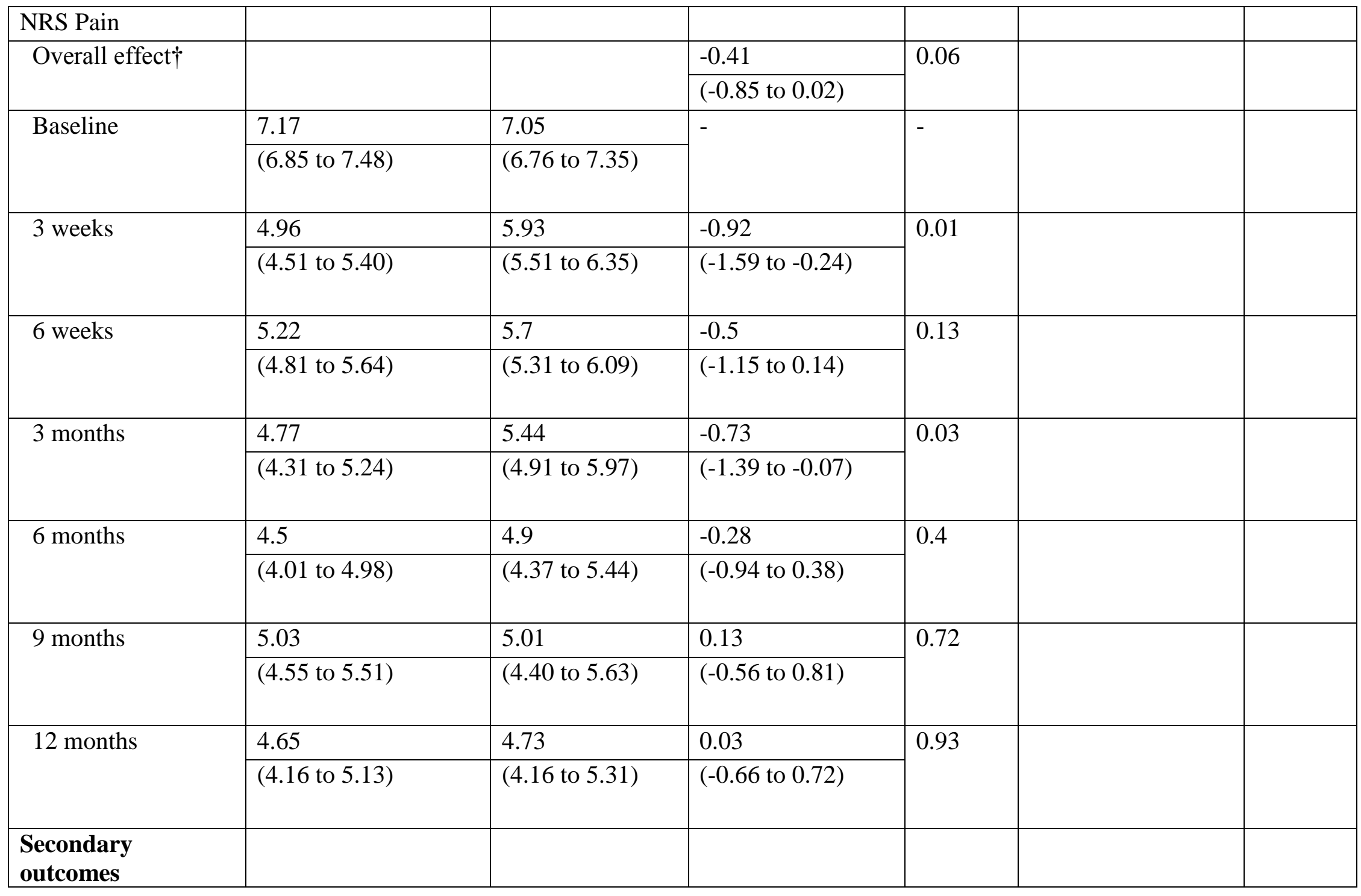

(C) 2017 American Medical Association. All rights reserved. 


\begin{tabular}{|c|c|c|c|c|c|c|}
\hline \multicolumn{7}{|c|}{ ODI Functioning* } \\
\hline \multirow[t]{2}{*}{ Overall effect } & & & -0.31 & \multirow[t]{2}{*}{0.86} & & \\
\hline & & & $(-3.79$ to 3.17$)$ & & & \\
\hline \multirow[t]{2}{*}{ Baseline } & 38.07 & 33.79 & \multirow[t]{2}{*}{-} & \multirow[t]{2}{*}{-} & & \\
\hline & (35.40 to 40.74$)$ & (30.82 to 36.76$)$ & & & & \\
\hline \multirow[t]{2}{*}{3 months } & 27.72 & 29.46 & -4.99 & \multirow[t]{2}{*}{0.02} & & \\
\hline & $(24.50$ to 30.95$)$ & (25.69 to 33.24$)$ & $(-9.27$ to -0.70$)$ & & & \\
\hline \multirow[t]{2}{*}{6 months } & 25.91 & 25.8 & -0.95 & \multirow[t]{2}{*}{0.67} & & \\
\hline & $(22.91$ to 29.05$)$ & (22.17 to 29.44$)$ & $(-5.26$ to 3.36$)$ & & & \\
\hline \multirow[t]{2}{*}{9 months } & 28.4 & 23.83 & 3.88 & \multirow[t]{2}{*}{0.08} & & \\
\hline & $(25.05$ to 31.75$)$ & (20.23 to 27.44$)$ & $(-0.53$ to 8.28$)$ & & & \\
\hline \multirow[t]{3}{*}{12 months } & 27.29 & 24.72 & 1.71 & \multirow[t]{2}{*}{0.45} & & \\
\hline & (23.89 to 30.69$)$ & (20.76 to 28.69$)$ & $(-2.75$ to 6.46$)$ & & & \\
\hline & $\begin{array}{l}\text { Success } \mathbf{n} / \mathbf{N}(\%) \\
\text { Intervention group }\end{array}$ & $\begin{array}{l}\text { Success n/N (\%) } \\
\text { Control group }\end{array}$ & RR $(95 \% C I)^{\S}$ & P-value & $\begin{array}{l}\text { Risk difference } \\
(95 \% \text { CI })\end{array}$ & NNT \\
\hline \multicolumn{7}{|l|}{ GPR Success } \\
\hline \multirow[t]{2}{*}{3 weeks } & \multirow[t]{2}{*}{ 28/94 (29.79) } & \multirow[t]{2}{*}{$8 / 82(9.76)$} & 3.02 & \multirow[t]{2}{*}{0.0048} & 20.03 & \multirow[t]{2}{*}{5} \\
\hline & & & (1.44 to 5.11$)$ & & (8.77 to 31.29$)$ & \\
\hline 6 weeks & 40/108 (37.04) & $9 / 89(10.11)$ & 3.91 & 0.0001 & 26.93 & 4 \\
\hline
\end{tabular}

(C) 2017 American Medical Association. All rights reserved. 


\begin{tabular}{|c|c|c|c|c|c|c|}
\hline & & & (2.06 to 6.13$)$ & & (15.87 to 37.98$)$ & \\
\hline \multirow{2}{*}{3 months } & \multirow{2}{*}{$43 / 110(39.09)$} & \multirow{2}{*}{$17 / 82(20.73)$} & 1.96 & \multirow{2}{*}{0.01} & 18.36 & \multirow[t]{2}{*}{5} \\
\hline & & & (1.17 to 2.87$)$ & & (4.7 to 31.01 ) & \\
\hline \multirow[t]{2}{*}{6 months } & \multirow[t]{2}{*}{$46 / 103(44.66)$} & \multirow[t]{2}{*}{$26 / 83(31.33)$} & 1.39 & \multirow[t]{2}{*}{0.16} & 13.33 & \multirow[t]{2}{*}{$\mathrm{NA}$} \\
\hline & & & (0.87 to 1.95$)$ & & $(-0.51$ to 27.18$)$ & \\
\hline \multirow[t]{2}{*}{9 months } & \multirow[t]{2}{*}{$36 / 101(35.64)$} & \multirow[t]{2}{*}{$23 / 73(31.51)$} & 1.15 & \multirow[t]{2}{*}{0.58} & 4.13 & \multirow[t]{2}{*}{$\mathrm{NA}$} \\
\hline & & & (0.67 to 1.75$)$ & & $(-10.03$ to 18.31$)$ & \\
\hline \multirow[t]{2}{*}{12 months } & \multirow[t]{2}{*}{$49 / 102(48.04)$} & \multirow[t]{2}{*}{$23 / 70(32.86)$} & 1.41 & \multirow[t]{2}{*}{0.14} & 15.18 & \multirow[t]{2}{*}{$\mathrm{NA}$} \\
\hline & & & (0.88 to 1.97$)$ & & (0.52 to 29.85$)$ & \\
\hline $\begin{array}{l}\text { COMBINATION } \\
\text { TRIAL } \\
\text { (WITHOUT } 14 \\
\text { PROTOCOL } \\
\text { VIOLATORS) } \\
\end{array}$ & $\begin{array}{l}\text { Mean Intervention } \\
\text { group }(95 \% \mathrm{CI}) \\
\mathbf{N}=93\end{array}$ & $\begin{array}{l}\text { Mean Control } \\
\text { group }(95 \% \mathrm{CI}) \\
\mathrm{N}=95\end{array}$ & $\begin{array}{l}\text { Mean difference } \\
(95 \% \mathrm{CI})\end{array}$ & P-value & & \\
\hline \multicolumn{7}{|l|}{ NRS Pain * } \\
\hline \multirow[t]{2}{*}{ Overall effect $\dagger$} & & & -0.19 & \multirow[t]{2}{*}{0.53} & & \\
\hline & & & $(-0.78$ to 0.40$)$ & & & \\
\hline \multirow[t]{2}{*}{ Baseline } & 7.28 & 7.45 & \multirow[t]{2}{*}{-} & \multirow[t]{2}{*}{-} & & \\
\hline & (6.98 to 7.58$)$ & (7.14 to 7.77 ) & & & & \\
\hline 3 weeks & 5.46 & 6.38 & -0.58 & 0.19 & & \\
\hline
\end{tabular}

(C) 2017 American Medical Association. All rights reserved. 


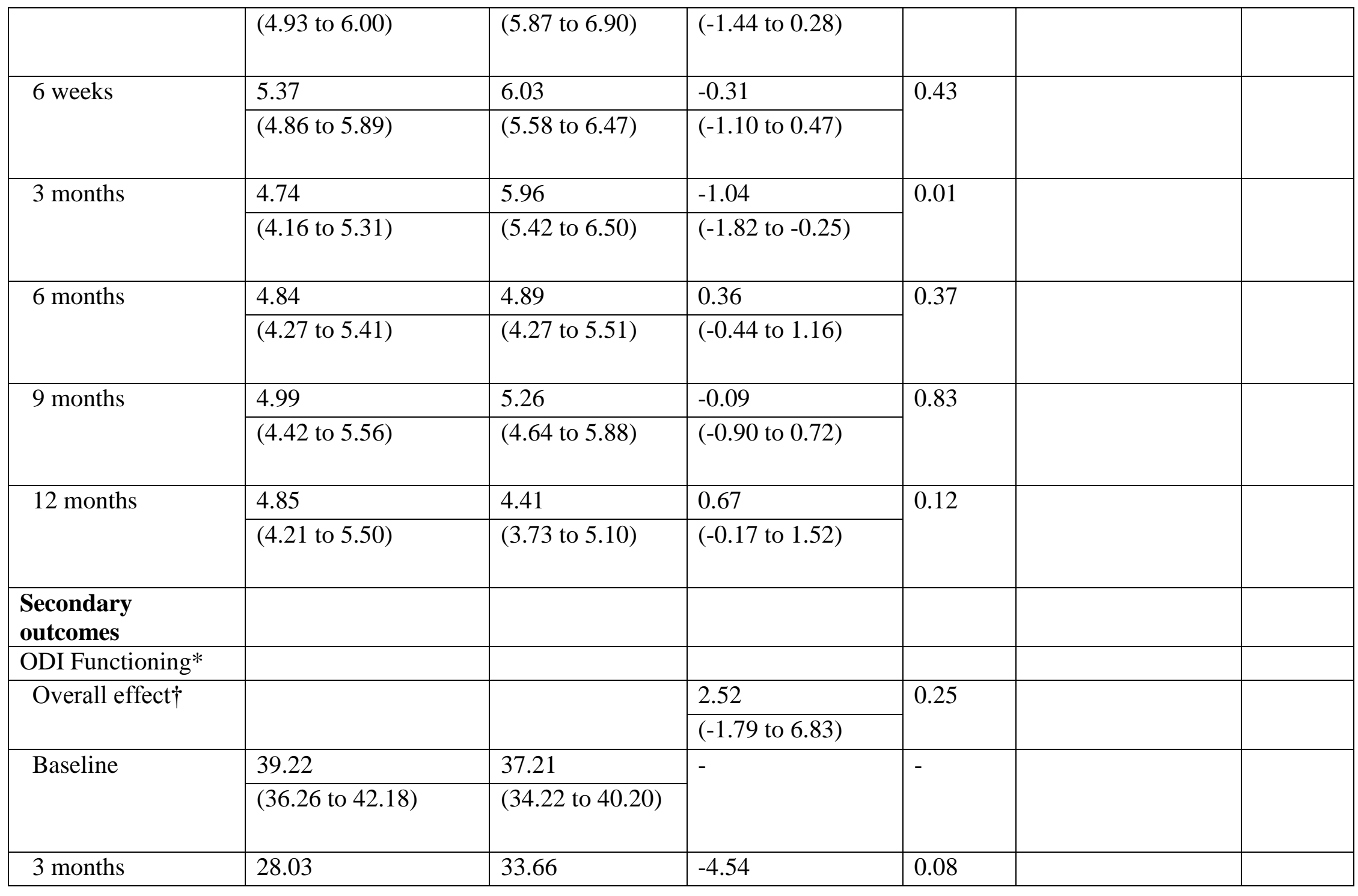

(C) 2017 American Medical Association. All rights reserved. 


\begin{tabular}{|c|c|c|c|c|c|c|}
\hline & (224.45 to 31.60$)$ & (29.74 to 37.58$)$ & $(-9.69$ to 0.61$)$ & & & \\
\hline \multirow[t]{2}{*}{6 months } & 30.75 & 28.51 & 5.31 & \multirow[t]{2}{*}{0.05} & & \\
\hline & (36.32 to 35.18$)$ & (24.50 to 32.51$)$ & (0.08 to 10.54$)$ & & & \\
\hline \multirow[t]{2}{*}{9 months } & 31.16 & 28.63 & 4.24 & \multirow[t]{2}{*}{0.12} & & \\
\hline & (27.05 to 35.27$)$ & (24.36 to 32.89$)$ & $(-1.06$ to 9.54$)$ & & & \\
\hline \multirow[t]{3}{*}{12 months } & 31.38 & 24.7 & 7.18 & \multirow[t]{2}{*}{0.01} & & \\
\hline & (27.16 to 35.60$)$ & (20.76 to 28.65$)$ & (1.71 to 12.64$)$ & & & \\
\hline & $\begin{array}{l}\text { Success } \mathrm{n} / \mathrm{N}(\%) \\
\text { Intervention group }\end{array}$ & $\begin{array}{l}\text { Success n/N (\%) } \\
\text { Control group }\end{array}$ & RR $(95 \% C I)^{\S}$ & P-value & $\begin{array}{l}\text { Risk difference } \\
(95 \% \mathrm{CI})\end{array}$ & NNT \\
\hline \multirow[t]{2}{*}{3 weeks } & \multirow[t]{2}{*}{$17 / 72(23.61)$} & \multirow[t]{2}{*}{$4 / 53(7.55)$} & 2.25 & \multirow[t]{2}{*}{0.15} & 16.06 & \multirow[t]{2}{*}{ NA } \\
\hline & & & (0.73 to 5.56$)$ & & (3.95 to 28.18 ) & \\
\hline \multirow[t]{2}{*}{6 weeks } & \multirow[t]{2}{*}{$24 / 84(28.57)$} & \multirow[t]{2}{*}{$7 / 79(8.86)$} & 2.4 & \multirow[t]{2}{*}{0.05} & 19.71 & \multirow[t]{2}{*}{5} \\
\hline & & & (0.98 to 4.89$)$ & & (8.20 to 31.23$)$ & \\
\hline \multirow[t]{2}{*}{3 months } & \multirow[t]{2}{*}{$30 / 80(37.50)$} & \multirow[t]{2}{*}{$13 / 76(17.10)$} & 2.07 & \multirow[t]{2}{*}{0.04} & 21.4 & \multirow[t]{2}{*}{5} \\
\hline & & & (1.02 to 3.43$)$ & & (8.02 to 35.27 ) & \\
\hline \multirow[t]{2}{*}{6 months } & \multirow[t]{2}{*}{$28 / 77(36.36)$} & \multirow[t]{2}{*}{ 27/71 (38.03) } & 0.78 & \multirow[t]{2}{*}{0.42} & -1.67 & \multirow[t]{2}{*}{ NA } \\
\hline & & & (0.40 to 1.34$)$ & & $(-17.25$ to 13.92$)$ & \\
\hline
\end{tabular}

(C) 2017 American Medical Association. All rights reserved. 


\begin{tabular}{|c|c|c|c|c|c|c|}
\hline \multirow[t]{2}{*}{9 months } & \multirow[t]{2}{*}{$27 / 76(35.52)$} & \multirow[t]{2}{*}{$21 / 66(31.81)$} & 1.08 & \multirow[t]{2}{*}{0.81} & 3.71 & \multirow[t]{2}{*}{ NA } \\
\hline & & & (0.55 to 1.78$)$ & & (-11.85 to 19.27$)$ & \\
\hline \multirow[t]{2}{*}{12 months } & \multirow[t]{2}{*}{$24 / 68(35.29)$} & \multirow[t]{2}{*}{$22 / 58(37.93)$} & 0.86 & \multirow[t]{2}{*}{0.63} & -2.64 & \multirow[t]{2}{*}{ NA } \\
\hline & & & (0.42 to 1.46$)$ & & $(-19.25$ to 14.24$)$ & \\
\hline
\end{tabular}

Values presented (for mean differences and Relative Risks) are model estimates of linear mixed-effects models with a random intercept, and adjusted for outcome at baseline and age, gender, BMI, education, smoking, marital status, back pain complaint history, patient expectations. Regression coefficients can be interpreted as mean differences between interventions at a certain follow-up moment compared to baseline. Abbreviations: SD, Standard Deviation; NRS, Numeric Rating Scale (0-10); GPR, Global Perceived Recovery (1-7; 1-2 indicate success); ODI, Oswestry Disability Index (0-100); RR, Relative Risk; NNT, Numbers Needed to Treat. * Higher score indicates more severe symptoms. ${ }^{\S}$ RRs are estimated based on the method of Zhang et al. ${ }^{32} \dagger$ The overall effect measures provide information over the total follow-up time of 12 months, instead of the time-by-treatment effects. 
eTable 4. Treatment Effects for Pain Intensity, Functional Status, and Global Perceived Recovery Based on an As-Treated After 3 Months

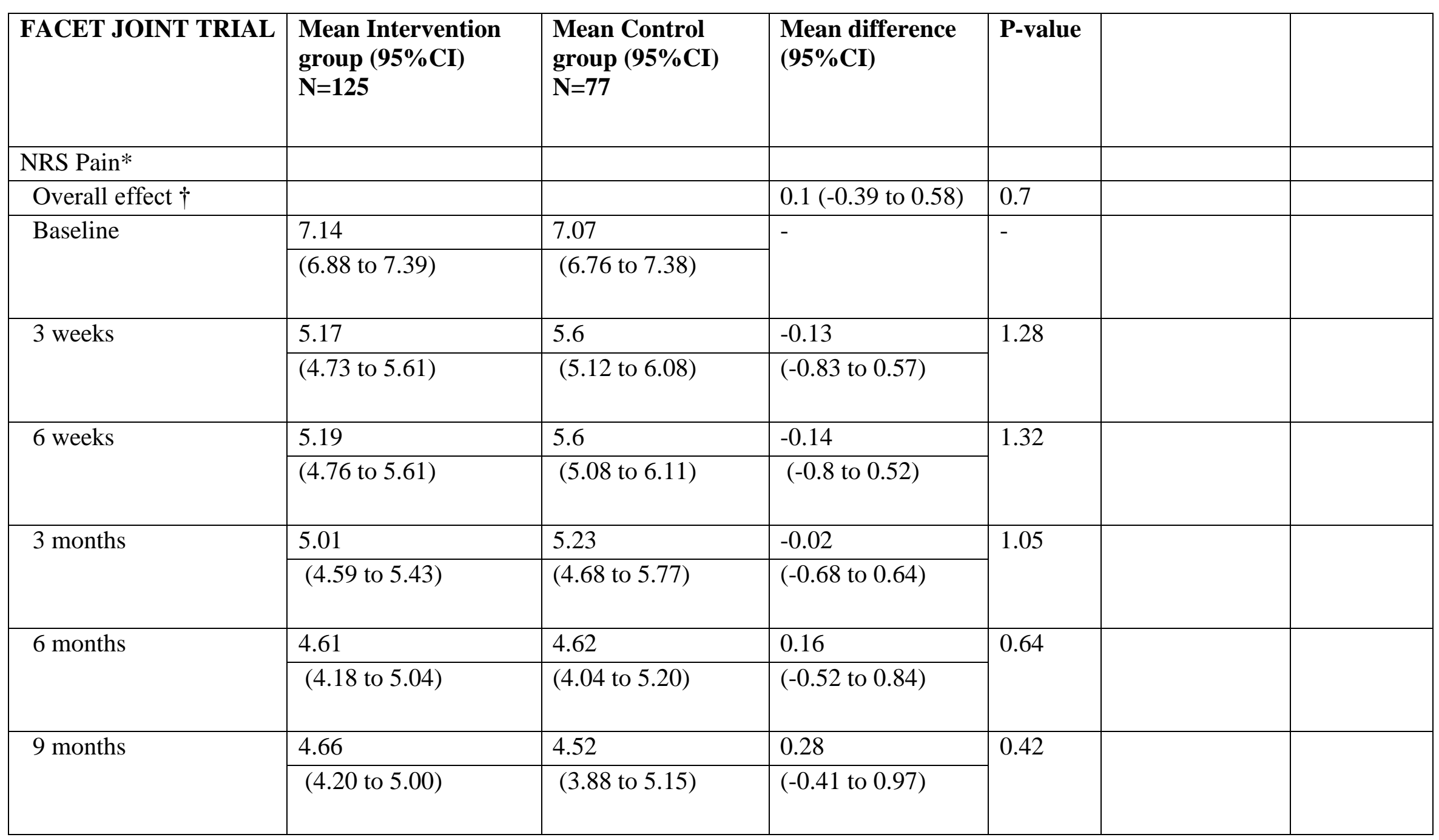




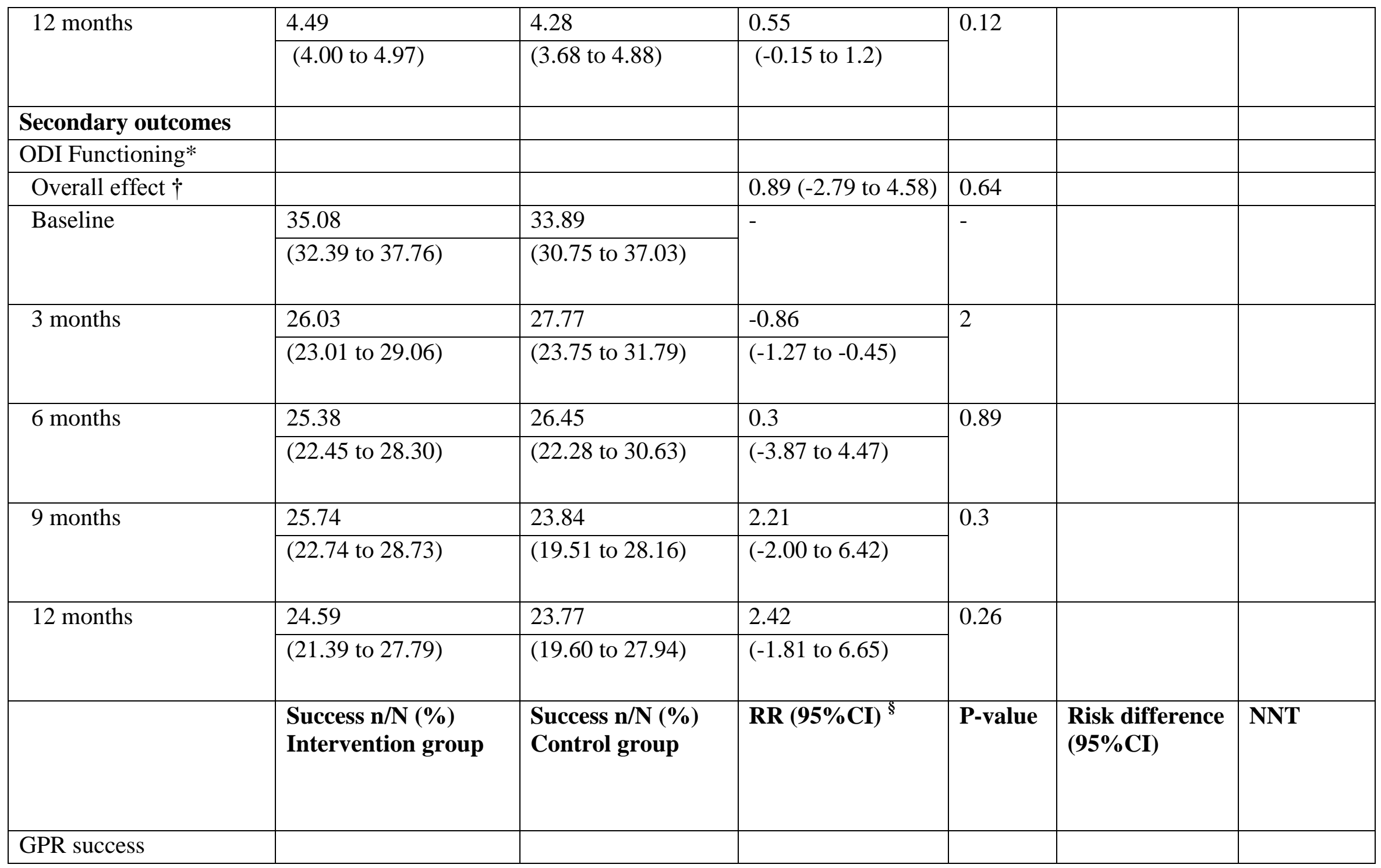

(C) 2017 American Medical Association. All rights reserved. 


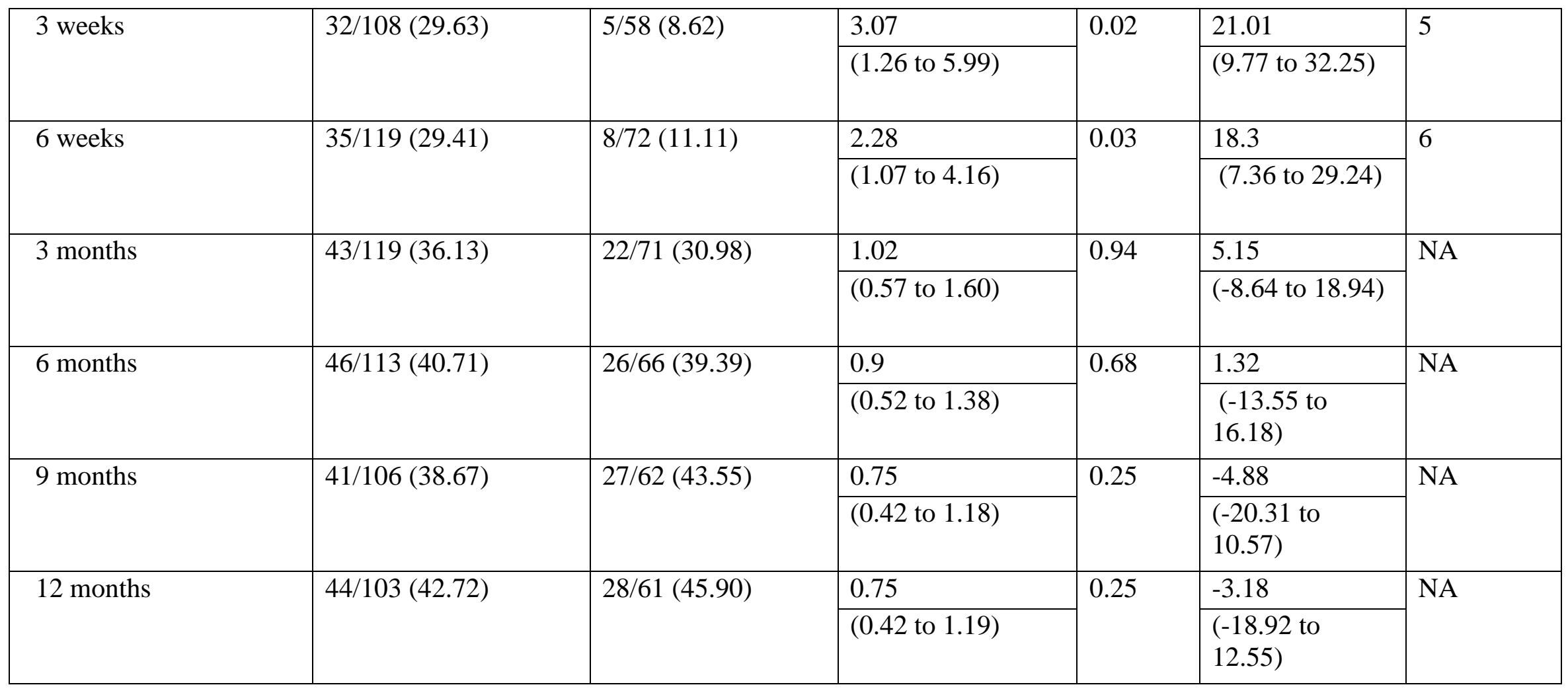


eTable 4. Treatment Effects for Pain Intensity, Functional Status, and Global Perceived Recovery Based on an As-Treated After 3 Months (continued)

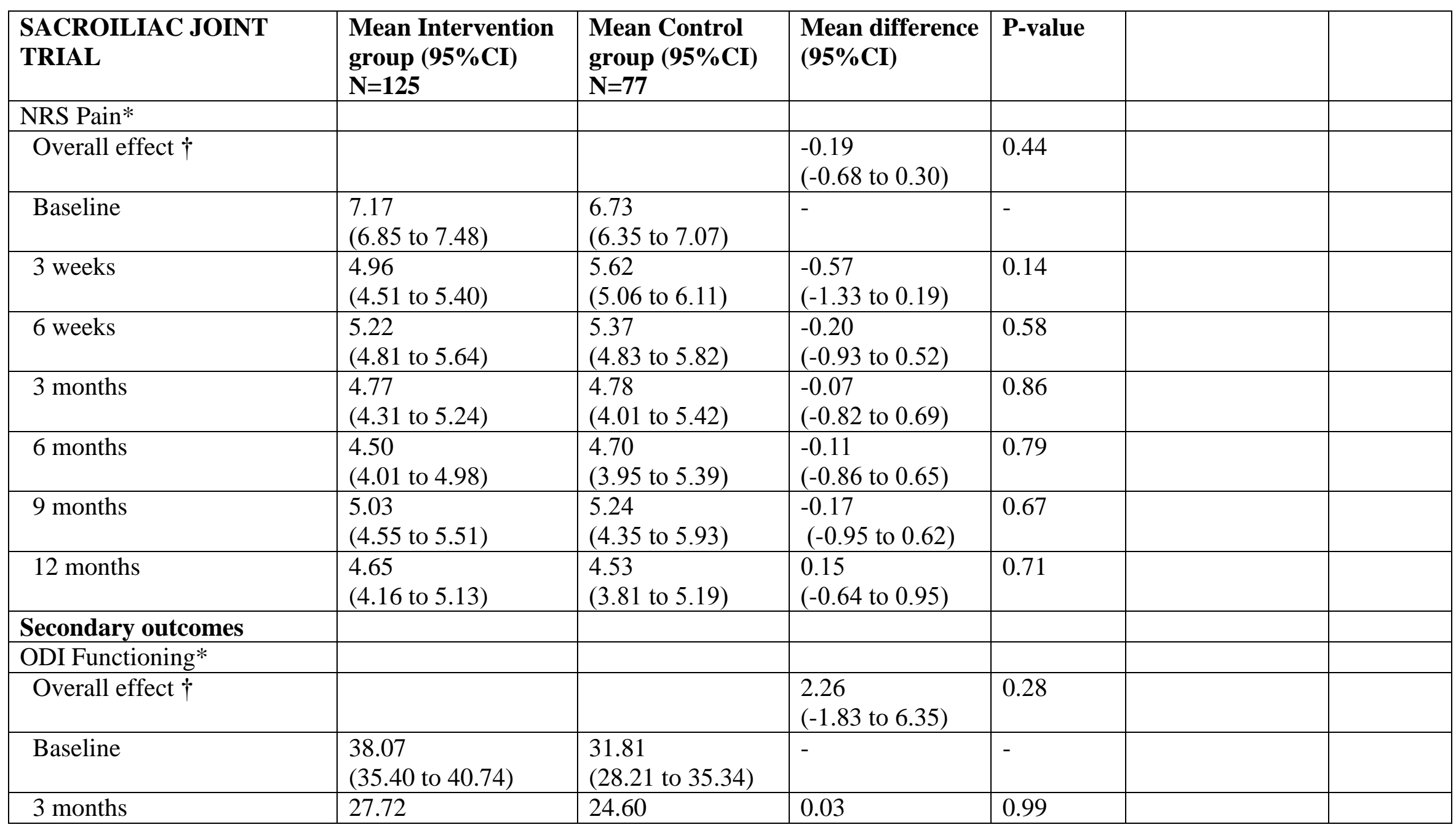




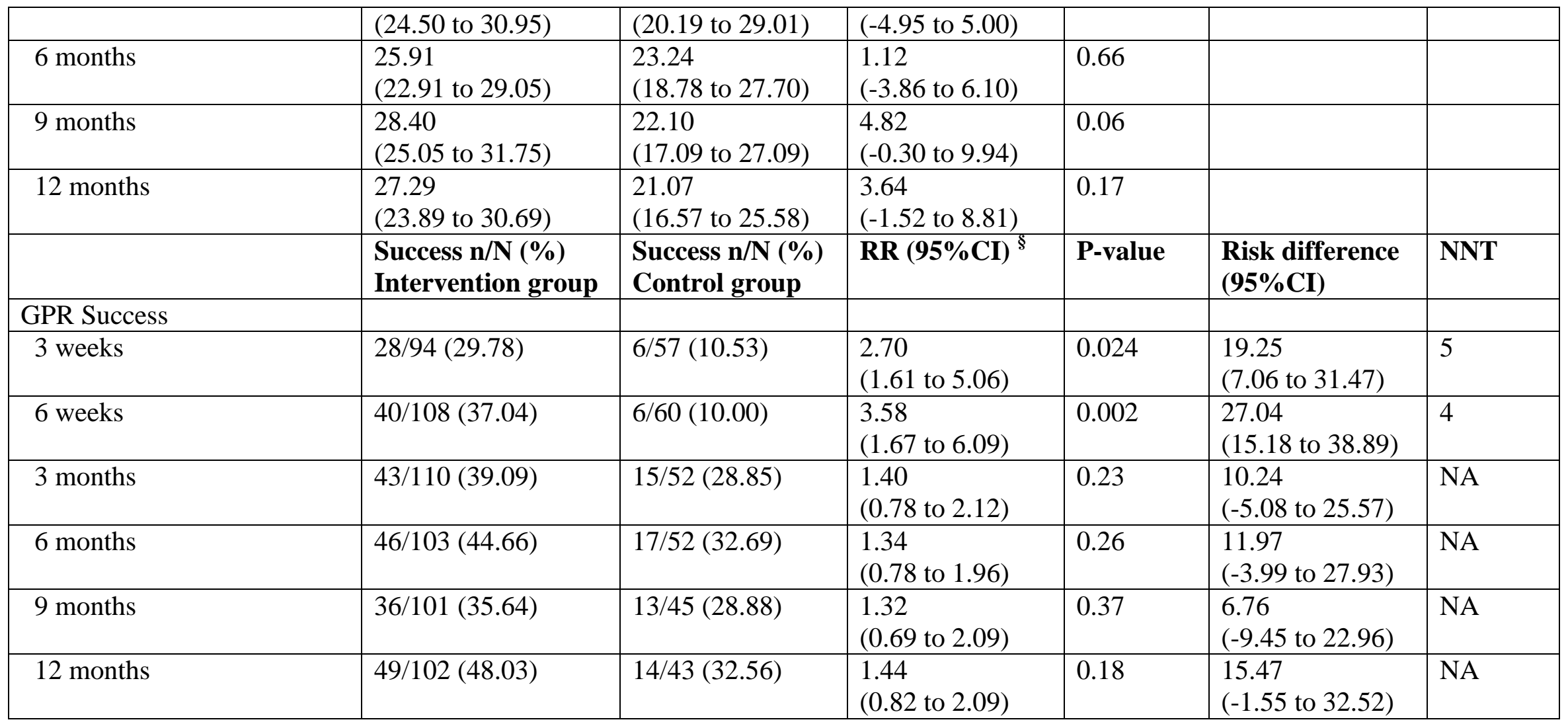


eTable 4. Treatment Effects for Pain Intensity, Functional Status, and Global Perceived Recovery Based on an As-Treated After 3 Months (continued)

\begin{tabular}{|c|c|c|c|c|c|c|}
\hline $\begin{array}{l}\text { COMBINATION } \\
\text { TRIAL }\end{array}$ & \begin{tabular}{|l|} 
Mean \\
Intervention \\
group $(95 \% \mathrm{CI})$ \\
$\mathbf{N}=103$ \\
\end{tabular} & $\begin{array}{l}\text { Mean Control } \\
\text { group }(95 \% \mathrm{CI}) \\
\mathrm{N}=68\end{array}$ & $\begin{array}{l}\text { Mean difference } \\
(95 \% \mathrm{CI})\end{array}$ & P-value & & \\
\hline \multicolumn{7}{|l|}{ NRS Pain (SD)* } \\
\hline Overall effect $\dagger$ & & & $\begin{array}{l}-0.22 \\
(-0.85 \text { to } 0.40)\end{array}$ & 0.48 & & \\
\hline Baseline & $\begin{array}{l}7.19 \\
\text { (6.91 to } 7.48)\end{array}$ & $\begin{array}{l}7.47 \\
\text { (7.08 to } 7.87 \text { ) }\end{array}$ & - & - & & \\
\hline 3 weeks & $\begin{array}{l}5.45 \\
(4.95 \text { to } 5.95)\end{array}$ & $\begin{array}{l}6.66 \\
(6.11 \text { to } 7.20)\end{array}$ & $\begin{array}{l}-0.75 \\
(-1.70 \text { to } 0.19)\end{array}$ & 0.12 & & \\
\hline 6 weeks & $\begin{array}{l}5.37 \\
\text { (4.89 to } 5.85)\end{array}$ & $\begin{array}{l}5.96 \\
\text { (5.37 to } 6.56)\end{array}$ & $\begin{array}{l}-0.08 \\
(-0.91 \text { to } 0.75)\end{array}$ & 0.85 & & \\
\hline 3 months & $\begin{array}{l}4.77 \\
(4.25 \text { to } 5.00)\end{array}$ & $\begin{array}{l}5.64 \\
\text { (4.94 to } 6.34)\end{array}$ & $\begin{array}{l}-0.73 \\
(-1.56 \text { to } 0.11)\end{array}$ & 0.09 & & \\
\hline 6 months & $\begin{array}{l}4.92 \\
\text { (4.39 to } 5.44)\end{array}$ & $\begin{array}{l}5.36 \\
\text { (4.57 to } 6.14)\end{array}$ & $\begin{array}{l}-0.07 \\
(-0.93 \text { to } 0.78)\end{array}$ & 0.87 & & \\
\hline 9 months & $\begin{array}{l}5.01 \\
(4.47 \text { to } 5.56)\end{array}$ & $\begin{array}{l}5.38 \\
(4.60 \text { to } 6.15)\end{array}$ & $\begin{array}{l}-0.26 \\
(-1.14 \text { to } 0.61)\end{array}$ & 0.55 & & \\
\hline 12 months & $\begin{array}{l}4.85 \\
\text { (4.24 to } 5.46)\end{array}$ & $\begin{array}{l}4.53 \\
(3.60 \text { to } 5.46)\end{array}$ & $\begin{array}{l}0.56 \\
(-0.34 \text { to } 1.45)\end{array}$ & 0.23 & & \\
\hline \multicolumn{7}{|l|}{ Secondary outcomes } \\
\hline \multicolumn{7}{|c|}{ ODI Functioning* } \\
\hline Overall effect $\dagger$ & & & $\begin{array}{l}1.59 \\
(-2.97 \text { to } 6.15)\end{array}$ & 0.49 & & \\
\hline Baseline & \begin{tabular}{|l|}
39.06 \\
$(36.25$ to 41.87$)$
\end{tabular} & $\begin{array}{l}36.34 \\
(32.79 \text { o } 38.90)\end{array}$ & - & - & & \\
\hline
\end{tabular}




\begin{tabular}{|c|c|c|c|c|c|c|}
\hline 3 months & $\begin{array}{l}28.00 \\
(24.65 \text { to } 31.35)\end{array}$ & \begin{tabular}{|l|}
30.96 \\
$(26.08$ to 35.84$)$
\end{tabular} & $\begin{array}{l}-3.10 \\
(-8.55 \text { to } 2.34)\end{array}$ & 1.74 & & \\
\hline 6 months & $\begin{array}{l}30.24 \\
(26.14 \text { to } 34.34)\end{array}$ & $\begin{array}{l}30.09 \\
(24.51 \text { to } 35.67)\end{array}$ & $\begin{array}{l}2.31 \\
(-3.25 \text { to } 7.88)\end{array}$ & 0.42 & & \\
\hline 9 months & $\begin{array}{l}30.73 \\
\text { (26.83 to } 34.63)\end{array}$ & \begin{tabular}{|l|}
27.74 \\
(22.00 to 33.48$)$
\end{tabular} & $\begin{array}{l}2.89 \\
(-2.83 \text { to } 8.60)\end{array}$ & 0.32 & & \\
\hline \multirow[t]{2}{*}{12 months } & \begin{tabular}{|l|}
31.20 \\
$(27.20$ to 35.20$)$
\end{tabular} & \begin{tabular}{|l}
23.94 \\
(18.51 to 29.38)
\end{tabular} & $\begin{array}{l}6.03 \\
(0.78 \text { to } 11.89)\end{array}$ & 0.04 & & \\
\hline & $\begin{array}{l}\text { Success n/N (\%) } \\
\text { Intervention } \\
\text { group }\end{array}$ & $\begin{array}{l}\text { Success n/N (\%) } \\
\text { Control } \\
\text { group }\end{array}$ & RR $(95 \% \mathrm{CI})^{\S}$ & P-value & $\begin{array}{l}\text { Risk difference } \\
(95 \% \mathrm{CI})\end{array}$ & NNT \\
\hline \multicolumn{7}{|l|}{ GPR success } \\
\hline 3 weeks & $17 / 77(22.07)$ & $2 / 33(6.06)$ & $\begin{array}{l}3.03 \\
(0.69 \text { to } 8.80)\end{array}$ & 0.13 & $\begin{array}{l}16.01 \\
(3.68 \text { to } 28.35)\end{array}$ & $\mathrm{NA}$ \\
\hline 6 weeks & $25 / 90(27.78)$ & $5 / 52(9.62)$ & $\begin{array}{l}2.16 \\
(0.76 \text { to } 4.89)\end{array}$ & 0.14 & $\begin{array}{l}18.16 \\
(5.92 \text { to } 30.40)\end{array}$ & NA \\
\hline 3 months & $30 / 88(34.09)$ & $10 / 50(20.00)$ & $\begin{array}{l}1.77 \\
\text { (1.64 to } 1.90)\end{array}$ & $\begin{array}{l}<0.000 \\
1\end{array}$ & $\begin{array}{l}14.09 \\
(-0.78 \text { to } 28.96)\end{array}$ & 7 \\
\hline 6 months & $30 / 85(35.29)$ & $15 / 45(33.33)$ & $\begin{array}{l}0.92 \\
(0.40 \text { to } 1.68)\end{array}$ & 0.81 & $\begin{array}{l}1.96 \\
(-15.15 \text { to } 19.08)\end{array}$ & NA \\
\hline 9 months & $29 / 82(35.36)$ & \begin{tabular}{|l|l|}
$13 / 41(31.71)$ \\
\end{tabular} & $\begin{array}{l}1.13 \\
(0.49 \text { to } 1.98)\end{array}$ & 0.74 & $\begin{array}{l}3.65 \\
(-13.95 \text { to } 21.26)\end{array}$ & $\mathrm{NA}$ \\
\hline 12 months & $26 / 75(34.67)$ & $11 / 36(30.56)$ & $\begin{array}{l}1.19 \\
(0.38 \text { to } 3.72)\end{array}$ & 0.76 & $\begin{array}{l}4.11 \\
(-14.39 \text { to } 22.62)\end{array}$ & $\mathrm{NA}$ \\
\hline
\end{tabular}

Values presented (for mean differences and Relative Risks) are model estimates of linear mixed-effects models with a random intercept, and adjusted for outcome at baseline and age, gender, BMI, education, smoking, marital status, back pain complaint history, patient expectations. Regression coefficients can be interpreted as mean differences between interventions at a certain follow-up moment compared to baseline. Abbreviations: SD, Standard Deviation; NRS, Numeric Rating Scale (0-10); GPR, Global Perceived Recovery (1-7, 1-2 indicate success); ODI, Oswestry Disability Index (0-100); RR, Relative Risk; NNT, Numbers Needed to Treat. * 
Higher score indicates more severe symptoms. ${ }^{\S}$ RRs are estimated based on the method of Zhang et al. ${ }^{32} \uparrow$ The overall effect measures provide information over the total follow-up time of 12 months, instead of the time-by-treatment effects. 
eTable 5. Treatment Effects for Complete Cases for Pain Intensity, Functional Status, and Global Perceived Recovery Based on Intention-To-Treat Analyses

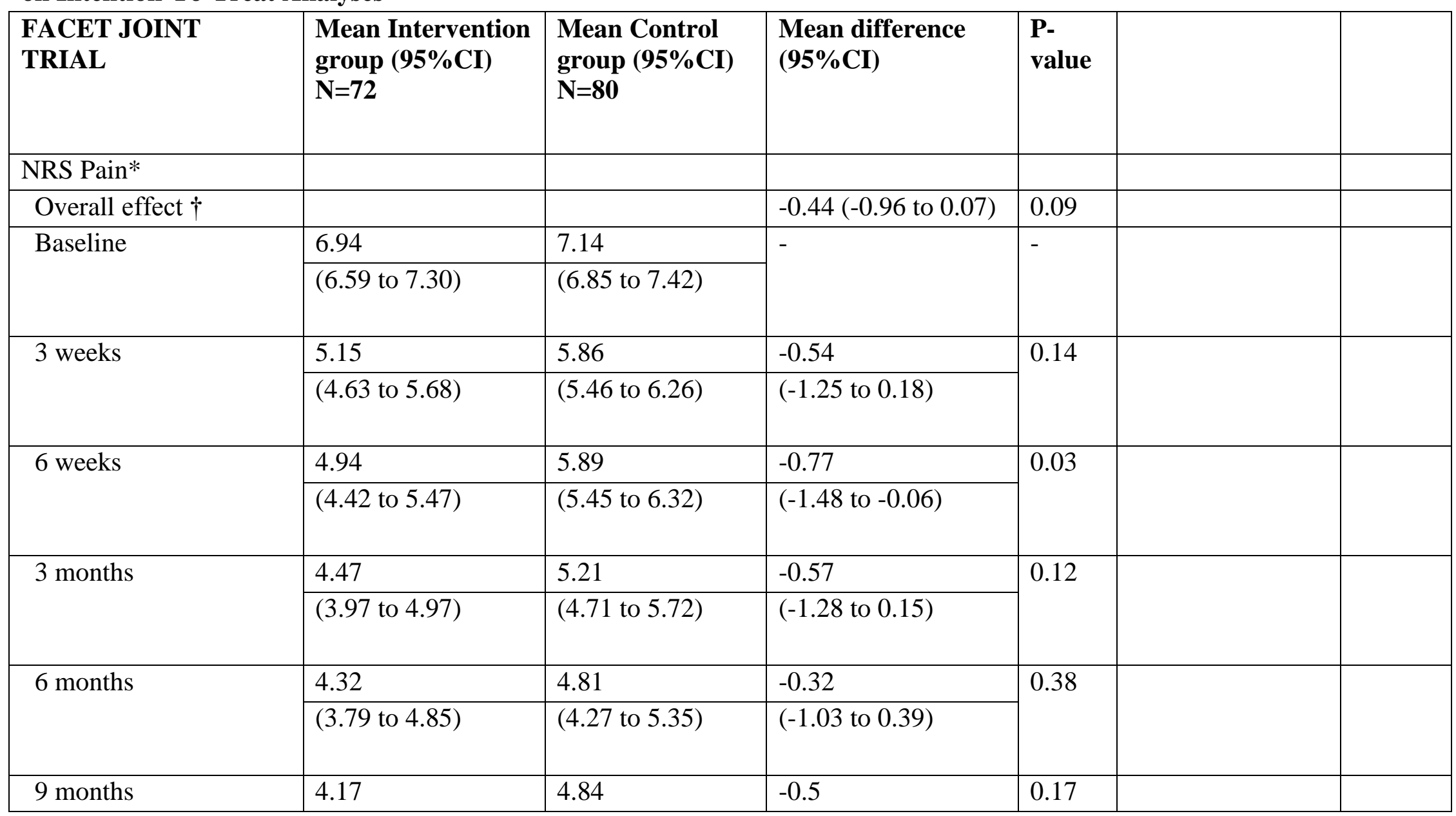




\begin{tabular}{|c|c|c|c|c|c|c|}
\hline & (3.62 to 4.71$)$ & (4.28 to 5.39$)$ & $(-1.21$ to 0.21$)$ & & & \\
\hline \multirow[t]{2}{*}{12 months } & 4.18 & 4.31 & 0.04 & \multirow[t]{2}{*}{0.91} & & \\
\hline & (3.59 to 4.77$)$ & (3.75 to 4.88$)$ & $(-0.67$ to 0.75$)$ & & & \\
\hline \multicolumn{7}{|c|}{ Secondary outcomes } \\
\hline \multicolumn{7}{|l|}{ ODI Functioning* } \\
\hline Overall effect $\dagger$ & & & $-1.17(-4.89$ to 2.55$)$ & 0.54 & & \\
\hline \multirow[t]{2}{*}{ Baseline } & 34.28 & 33.47 & \multirow[t]{2}{*}{-} & \multirow[t]{2}{*}{-} & & \\
\hline & (31.02 to 37.53$)$ & (30.99 to 35.96$)$ & & & & \\
\hline \multirow[t]{2}{*}{3 months } & 23.31 & 26.9 & -3.6 & \multirow[t]{2}{*}{0.1} & & \\
\hline & (19.80 to 26.81$)$ & (23.75 to 30.05$)$ & $(-7.83$ to 0.63$)$ & & & \\
\hline \multirow[t]{2}{*}{6 months } & 24.06 & 25.1 & -1.05 & \multirow[t]{2}{*}{0.63} & & \\
\hline & (20.48 to 27.63$)$ & (21.75 to 28.45$)$ & $(-5.28$ to 3.18$)$ & & & \\
\hline \multirow[t]{2}{*}{9 months } & 23.58 & 24.25 & -0.67 & \multirow[t]{2}{*}{0.76} & & \\
\hline & (20.23 to 26.94) & (21.05 to 27.45$)$ & (-4.90 to 2.56$)$ & & & \\
\hline \multirow[t]{3}{*}{12 months } & 24.22 & 23.57 & 0.64 & \multirow[t]{2}{*}{0.77} & & \\
\hline & (20.46 to 27.99) & (20.22 to 26.93) & $(-3.59$ to 4.87$)$ & & & \\
\hline & $\begin{array}{l}\text { Success n/N (\%) } \\
\text { Intervention } \\
\text { group }\end{array}$ & $\begin{array}{l}\text { Success n/N (\%) } \\
\text { Control group }\end{array}$ & RR $(95 \% C I) \S$ & $\begin{array}{l}\text { P- } \\
\text { value }\end{array}$ & $\begin{array}{l}\text { Risk difference } \\
(95 \% \mathrm{CI})\end{array}$ & NNT \\
\hline
\end{tabular}




\begin{tabular}{|c|c|c|c|c|c|c|}
\hline \multicolumn{7}{|l|}{ GPR Success } \\
\hline \multirow[t]{2}{*}{3 weeks } & \multirow[t]{2}{*}{$22 / 72(30.56)$} & \multirow[t]{2}{*}{$5 / 80(6.25)$} & 4.83 & \multirow[t]{2}{*}{0.0011} & 24.31 & \multirow[t]{2}{*}{4} \\
\hline & & & (1.98 to 9.10$)$ & & (12.42 to 36.19$)$ & \\
\hline \multirow[t]{2}{*}{6 weeks } & \multirow[t]{2}{*}{$20 / 72(27.78)$} & \multirow[t]{2}{*}{$8 / 80(10.00)$} & 2.73 & \multirow[t]{2}{*}{0.13} & 17.88 & \multirow[t]{2}{*}{ NA } \\
\hline & & & $(0.72$ to 6.45$)$ & & (5.52 to 30.04$)$ & \\
\hline \multirow[t]{2}{*}{3 months } & \multirow[t]{2}{*}{$31 / 72(43.06)$} & \multirow[t]{2}{*}{$21 / 80(26.25)$} & 1.63 & \multirow[t]{2}{*}{0.07} & 16.81 & \multirow[t]{2}{*}{ NA } \\
\hline & & & (0.95 to 1.88$)$ & & (1.85 to 31.76$)$ & \\
\hline \multirow[t]{2}{*}{6 months } & \multirow[t]{2}{*}{$31 / 72(43.06)$} & \multirow[t]{2}{*}{$30 / 80(37.50)$} & 1.14 & \multirow[t]{2}{*}{0.61} & 5.56 & \multirow[t]{2}{*}{ NA } \\
\hline & & & $(0.67$ to 1.65$)$ & & $(-10.04$ to 21.16$)$ & \\
\hline \multirow[t]{2}{*}{9 months } & \multirow[t]{2}{*}{$30 / 72(41.67)$} & \multirow[t]{2}{*}{$30 / 80(37.50)$} & 1.09 & \multirow[t]{2}{*}{0.72} & 4.17 & \multirow[t]{2}{*}{ NA } \\
\hline & & & $(0.63$ to 1.61$)$ & & $(-11.40$ to 19.73$)$ & \\
\hline \multirow[t]{2}{*}{12 months } & \multirow[t]{2}{*}{$31 / 72(43.06)$} & \multirow[t]{2}{*}{$33 / 80(41.25)$} & 1.02 & \multirow[t]{2}{*}{0.92} & 1.81 & \multirow[t]{2}{*}{ NA } \\
\hline & & & (0.84 to 1.49$)$ & & $(-13.92$ to 17.53$)$ & \\
\hline $\begin{array}{l}\text { SACROILIAC JOINT } \\
\text { TRIAL }\end{array}$ & $\begin{array}{l}\text { Mean Intervention } \\
\text { group }(95 \% \mathrm{CI}) \\
\mathbf{N}=75\end{array}$ & $\begin{array}{l}\text { Mean Control } \\
\text { group }(95 \% \mathrm{CI}) \\
\mathrm{N}=57\end{array}$ & $\begin{array}{l}\text { Mean difference } \\
(95 \% \mathrm{CI})\end{array}$ & $\begin{array}{l}\text { P- } \\
\text { value }\end{array}$ & & \\
\hline \multicolumn{7}{|l|}{ NRS Pain* } \\
\hline Overall effect $\dagger$ & & & $-0.29(-0.84$ to 0.25$)$ & 0.29 & & \\
\hline Baseline & 7.07 & 7.12 & - & - & & \\
\hline
\end{tabular}




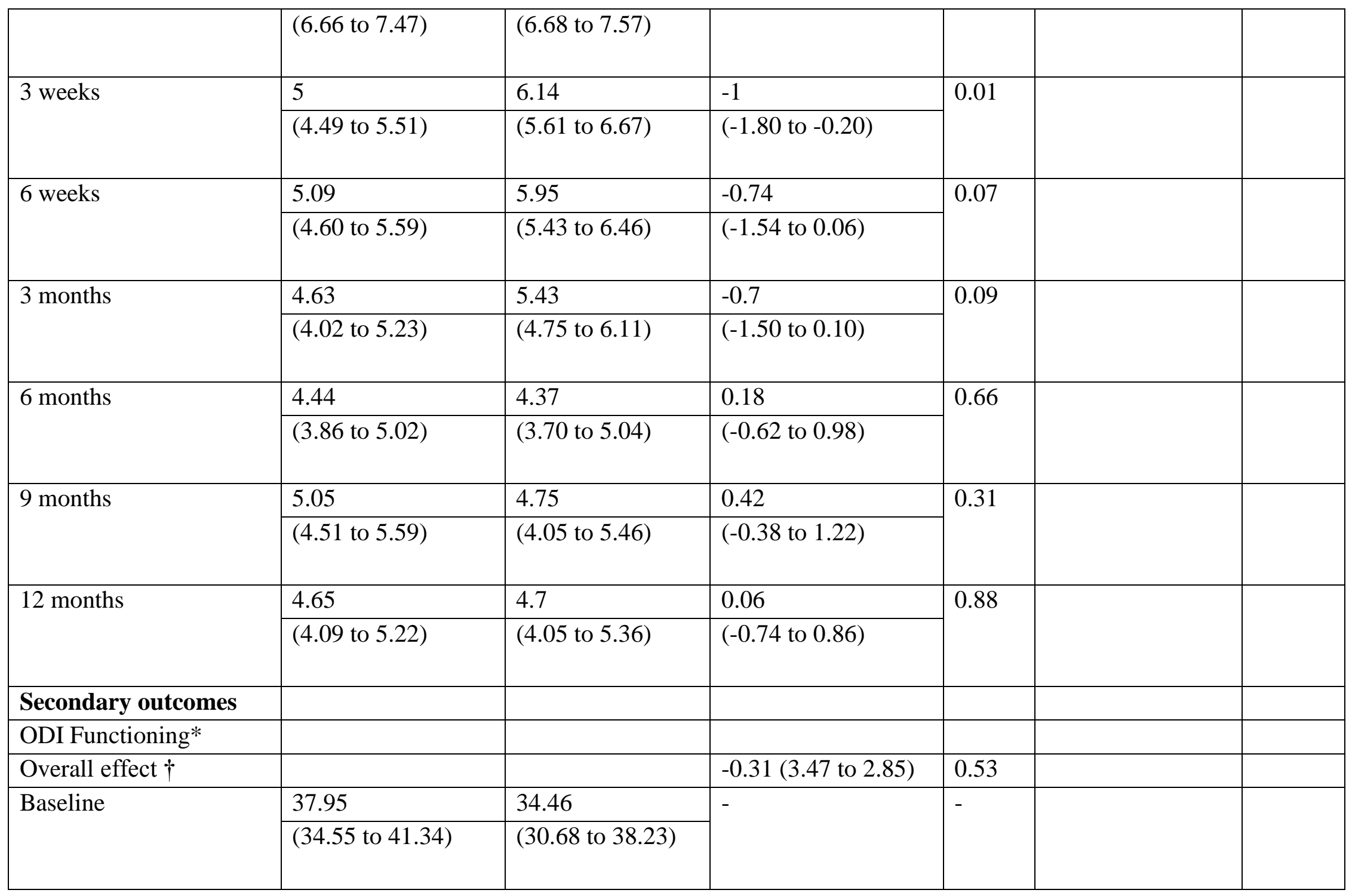




\begin{tabular}{|c|c|c|c|c|c|c|}
\hline \multirow[t]{2}{*}{3 months } & 27.12 & 30.46 & -5.17 & \multirow[t]{2}{*}{0.07} & & \\
\hline & (22.91 to 31.33$)$ & (25.54 to 35.38$)$ & $(-9.28$ to -1.06$)$ & & & \\
\hline \multirow{2}{*}{6 months } & 26.03 & 22.95 & 0.45 & \multirow[t]{2}{*}{0.47} & & \\
\hline & (22.26 to 29.80$)$ & (18.91 to 26.98$)$ & $(-3.87$ to 4.36$)$ & & & \\
\hline \multirow[t]{2}{*}{9 months } & 29.2 & 22.6 & 2.84 & \multirow[t]{2}{*}{0.03} & & \\
\hline & (25.19 to 33.21$)$ & (18.66 to 26.53$)$ & $(-1.27$ to 6.95$)$ & & & \\
\hline \multirow[t]{3}{*}{12 months } & 27.79 & 23.82 & 0.84 & \multirow[t]{2}{*}{0.3} & & \\
\hline & (23.71 to 31.86$)$ & (19.56 to 28.09$)$ & $(-3.28$ to 4.95$)$ & & & \\
\hline & $\begin{array}{l}\text { Success n/N (\%) } \\
\text { Intervention } \\
\text { group }\end{array}$ & $\begin{array}{l}\text { Success n/N (\%) } \\
\text { Control group }\end{array}$ & $\operatorname{RR}(95 \% \mathrm{CI})^{\S}$ & $\begin{array}{l}\text { P- } \\
\text { value }\end{array}$ & $\begin{array}{l}\text { Risk difference } \\
(95 \% \mathrm{CI})\end{array}$ & NNT \\
\hline \multicolumn{7}{|c|}{ GPR Success } \\
\hline \multirow[t]{2}{*}{3 weeks } & \multirow[t]{2}{*}{$21 / 75(28.00)$} & \multirow[t]{2}{*}{$7 / 57(12.28)$} & 2.32 & \multirow[t]{2}{*}{0.049} & 15.72 & \multirow[t]{2}{*}{6} \\
\hline & & & (1.00 to 4.33$)$ & & (2.46 to 28.98$)$ & \\
\hline \multirow[t]{2}{*}{6 weeks } & \multirow[t]{2}{*}{$29 / 75(38.66)$} & \multirow[t]{2}{*}{$5 / 57(8.78)$} & 4.53 & \multirow[t]{2}{*}{0.001} & 29.88 & \multirow[t]{2}{*}{3} \\
\hline & & & (2.00 to 7.64$)$ & & (16.65 to 43.14$)$ & \\
\hline \multirow[t]{2}{*}{3 months } & \multirow[t]{2}{*}{$31 / 75(41.33)$} & \multirow[t]{2}{*}{$14 / 57(24.56)$} & 1.7 & \multirow[t]{2}{*}{0.08} & 16.77 & \multirow[t]{2}{*}{$\mathrm{NA}$} \\
\hline & & & (0.93 to 2.58$)$ & & (0.99 to 32.55$)$ & \\
\hline
\end{tabular}




\begin{tabular}{|c|c|c|c|c|c|c|}
\hline \multirow[t]{2}{*}{6 months } & \multirow[t]{2}{*}{$35 / 75(46.66)$} & \multirow[t]{2}{*}{$23 / 57(40.35)$} & 1.15 & \multirow[t]{2}{*}{0.55} & 6.31 & \multirow[t]{2}{*}{ NA } \\
\hline & & & (0.68 to 1.65$)$ & & $(-10.70$ to 23.34$)$ & \\
\hline \multirow[t]{2}{*}{9 months } & \multirow[t]{2}{*}{$27 / 75(36.00)$} & \multirow[t]{2}{*}{$20 / 57(35.08)$} & 1.03 & \multirow[t]{2}{*}{0.94} & 0.92 & \multirow[t]{2}{*}{ NA } \\
\hline & & & (0.55 to 1.62$)$ & & $(-15.57$ to 17.39$)$ & \\
\hline \multirow[t]{2}{*}{12 months } & \multirow[t]{2}{*}{$36 / 75(48.00)$} & \multirow[t]{2}{*}{$21 / 57(36.84)$} & 1.31 & \multirow[t]{2}{*}{0.28} & 11.16 & \multirow[t]{2}{*}{ NA } \\
\hline & & & (0.78 to 1.85$)$ & & (-5.71 to 28.03$)$ & \\
\hline $\begin{array}{l}\text { COMBINATION } \\
\text { TRIAL }\end{array}$ & $\begin{array}{l}\text { Mean Intervention } \\
\text { group }(95 \% \mathrm{CI}) \\
\mathrm{N}=60\end{array}$ & $\begin{array}{l}\text { Mean Control } \\
\text { group }(95 \% \mathrm{CI}) \\
\mathbf{N}=45\end{array}$ & $\begin{array}{l}\text { Mean difference } \\
(95 \% \mathrm{CI})\end{array}$ & $\begin{array}{l}\text { P- } \\
\text { value }\end{array}$ & & \\
\hline \multicolumn{7}{|l|}{ NRS Pain (SD)* } \\
\hline Overall effect $\dagger$ & & & $0.17(-0.52$ to 0.85$)$ & 0.63 & & \\
\hline \multirow[t]{2}{*}{ Baseline } & 7.3 & 7.47 & \multirow[t]{2}{*}{ - } & \multirow[t]{2}{*}{-} & & \\
\hline & (6.97 to 7.63 ) & (7.09 to 7.84$)$ & & & & \\
\hline \multirow[t]{2}{*}{3 weeks } & 5.4 & 6.39 & -0.85 & \multirow[t]{2}{*}{0.1} & & \\
\hline & (4.78 to 6.00$)$ & (5.63 to 7.04$)$ & $(-1.87$ to 0.17$)$ & & & \\
\hline \multirow[t]{2}{*}{6 weeks } & 5.73 & 5.93 & 0.03 & \multirow[t]{2}{*}{0.95} & & \\
\hline & (5.19 to 6.27$)$ & (5.24 to 6.53$)$ & $(-0.89$ to 0.95$)$ & & & \\
\hline 3 months & 5.1 & 5.67 & -0.6 & 0.2 & & \\
\hline
\end{tabular}




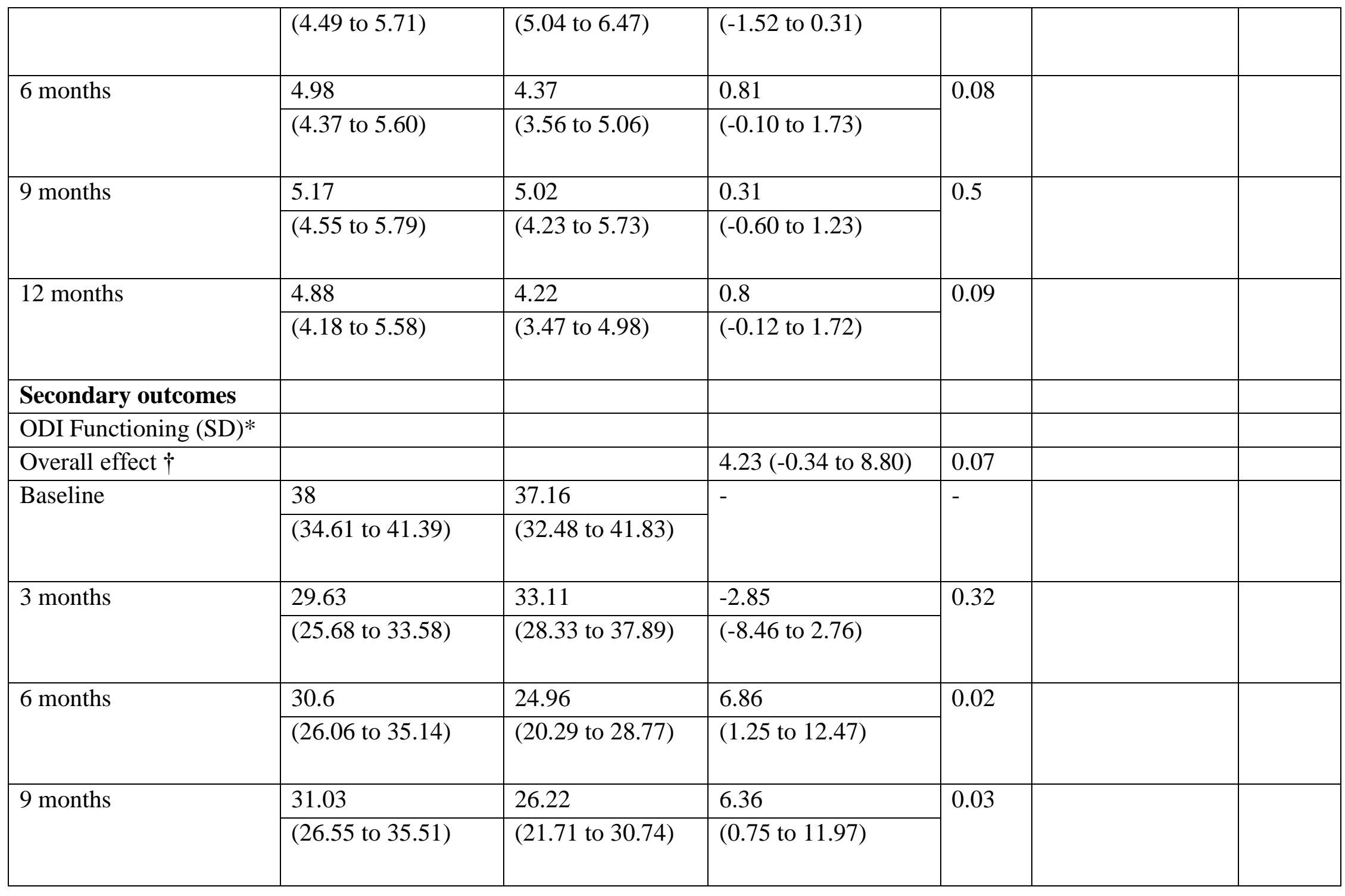




\begin{tabular}{|c|c|c|c|c|c|c|}
\hline \multirow[t]{3}{*}{12 months } & 30.27 & 25.3 & 6.56 & \multirow[t]{2}{*}{0.02} & & \\
\hline & (25.79 to 34.74$)$ & (20.89 to 28.98$)$ & (0.95 to 12.17$)$ & & & \\
\hline & $\begin{array}{l}\text { Success n/N (\%) } \\
\text { Intervention } \\
\text { group }\end{array}$ & $\begin{array}{l}\text { Success n/N (\%) } \\
\text { Control group }\end{array}$ & RR $(95 \% C I)^{\S}$ & $\begin{array}{l}\text { P- } \\
\text { value }\end{array}$ & $\begin{array}{l}\text { Risk difference } \\
(95 \% \mathrm{CI})\end{array}$ & NNT \\
\hline \multicolumn{7}{|c|}{ GPR Success } \\
\hline \multirow[t]{2}{*}{3 weeks } & \multirow[t]{2}{*}{$10 / 60(16.67)$} & \multirow[t]{2}{*}{$2 / 45(4.44)$} & 2.57 & \multirow[t]{2}{*}{0.23} & 12.23 & \multirow[t]{2}{*}{ NA } \\
\hline & & & (0.53 to 9.17$)$ & & (1.03 to 23.41$)$ & \\
\hline \multirow[t]{2}{*}{6 weeks } & \multirow[t]{2}{*}{$14 / 60(23.33)$} & \multirow[t]{2}{*}{$5 / 45(11.11)$} & 1.68 & \multirow[t]{2}{*}{0.36} & 12.22 & \multirow[t]{2}{*}{$\mathrm{NA}$} \\
\hline & & & $(0.53$ to 4.10$)$ & & $(-1.88$ to 26.32$)$ & \\
\hline \multirow[t]{2}{*}{3 months } & \multirow[t]{2}{*}{$17 / 60(28.33)$} & \multirow[t]{2}{*}{$8 / 45$ (17.78) } & 1.61 & \multirow[t]{2}{*}{0.32} & 10.55 & \multirow[t]{2}{*}{ NA } \\
\hline & & & (0.61 to 3.24$)$ & & $(-5.41$ to 26.52$)$ & \\
\hline \multirow[t]{2}{*}{6 months } & \multirow[t]{2}{*}{$20 / 60(33.33)$} & \multirow[t]{2}{*}{$22 / 45(47.89)$} & 0.58 & \multirow[t]{2}{*}{0.11} & -14.56 & \multirow[t]{2}{*}{ NA } \\
\hline & & & $(0.24$ to 1.10$)$ & & $(-34.41$ to 3.30$)$ & \\
\hline \multirow[t]{2}{*}{9 months } & \multirow[t]{2}{*}{$19 / 60(31.67)$} & \multirow[t]{2}{*}{$16 / 45(35.56)$} & 0.78 & \multirow[t]{2}{*}{0.5} & -3.89 & \multirow[t]{2}{*}{ NA } \\
\hline & & & $(0.32$ to 1.49$)$ & & $(-22.17$ to 14.39$)$ & \\
\hline \multirow[t]{2}{*}{12 months } & \multirow[t]{2}{*}{$19 / 60(31.67)$} & \multirow[t]{2}{*}{$16 / 45(35.56)$} & 0.48 & \multirow[t]{2}{*}{0.5} & -3.89 & \multirow[t]{2}{*}{ NA } \\
\hline & & & $(0.32$ to 1.49$)$ & & $(-22.17$ to 14.39$)$ & \\
\hline
\end{tabular}


Values presented (for mean differences and Relative Risks) are model estimates of linear mixed-effects models with a random intercept, and adjusted for outcome at baseline and age, gender, BMI, education, smoking, marital status, back pain complaint history, patient expectations. Regression coefficients can be interpreted as mean differences between interventions at a certain follow-up moment compared to baseline. Abbreviations: SD, Standard Deviation; NRS, Numeric Rating Scale (0-10); GPR, Global Perceived Recovery (1-7, 1-2 indicate success); ODI, Oswestry Disability Index (0-100); RR, Relative Risk; NNT, Numbers Needed to Treat. *

Higher score indicates more severe symptoms. ${ }^{\S}$ RRs are estimated based on the method of Zhang et al. ${ }^{32} \dagger$ The overall effect measures provide information over the total follow-up time of 12 months, instead of the time-by-treatment effects.

\section{eREFERENCES}

1. Cohen SP, Hurley RW, Buckenmaier 3rd CC, Kurihara C, Morlando B, Dragovich A. Randomized placebo-controlled study evaluating lateral branch radiofrequency denervation for sacroiliac joint pain. Anesthesiology. 2008;109(2):279-288..

2. Cosman Jr. ER, Gonzalez CD. Bipolar radiofrequency lesion geometry: implications for palisade treatment of sacroiliac joint pain. Pain Pr. 2011;11(1):3-22.

3. Schmidt PC, Pino CA, Vorenkamp KE. Sacroiliac joint radiofrequency ablation with a multilesion probe: A case series of 60 patients. Anesth Analg. 2014;119(2):460-462.

4. Gauci CA, Jankowiak B. Manual of RF Techniques: A Practical Manual of Radiofrequency Procedures in Chronic Pain Management. CoMedical; 2011. 